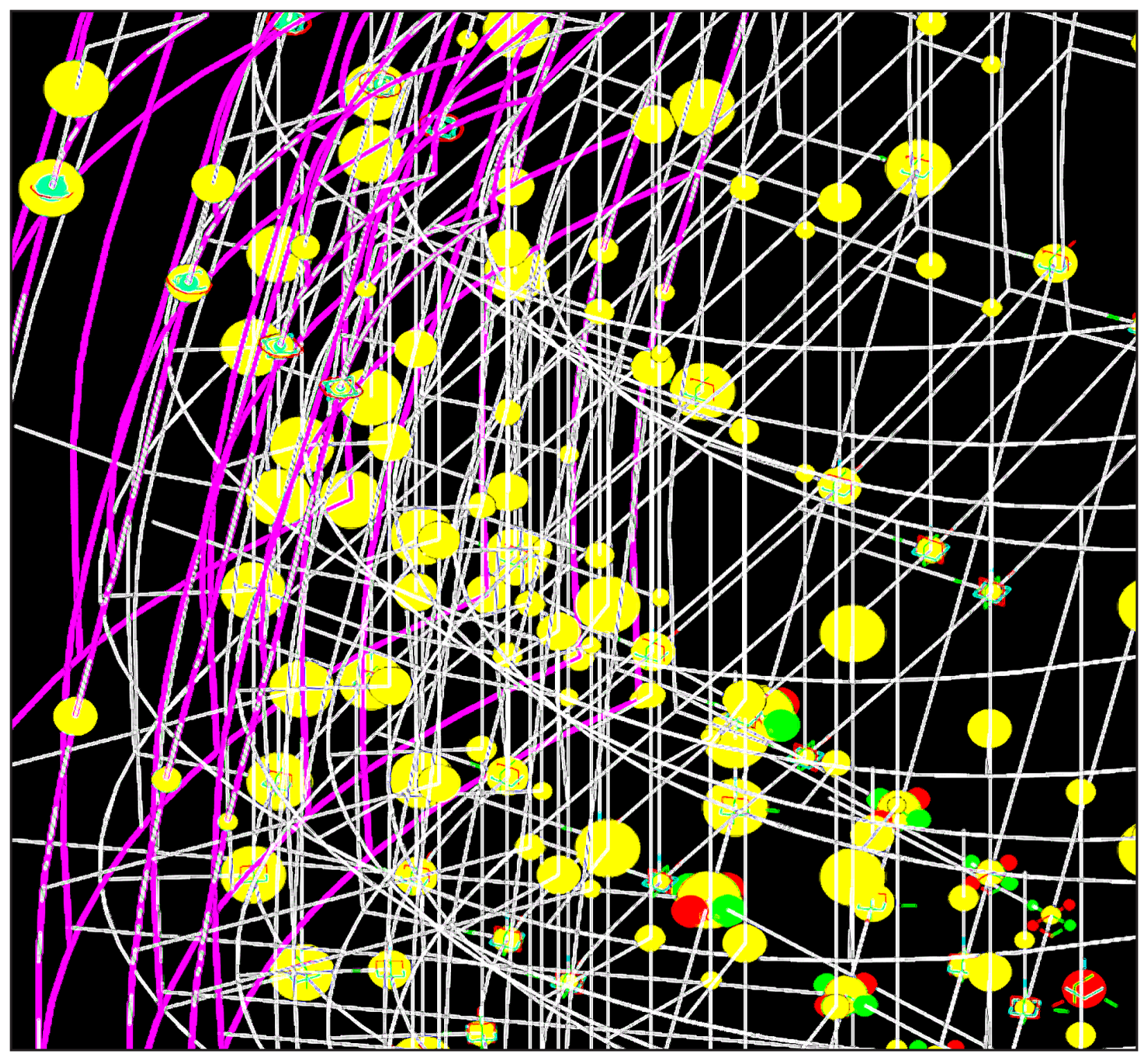

\title{
Parametric Solar Architecture
}

How a new Design Methodology Can improve the Urban Integration of Photovoltaic Systems 



\title{
PARAMETRIC SOLAR ARCHITECTURE
}

\author{
by \\ Viktor Paul Kuslikis \\ BArchSc, Ryerson University, 2005. \\ A design thesis|project \\ presented to Ryerson University \\ in partial fulfillment of the \\ requirements for the degree of \\ Master of Architecture \\ in the program of \\ Architecture
}

Toronto, Ontario, Canada, 2010

○Viktor Kuslikis 2010 
I hereby declare that I am the sole author of this thesis|project. I authorize Ryerson University to lend this thesis|project to other institutions or individuals for the purpose of scholarly research.

* Viktor Kuslikis

I further authorize Ryerson University to reproduce this thesis|project by photocopying or by other means, in total or in part, at the request of other institutions or individuals for the purpose of scholarly research.

*Viktor Kuslikis 


\section{PARAMETRIC SOLAR ARCHITECTURE}

Master of Architecture

in the Program of Architecture

Ryerson University

Viktor Kuslikis 2010

\section{Abstract}

Integrating photovoltaic systems into the urban landscape is fundamental to the wide scale acceptance of the technology. It is also one of the major factors currently limiting its popularity, coupled with high costs, and the lack of adequate storage methods. Contributing to the lack of architectural integration are shortcomings in design tools and an overall lack of forward thinking proposals suggesting how society can begin implementing solar power on a large scale. Research conducted by the International Energy Agency 'Task 41: Solar Energy and Architecture' has identified the need for more developed toolsets to help designers quantify solar exposure and shading coefficients during the conceptual design phase. Although software to calculate incident surface radiation is available, it is largely detached from the traditional design process and workflow. What is required to improve the architectural integration of photovoltaic systems is a new design methodology. A method that must be both inherently flexible and quantifiable, so that designers can validate and modify designs quickly and efficiently. In a process where innovative digital tools combined with the intuition of the designer expand the creative possibilities of intelligent solar architecture. The aim of the project is to develop a new design methodology by combining parametric and environmental analysis tools, providing quantitative performance indicators in order to assist architects at the early design stage. Using case studies, the project will demonstrate how this methodology is applicable to a wide array of project typologies within an urban context. In addition to demonstrating the applicability of the system, the case studies would also illustrate the potential for photovoltaic installations to alter the landscape of the city and facilitate a fresh dialogue between public space and renewable energy generation. 


\section{Acknowledgements}

I would like to thank my advisor, Dr. Miljana Horvat, for supporting my interests and helping me develop them into a coherent, architecturally relevant, and defendable thesis project. I would also like to thank John Cirka, Autodesk, CH2MHILL, and Bentley Systems for providing me with the digital tools and technical support needed to successfully conduct my research. 


\section{Table of Contents:}

\section{Chapter.1 - Background}

1.1 - Problem Summary

1.2 - The Environmental Aspect

1.3 - Impediments to Mainstream Acceptance .... 4

1.3.1 - Economics ........................................................ 4

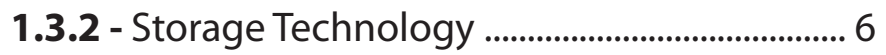

1.3.3 - Urban Integration ............................................. 7

1.4 - Architectural Relevance ................................... 9

1.5 - Aim + Scope ........................................................ 12

Chapter.2 - Proposed Methodology

2.1- Technical Background ........................................... 13

2.1.1 - The Photovoltaic Effect ..................................... 14

2.1.2 - Output of Photovoltaic Systems

2.2 - Digital Tools ........................................................... 22

2.2.1 - Parametric Systems ....................................... 22

2.2.2 - Parametric Panel System .................................. 25

2.2.3 - Solar Analysis Modeling ................................... 26

2.2.4 - Parametric + Analysis Workflow .................... 28

2.3 - The Human Interface ............................................ 31

Chapter.3 - Applicability

3.1.2 - Silos in Context ..................................................... 36

3.1.2 - Silos Design Concept ......................................... 38

3.2.1 - Pedestrian Canopy in Context ........................ 43

3.2.2 - Pedestrian Canopy Design Concept ............. 47

3.3.1 - AD Space in Context ...................................... 50

3.3.2 - AD Space Design Concept .............................. 53

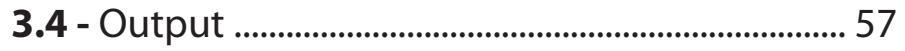

3.5 - Conclusion ............................................................. 58

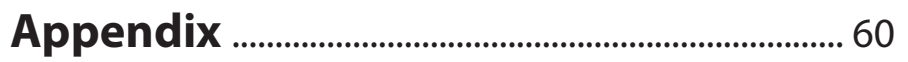

Works Cited .................................................................... 61 


\section{List of Diagrams:}

Diagram.1(9) - Common Methods of Building integrated Photovoltaic Systems.

Diagram.2(9)- Cold Façade Building Integrated Photovoltaic System (Thomas \& Fordham, 2001).

Diagram.3(14) - How Solar Cells Work (Maycock \& Stirewalt 1981).

Diagram.4(14)- Visible Light Spectrum (Maycock \& Stirewalt 1981).

Diagram.5(14) - Solar Cell Composition (Maycock \& Stirewalt 1981).

Diagram.6(16) - The Relationship Between Current and Voltage (Thomas \& Fordham, 2001).

Diagram.7(16) - Grid Connected Photovoltaic System (Thomas \& Fordham, 2001).

Diagram.8(18) - Annual Solar Radiation Values (kWh/m²) (The German Solar Energy Society, 2005).

Diagram.9(22) - Parametric Relationships

Diagram.10(23) - Guggenheim Museum Bilbao Digital Work Flow (El Croquis, 1995).

Diagram.11(25) - Parametric Panel System

Diagram.12(27) - Ecotect Visual Analysis

Diagram.13(29) - Ecotect/GC File Exchange

Diagram.14(29) - Ecotect/GC Link

Diagram.15(30) - Ecotect/GC Link Work Flow

Diagram.16(33) - Maison Domino (Fondation Le Corbusier),

Diagram.17(36) - Silos Site Context

Diagram.18(37) - West8 + DTAH Toronto Waterfront Master Plan (West8+DTAH, 2006),

Diagram.19(38) - Preliminary Silo Massing Studies

Diagram.20(38) - Silo Orientation

Diagram.21(39) - Silo Design Process

Diagram.22(40) - Silos 2-D Work Flow

Diagram.23(40) - Silos final Design Iteration

Diagram.24(41) - Silos West Rendering

Diagram.25(42) - Silos East Rendering

Diagram.26(43) - Kensington Market Street Photos

Diagram.27(44) - Energy Roof Perugia (Coop Himmelb(I)au, 2010)

Diagram.28(45) - The Great Canopy, West Kowloon Cultural District, HK. (Whitehead \& Peters, 2008)

Diagram.29(46) - Kensington Market Canopy - Panel System

Diagram.30(47) - Pedestrian Canopy Design Process

Diagram.31(48) - Summer Shadow Study

Diagram.32(48) - Winter Shadow Study

Diagram.33(49) - Pedestrian Canopy in Context

Diagram.34(50) - Yonge Street Site Context

Diagram.35(51) - Brand ' $X$ 'Toothpaste

Diagram.36(53) - Yonge Street Shade Analysis

Diagram.37(54) - Yonge Street Design Process

Diagram.38(55) - Yonge Street AD Space

Diagram.39(56) - Yonge Street Installation in Context

Diagram.40(57) - Output in Context

Diagram.41(58) - Conclusion 


\subsection{Problem Summary}

- The Intergovernmental Panel on Climate

Change (IPCC) estimates that the earth's average temperature will rise by $3.8^{\circ} \mathrm{C}\left(7^{\circ} \mathrm{F}\right)$ by 2050 and as much as $5.5^{\circ} \mathrm{C}\left(10^{\circ} \mathrm{F}\right)$ by 2100 (Roberts 2005$)$.

\section{Chapter One: Background}

- In order to curb Carbon Dioxide emissions and limit the effects of global warming, society will have to increase its reliance on non-polluting renewable energy sources.

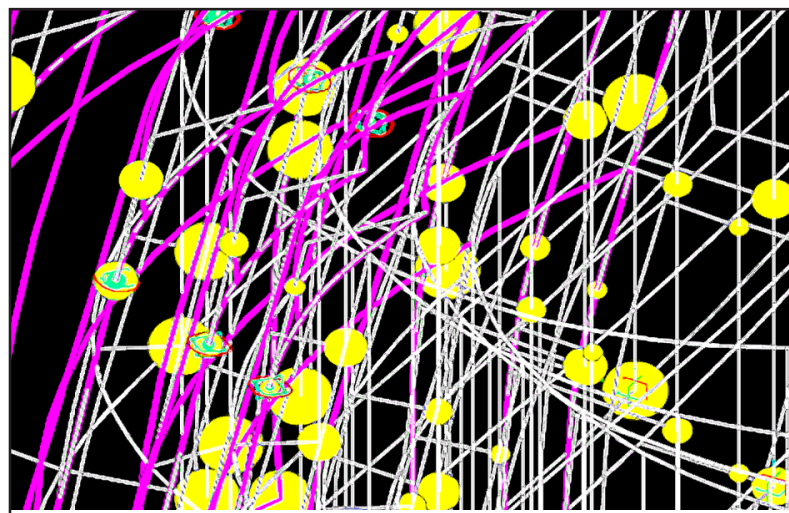

- In addition to Carbon Dioxide, electricity

production is responsible for Sulfur Dioxide, Lead, Hydrocarbon, and Nitrous Oxide emissions, which are responsible for air pollution (Geller 2003).

- Shell Oil believes that renewable energy could account for $50 \%$ of global consumption by 2060 (Scheer 2002).

- Every year the solar radiation that hits the earth's surface is fifteen thousand times more energy than required, not mentioning that is free, reliable, and non-polluting (Scheer 2002).

- Photovoltaic cells are the most direct method of converting sunlight into electricity, with conversion efficiencies ranging from $8-15 \%$, while photosynthesis is $0.5-1.5 \%$ (Roberts 2005).

- Currently, three major obstacles that prevent the wide scale acceptance of solar electricity are high costs, inadequate storage technologies, and lack of architectural/urban integration. 


\subsection{The Environmental Aspect}

Climate change associated with the emissions of Greenhouse Gas (GHG) emitted by burning fossil fuels is the primary reason why renewable energy generation is such a vital topic in current social and architectural praxis. In addition to global warming, pollution and depleting natural reserves are also of great concern to society. Energy is fundamental to the survival to all life forms, and nature's inherent ability to harness and use energy effectively is crucial to the quality of life. Broadly defined, energy is anything that allows something or someone to do work. Materials such as wood, petroleum, coal, and uranium are fuel sources that one can convert to heat energy through a chemical reaction. It is important to distinguish that fuel is not energy, but a carrier of energy. When most people think of energy consumption, they are really referring to fuel consumption. In most cases, they are not talking about an energy problem but a fuel problem, especially when they are referring to petroleum and electricity. Petroleum based fuels are generally responsible for the transportation of goods and services in society, ranging in scale from a standard family sedan, to a commercial aviation jet, to a $300 \mathrm{~m}$ long diesel powered container ship. Conversely, electricity is not a fuel but a process of delivering energy to a wide variety of end use technologies. Electricity occurs in real time, simultaneously throughout the entire system, it is not a physical commodity like oil (Patterson, 2007). The correlation is that one can use fuel to generate electricity. By converting the fuel to heat, they can boil water and create steam. The ensuring steam turns a series of turbines connected to generators and generates electricity. Although this process is far from perfect, with two thirds of the available energy typically wasted as heat, it is reliable and has been in use for over a century (Ibid.). Today fuel based electricity makes up the majority of aggregate generation, with coal, uranium, and natural gas being the primary fuel sources.

Regardless of its environmental perils, coal is still the most popular fuel source used to generate electricity. Industries have been using coal for over two hundred years, and today it is still one of the simplest and most reliable ways of generating electricity. Experts estimate global coal reserves to be around 560 million tones, which at current consumption rates is enough to last another 169 years (Scheer, 2002). Given these reasons, it is not surprising why much of the world depends on the fuel source for its electricity. In the United States, over sixty-five percent of electricity comes from burning non-renewable fossil fuel resources, $48 \%$ from coal, and $20 \%$ from natural gas and cogeneration (Johnson, 2009). China is the world's largest producer and consumer of coal, using close to 2 billion tons per year, accounting for $70 \%$ of the countries power generation (Berrah, Feng, Priddle, $\&$ Wang, 2007). The problems with coal-generated electricity are the harmful environmental side effects associated with it. Besides releasing Carbon Dioxide emissions into the atmosphere, coal fired power plants are also major contributors to sulfur dioxide emissions and nitrogen oxide emissions. Sulfur Dioxide reacts with water vapor in the atmosphere to cause acid rain, and Nitrogen Oxide emissions contribute to smog, poor air quality, and ultimately respiratory problems. According to the 
European Union, coal emissions are responsible for 70 billion dollars worth of damage to human health, buildings, and agriculture. In order to counteract the damage caused by coal emissions European Consumers would have to pay an additional 4.5 cents per kWh on top of conventional electricity rates (Geller, 2003). Coal is part of a larger global problem concerning society's addiction to non-renewable fossil fuels and its drastic environmental consequences.

It is impossible for society to address climate change without rethinking the energy problem, or more accurately the fuel problem. Since $90 \%$ of anthropogenic Carbon Dioxide and $23 \%$ of Methane comes from the burning of fossil fuels, which account for $85 \%$ of aggregate global energy consumption (Roberts, 2004). Carbon Dioxide and Methane are problematic because they act as atmospheric insulators preventing excess heat from dissipating into space. Analogous to a one-way mirror, Carbon Dioxide trapped in the atmosphere allows sunlight to pass through and heat the earth's crust, but does not allow the resulting radiating heat to escape back into space. Together the two gases account for $80 \%$ of global warming caused by the green house effect (Geller, 2003). Scientists believe that these increased levels of Carbon Dioxide in the atmosphere are responsible for $a .3^{\circ} \mathrm{C}$ $\left(0.6^{\circ} \mathrm{F}\right)$ rise in the earth's average temperature (Ibid.). Although an increase of less than a third of a degree is barely palpable it is nonetheless worrisome, considering that a three-degree average change in the earth's average temperature triggered the last ice age five thousand years ago. The United Nations Intergovernmental Panel on Climate Change (IPCC) estimates that unless we drastically lower Carbon Dioxide emissions within the next several decades, the earth's average temperature will rise by $3.8^{\circ} \mathrm{C}\left(7^{\circ} \mathrm{F}\right)$ by 2050 and as much as $5.5^{\circ} \mathrm{C}\left(10^{\circ} \mathrm{F}\right)$ by 2100 . Such a drastic change would completely melt the polar ice caps, rising sea levels by as much as half a meter, while turning other portions of the earth into deserts. Climate change models also predict that a $2.75^{\circ} \mathrm{C}\left(5^{\circ} \mathrm{F}\right)$ would result in 80 million new cases of malaria each year (Roberts, 2004). Global warming's severe consequences highlight the importance of the energy question, or more importantly the fuel question.

Electricity is not the problem, rather it is the fuel used to generate the electricity. Fortunately, society does not have to rely on fossil fuels to generate electricity, but can use renewable nonpolluting methods such as solar or wind. In these cases, there is no fuel required, only the infrastructure needed to convert the existing natural energy to electricity, and then deliver it to the end-users. For example, to convert sunlight into electricity, one does not pay for the sunlight or the 'fuel' for the process, but only for the required physical infrastructure such as the photovoltaic panels, inverters, or cables. Sustainable electricity concerns a major paradigm shift away from thinking about energy in terms of fuel, to thinking about it in terms of infrastructure (Patterson, 2007). The new question for society is how to integrate the required renewable electricity infrastructure in to the built environment. This is why electricity in the twenty first century is no longer a question solely reserved for electrical engineers and politicians, but also needs to involve architects, urban planners, civil engineers, and others. 


\subsection{Impediments to Mainstream Acceptance}

In order for our society to avoid the ecological perils of climate change as predicted by expert scientists, it will have to decrease its use of fossil fuels and increase its reliance on renewable energy sources. According to the United Nations, in order to prevent or in the worse case, stabilize the disastrous consequences of global warming, carbon free energy sources would have to account for $14 \%$ off aggregate consumption by $2030,33 \%$ by 2050 , and $50 \%$ afterwards (Roberts 2004). Shell Oil, one of the world's largest energy companies supports the UN hypothesis and believes that renewable energy could account for $50 \%$ of global consumption by 2060 (Scheer 2002). Currently renewable energy sources, including hydroelectric power generation, account for only $8 \%$ of total worldwide production. Conversely, solar and wind power account for less than $0.5 \%$ of total global production (Roberts 2004). Every year the solar radiation that hits the earth's surface is fifteen thousand times more energy than required, not mentioning that is free, reliable, and non-polluting (Scheer, 2002). Solar energy is one of societies most logical and advantageous option to decrease its reliance on fossil fuels. In fact, all living systems already depend on the sun for energy via photosynthesis, by which plants convert sunlight into glucose used as food. Photosynthesis is approximately $1 \%$ efficient, while photovoltaic cells the most direct method of converting solar energy in electricity are 8-18\% efficient (Roberts, 2005). Regardless of the environmental perils and obvious potential of solar energy, there are several obstacles preventing its wide spread use. These include economics, inadequate storage systems, and lack of architectural/urban integration.

\subsubsection{Economics}

High cost is the biggest barrier to the use of photovoltaic electricity. Very few investors will spend the large amounts of money required for solar energy systems based on purely altruistic intentions of curbing carbon dioxide emissions. Considering financing a basic domestic solar power system is equal to paying twenty years of electricity in one lump sum, the cost of solar power is not simply an accounting matter but a crucial detriment in determining its wide scale popularity (Gevorkian 2008). Ultimately, the economic feasibility of solar electricity depends on two factors, the price of grid-based electricity, and the amount of sunlight relative to geographical location (Bradford 2006). Currently, standard residential photovoltaic systems are capable of producing electricity at $\$ 0.20 \mathrm{kWh}$ without subsidies, which is competitive with electricity rates in many places of the world, notably Europe and Japan. The problem is that North Americans enjoy the lowest electricity rates in the world at an average of ten cents per kilowatt-hour, and hence have no real economic incentives to invest in solar power at the retail level. For the electrical utilities, the solar option is even less desirable since they can generate electricity between 2-5 cents per kWh (Perlin, 1999). Given the price history of solar cells, it may be safe to assume that the cost of photovoltaic electricity will continue to fall until it becomes competitive with grid electricity, at least at the retail level. 
In 1956, silicon crystalline solar cells cost about $\$ 144$ per $\mathrm{kWh}$, equivalent to $\$ 1.43$ million to power an average sized residential home. At the end of the sixties, despite a $300 \%$ cost reduction between 1956 and 1971, solar cells still cost about $\$ 100$ per Watt - more than 200 times the price of conventional electricity. Between 1970 and 1980, solar cells were cheaper than batteries or gas generators for remote applications at $\$ 1$ per kWh. Finally, in the last decade with strong support for solar electricity in Germany and Japan, the cost of photovoltaic cells fell to about $\$ 0.25 \mathrm{kWh}$, still more than double the average conventional North American electricity price of about $\$ 0.10 \mathrm{kWh}$ (Perlin 1999). Looking towards the future, a research team from the University of New South Wales in Australia predicts that silicon based photovoltaic panels will continue to drop in price with economies of scale until they reach $\$ 2.00$ per watt or 8-12 cents per kWh. Any further reductions in price will be a result of new non-silicon based technologies (Bradford 2006).

Comparing the costs of solar electricity with conventional sources is not a fair comparison, since it does not take into account indirect costs, large government subsidies, and the potential savings with distributed generation systems. Every year governments around the world pay billions of dollars in subsidies to fossil fuel and nuclear electrical utilities. For example, in 1995 the European Union gave 9.68 billion dollars to fossil fuel electricity producers, 4.1 billion dollars to nuclear electricity, and only 1.24 billion dollars to renewable energy sources. Conversely, in 1994 America spent 20 billion dollars supporting fossil fuel and nuclear electricity, and only 1 billion on green electricity (Scheer 2002). In 2006, governments spent a total of 131 billion dollars worldwide subsidizing conventional nonrenewable energy production. If conventional electricity producers did not receive these large government subsidies, and took into account the indirect costs associated with environmental damaging carbon emissions, nuclear waste disposal, and military interventions aimed at securing fossil fuel reserves the real cost of production would be much higher (Bradford 2006). Lastly, besides neglecting to account for hidden costs associated with conventional electricity production, the comparison does not take into account distribution and infrastructure costs. At the retail level, the majority of what consumers pay-for is not the actual electric power, but the effort required in transporting and distributing it. A general rule of thumb is that, half the retail price of electricity is the distribution and maintenance of the required infrastructure such as of transformers, power lines, required transporting it from the generation plants to the end consumers. One advantage of solar cells is that they produce and consume electricity in-situ, resulting in savings by avoiding distribution costs (Scheer 2002). Any analysis of the retail and production costs of conventional electricity generation is complex, making a direct and accurate comparison difficult. Nonetheless, electrical utilities find it difficult to embrace solar electricity because of its intermittent generation and high capital costs. 
At the production level, photovoltaic electricity can play a significant generation role during times of peak demand or unpredicted spikes in usage. Utilities categorize electricity production into three categories: base load, intermediate load, and peak load. Base load generation supplies the minimum amount of electricity that the grid needs to ensure uninterrupted operation. Typically, utilities use nuclear power, hydro, or coal to produce their base load power steadily running at full capacity 24 hours a day. Intermediate load is the electricity that utilities can produce without start up delays, which they use to meet part time demand and accounts for $30-50 \%$ of total generation. Lastly, peak load is electricity that generators can bring online quickly to meet rapid unexpected changes in demand, which accounts for 5-10\% of total demand (Bradford 2006). From a utilities perspective the problem with solar and wind power is its intermittent nature of generation, making them only suitable for peak load generation. Solar electricity works especially well for this purpose because peak demand occurs during summer afternoons when air conditioners are running at full capacity, precisely at the same time when output from photovoltaic systems is the greatest. Conveniently, since maximum production occurs when demand for grid electricity is the greatest, it makes sense for generators to use solar power for peak load demand (Scheer 2002). Therefore, until society develops a suitable means of energy storage to counteract the intermittent nature of supply versus the constant nature of demand, power generators will only be able to use solar power for peak demand. Since peak demand accounts for at best $10 \%$ of aggregate demand, it becomes very difficult for society to implement the technology on a large scale.

\subsubsection{Storage Technology}

The second major impediment to solar energy is inadequate storage systems, or means of storing electricity to meet demand when there is no sunlight available. A chemical battery is currently the only practical means of storing electricity. Photovoltaic installations that rely solely on batteries for backup power are stand-alone systems. These systems are best suited in providing electricity to physically remote locations divorced from any electrical infrastructure. However, batteries are limited in terms of capacity, take up space, are often expensive, and can be environmentally malignant. Conversely, grid connected systems, which rely on the central electricity grid for backup are a better solution in most cases. In these systems, users can 'download' or purchase electricity at the standard rate from the grid as needed, and 'upload' or sell surplus electricity back to the grid at a premium rate (The German Solar Energy Society 2005). The problem with grid-connected systems within the environmental context is that they still ultimately rely on conventional methods of electricity generation, which as previously demonstrated are major sources of pollution and carbon dioxide emissions. Hence, with the lack of a suitable storage system, even if society were to increase its reliance on solar energy to the amounts needed to curb the effects of global warming, it would still be dependent on conventional polluting grid electricity for base load power. 
From the plethora of storage options, which range from compressed air to electromechanical storage, many experts tout hydrogen as the most advantageous option due to its high energy density and zero carbon offset (Scheer 2002). While Hydrogen is the most abundant chemical element, it does not exist naturally in the environment like coal or oil. Rather one has to isolate it through a chemical process. Catalytic cracking is the most common method of hydrogen production, which combines steam and natural gas in a controlled environment, isolating hydrogen atoms and producing carbon dioxide as the by-product. This method is currently the cheapest and most efficient way of producing hydrogen, but its reaction relies on non-renewable energy sources and emits carbon dioxide (Rifkin 2002). Electrolysis is another method of producing hydrogen, which uses electricity to separate oxygen and hydrogen atoms from water molecules. When electrical current flows through two electrodes submerged in a water-electrolyte solution, hydrogen bubbles up at the negatively charged electrode and oxygen at the positively charged electrode. The benefit of electrolysis is that the only by-product is oxygen, and if the electricity comes from renewable resources such as solar or wind, it is a completely sustainable and non-polluting method of generating energy (Rifkin 2002). Conversely, by reversing the electrolysis process, one can convert hydrogen to electricity. Fuel cells use hydrogen, oxygen, and a catalyst (typically a thin platinum membrane) to create electricity and water, instead of using water and electricity to create hydrogen (ibid.). Fuel cells are one of societies few viable options to replace the internal combustion engine, with a hydrogen powered electrical engine. Although the required infrastructure and technology to support a hydrogen-powered transportation infrastructure is far from developed, it does offer a sustainable paradigm for how society can transition from the perils of fossil fuels a sustainable carbon free one.

\subsubsection{Urban Integration}

In addition to cost and storage, urban integration is the third major impediment to the wide scale acceptance of solar energy. Although the integration of passive and active solar energy systems into architecture has evolved drastically over the past fifty years, it is still far from mainstream practice. Up until the 1973 OPEC oil embargo, the construction of active and passive solar architecture was limited to academia, with $75 \%$ of all projects funded by universities. After the oil embargo, which was the first modern energy crisis and caused gasoline prices to triple overnight, both public and private bodies began noticing energy conscious architecture. Although the oil embargo was temporary, its impact on the development of renewable energy technologies last well into the next decade. In 1977, the Carter Administration founded the Department of Energy and the Solar Energy Research Institute and began offering tax credits for solar energy systems. Fervor for solar energy climaxed in 1979, when President Jimmy Carter installed a solar hot water heating system on the roof of the White House. However, in the middle of the eighties when oil prices stabilized, enthusiasm for solar architecture subsided. In 1986, President Ronald Regan adamantly removed the solar water heating system from 


\section{The United States}

\section{Department of Energy}

estimates that it would take

$40,500 \mathrm{~km}^{2}$ of photovoltaic

panels at current conversion

rates, or $0.4 \%$ of the

country's total area to

meet domestic electricity

demand. -DOE (Bradford,2006)

the White House, and drastically reduced funding for solar energy research programs (Borasi and Zardini 2007). This devastated the solar energy industry, which recovered a decade later spurred by renewed interest in Germany and Japan. It has only been within the last decade that society has begun to reconsider photovoltaic and solar heating systems as a viable option.

In order for solar energy to make a significant impact on global electricity supply, society will need to figure out how to integrate large amounts of functional surface area in to the environment. Solar electricity has an inherently low energy density at $0.1 \mathrm{~kW} / \mathrm{m}^{2}$ as per compared to conventional energy generation methods such as coal at $500 \mathrm{~kW} / \mathrm{m}^{2}$, or nuclear at $650 \mathrm{~kW} /$ $\mathrm{m} 2$ (Scheer 2002). This low density means that it requires large amounts of exposed surface area to generate the needed amounts of electricity. A study by the United States Department of Energy estimates that it would take $40,500 \mathrm{~km} 2$ of photovoltaic panels at current conversion rates, or $0.4 \%$ of the country's total area to meet domestic electricity demand. Forty thousand square kilometers would only account for $7 \%$ of the area in the United States occupied by urban centers (Bradford 2006). To meet this required area, utilities could easily install extensive photovoltaic arrays in remote locations and transport the electricity into urban centers via existing electrical infrastructures. A better solution is to produce the electricity in situ, saving the costs incurred with the transmission and distribution of electricity, which accounts for $50-80 \%$ of the final cost (Scheer 2002). Ultimately, if society is to increase its reliance on solar energy, it needs to figure out how to integrate hundreds of square kilometers of photovoltaic arrays into the urban fabric. It is the role of architects, designers, and engineers to offer innovative and creative strategies to the public.

\subsection{Architectural Relevance}

Architectural surfaces offer a great opportunity for society to produce large amounts of electricity in an urban context. The fundamental idea that any exterior surface exposed to sunlight can produce electricity is extremely powerful and is bound to have a profound impact on the future of architecture, both aesthetically and pragmatically. In many locations, the incident solar energy on the roof of a typical home exceeds household consumption. In these areas it is possible for homeowners 


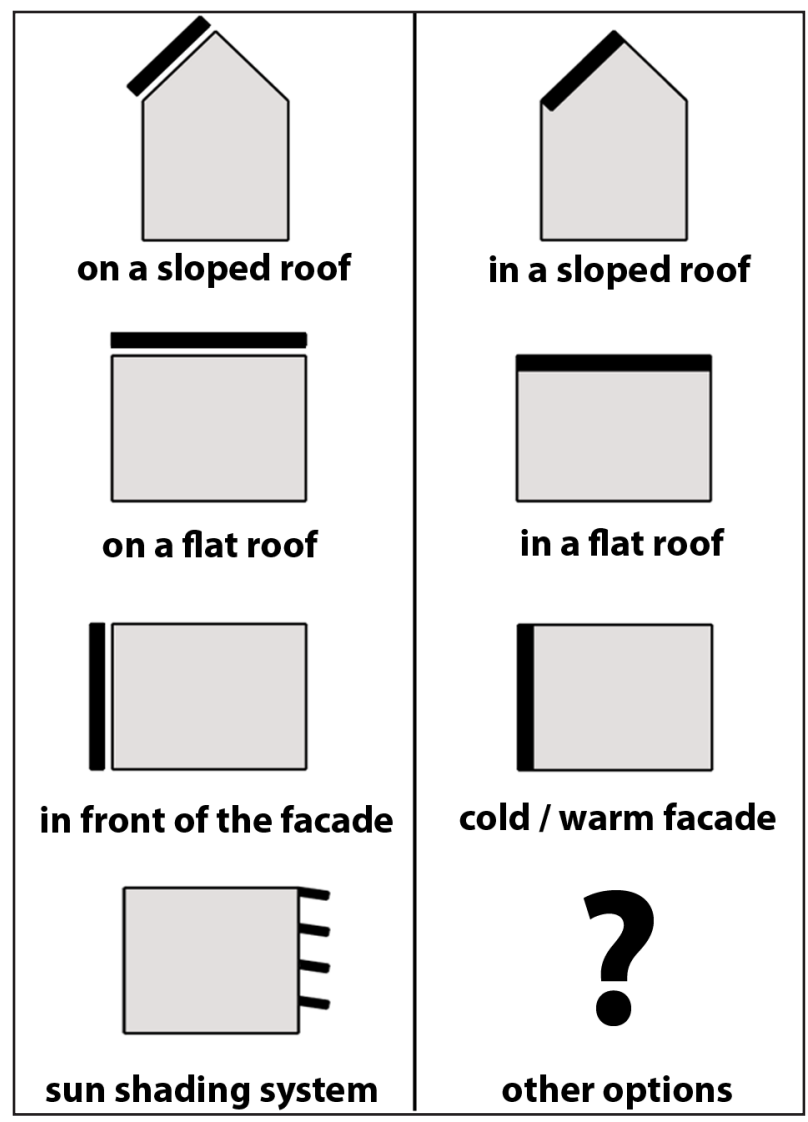

Diagram.1-Common Methods of Building integrated Photovoltaic Systems.

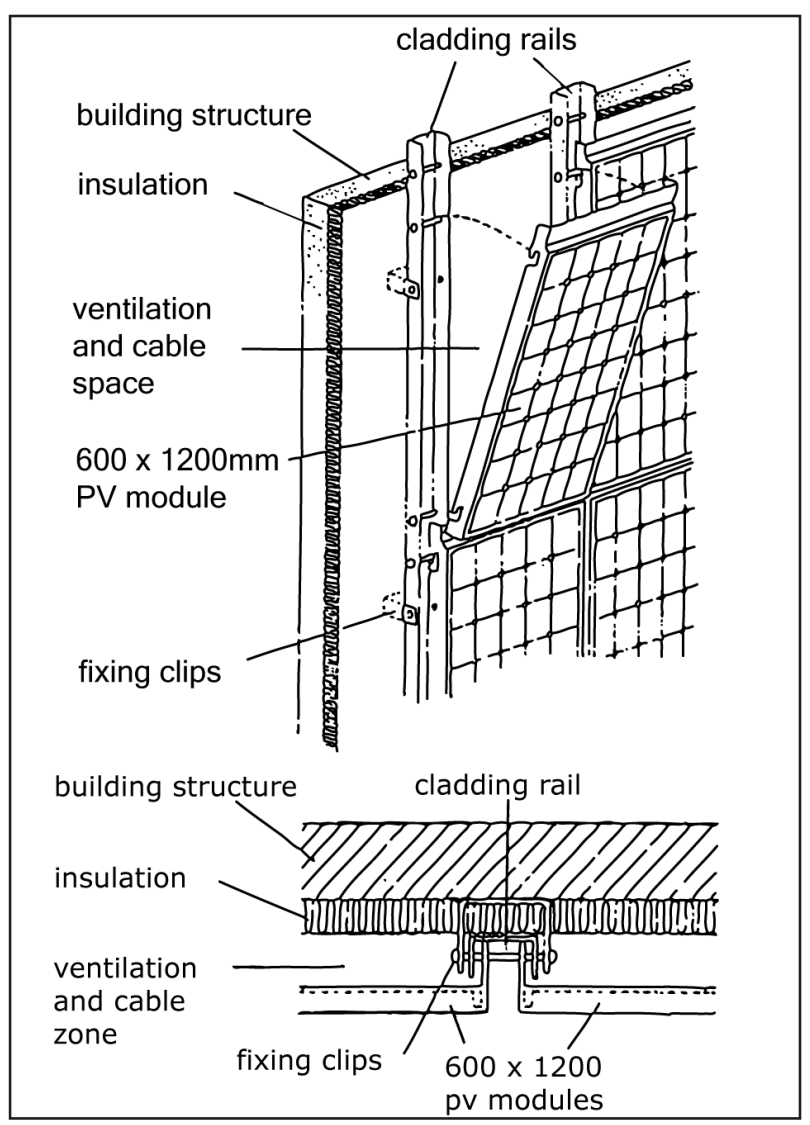

Diagram.2 - Cold Façade Building Integrated Photovoltaic System (Thomas \& Fordham, 2001).

with a properly designed photovoltaic system in addition to effective passive measures to achieve a net zero energy consumption (Dubois \& Horvat, 2010). Photovoltaic systems are not only limited to residential applications, but architects can incorporate them into a variety of architectural solutions. Diagram. 1 illustrates the seven basic ways of integrating solar energy collection with architecture. Regarding the incorporation of active solar energy systems into buildings, additive and integrated solutions are the two main methods available to architects. Additive solutions are cases where the photovoltaic modules are an additional building component, on top of or in addition to an existing one. The major benefit of additive systems is that one can attach them to any existing structure not limited to buildings. Conversely, integrative systems involve replacing building components with photovoltaic modules, which become part of the envelope. Diagram.2 illustrates an example of an integrative solution suitable for cold climates. The benefits of integrated systems are that they are much more aesthetically and economically appealing if introduced at the early design phase. However, with integrative systems the solar cell's primary function is as an envelope component, so the architect must address issues of waterproofing, durability, and maintenance in addition to energy generation. Using the photovoltaic module to clad the structure and produce electricity offsets the capital cost of the system, because of its dual purpose. With building integrated systems, the deciding 
is not the price per kWh compared to conventional electricity rates, but the capital cost difference between the active and non-active envelope components (Scheer 2002). While both methods are relevant to architecture, integrated systems are more relevant to the traditional architectural design process.

As integrating solar energy systems into the design affects the orientation, form, layout, and footprint of the building; it is important for the design team to consider them from the start of the design process (Thomas and Fordham 2001). Decisions made in the Early Design Phase (EDP) have the greatest impact on the performance of the project in terms of energy efficiency. During this time, the design team makes approximately $80 \%$ of the design decisions that affect the energy performance of a building. The team makes the remaining $20 \%$ during the detailed design phase (Dubois \& Horvat, 2010). Given the importance of the EDP in designing high performance active solar buildings, architects need, "tools that adequately support EDP decisions and allow an optimization of the building envelope as a passive and active solar energy collector" (Ibid.), design tools and methodologies is the central focus of the research problem.

In addition to the need for better tools to support a solar architecture design process, other factors such as limited manufacturer options, lack of technical expertise from architects and clients, and a lack of forward thinking and creative proposals remain. Integrating active solar energy systems into the building envelope requires special consideration from the architect with respect to aesthetics and overall architectural composition. Limited product options make it difficult for architects to integrate solar components into the envelope, while simultaneously maintaining the overall aesthetic composition of the building. This goes beyond the materiality and surface finish of the modules, but also includes the size, proportion, mullions, and sub-division of the panels (Herzog, Krippner and Lang 2004). Albeit, manufactures are offering more options to architects in regards to the appearance of solar energy collectors, especially in Europe. A survey of European Architects still identified the lack of choices concerning the size, texture, color, joint treatment, and shape of the solar collectors as a barrier in designing a system coherent with the overall building design. To support a higher degree of flexibility, façade manufactures should provide a complete envelope system that harmoniously incorporates both active and non-active 'dummy' components. Since not all building elevations are suitable for solar collectors, there is a need for façade components that are similar in appearance to active elements, but only fulfill the envelope function are required for a coherent architectural composition (Munari-Probst 2008). Even with increased manufacturer options the design of quality building integrated photovoltaic systems requires a high degree of specialized knowledge that is largely absent from the broader architectural community.

Research completed under the Task41 Solar Energy and Architecture, Subtask B; Methods and Tools for Solar Design identified the lack of technical knowledge regarding the design of building integrated photovoltaic systems as a major impediment to utilization of solar energy systems (Dubois 
\& Horvat, 2010). The report continues to identify the lack of education regarding solar energy systems in architecture schools as a significant part of the problem. It highlights the need for academia to teach students not only the empirical fundamentals behind solar energy, but also how to integrate these collection systems into building envelopes at a detailed level (Ibid.). This lack of technical expertise coupled with little market demand contribute to the third impediment, a general disinterest from the North American architectural community concerning how to integrate solar energy into the built environment. Within contemporary architectural discourse, there is little interest in applying the innovation inherent in the profession to propose a strategy how to incorporate photovoltaic systems into architecture on a large scale. This inactivity has resulted in shaping the general perception of solar energy collection systems as rooftop additions heterogeneous to the overall building aesthetic. Impinging on this lack of interest and technical knowledge is the inadequacy of available design tools to support the building integration of photovoltaic systems, especially at the EDP.

The central problem with the design tools currently available is not that they are incapable of helping design photovoltaic systems, but that they are unsuitable for the EDP, which as previously mentioned is the most important in terms of energy performance. As of yet there are no solar design tools directly aimed at supporting the early design phase of the project, which is an significant barrier in designing high quality solar buildings. Architects need design tools that support early design phase decisions in helping them optimize the building envelope in terms of solar energy collection (Dubois \& Horvat, 2010). At the early design stage, it is crucial that the architect can easily modify with a'mouse click' the overall volume, geometry, and orientation of the building. More importantly, the architect must be able to validate the design modifications through empirically objective solar analysis parameters pertaining to incident radiation collection. To date there are no tools available that can provide direct, iterative, and intuitive feedback from analysis models into the early design phase of the project (Ibid.). This outlined shortcoming in design tools geared towards the early design phase of intelligent solar buildings is a major impediment to the lack of architectural integration as illustrated in the Task41 Subtask B.

The majority of software aimed at the design and analysis of solar collection systems are more suited towards the detailed design phase of the project, where extensive information is available and the majority of the major design decisions have already been made (Dubois \& Horvat, 2010). A study cited in Subtask B concerning the design methods of energy efficient buildings clearly identified that the available design tools are inadequate to evaluate the impact of early design decisions on the buildings energy efficiency. The absence of these tools creates a disjunction between the traditional design process and the required feedback from the analysis software. In order to improve the architectural integration of photovoltaic systems a new design methodology is required, one that is inherently flexible and quantifiable, so that architects can validate and subsequently modify the design as required in an efficient manner. 


\subsection{Aim + Scope}

The aim of this thesis is to propose a new design methodology by combining parametric and environmental analysis tools, to provide quantitative performance indicators to assist architects at the early design phase. Through case studies, the research will demonstrate how the methodology can be applicable to a wide array of project typologies within an urban context. These case studies will illustrate the potential for photovoltaic installations to alter the landscape of the city and facilitate a fresh dialogue between public space and renewable energy generation. The proposed methodology consists of three parts, starting with gaining a general technical understanding of how photovoltaic systems work. This first step is crucial in order for one to successfully interpret and apply the analysis data during the design process. Next, the method introduces parametric and environmental analysis modeling, examining how the two platforms can effectively work together and why they are vital to a successful solar design process. Lastly, the process reiterates the importance of the designer to interpret the analysis data in combination with other external non-quantifiable variables such as aesthetics and site-specific conditions and successfully apply it to the architectural massing. With the proposed methodology outlined, the final design component will illustrate how architects can apply the process to three unique photovoltaic installations in the Greater Toronto Area. With each installation, the designer will have to respond to various different social and physical conditions, combining the empirical feedback from the analysis with design intuition. The three sites include redefining the Canadian Malting Silos, designing a pedestrian canopy in Kensington Market, and rethinking advertising space on Yonge Street. The ultimate hope of the design intervention is to highlight and inspire people to the potential photovoltaic systems have in helping shape the city towards a carbon neutral future. 


\subsection{Technical Background}

The first part of the methodology

consists of gaining a basic technical

understanding of how photovoltaic systems

work. This part is crucial because without a

general understanding of how solar cells convert

Chapter Two: Proposed

\section{Methodology}

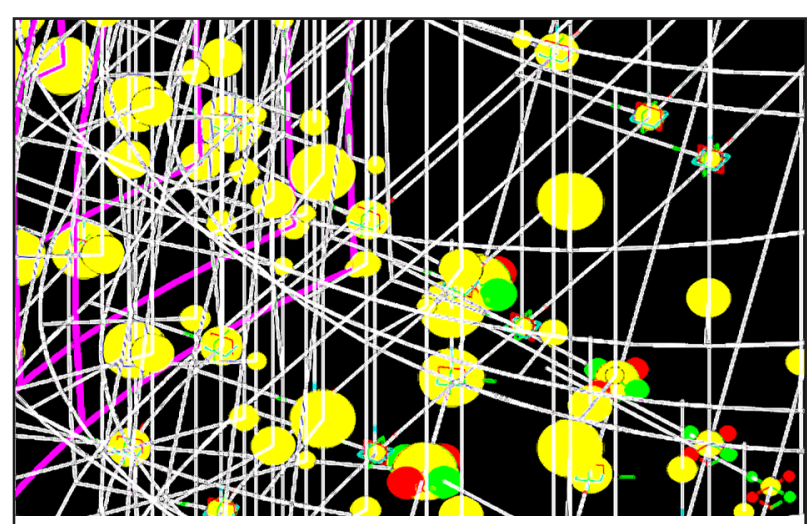

sunlight into electricity, or what factors influence the output of systems, it is almost impossible for the architect to effectively interpret and apply the data from the analysis models.

\subsubsection{The Photovoltaic Effect}

Photovoltaic cells are the most direct method of converting sunlight into electricity. They consist of semiconductors, which are materials that can function both as insulators and as conductors of electricity. Silicon, made from silica sand, is the most common semi conductor used in the electronics industry. When a semiconductor absorbs light, the energy excites the electrons to such a degree that they break free from their individual atomic orbits. These freed electrons can travel through an electrical circuit via electrical contacts on the surface of the semiconductor. This process is the photovoltaic effect and is the basis for all solar electricity technology. Diagram.3 illustrates how solar cells convert sunlight into electricity. However, solar cells are only able to convert a fraction of the sunlight that they absorb because the photon energy is either too high or too low. The amount of energy that light carries is light quanta or photons and depends on its wavelength. Shorter wavelengths are more powerful, and longer wavelengths carry less energy. For example, red has the longest wavelength or frequency in the 


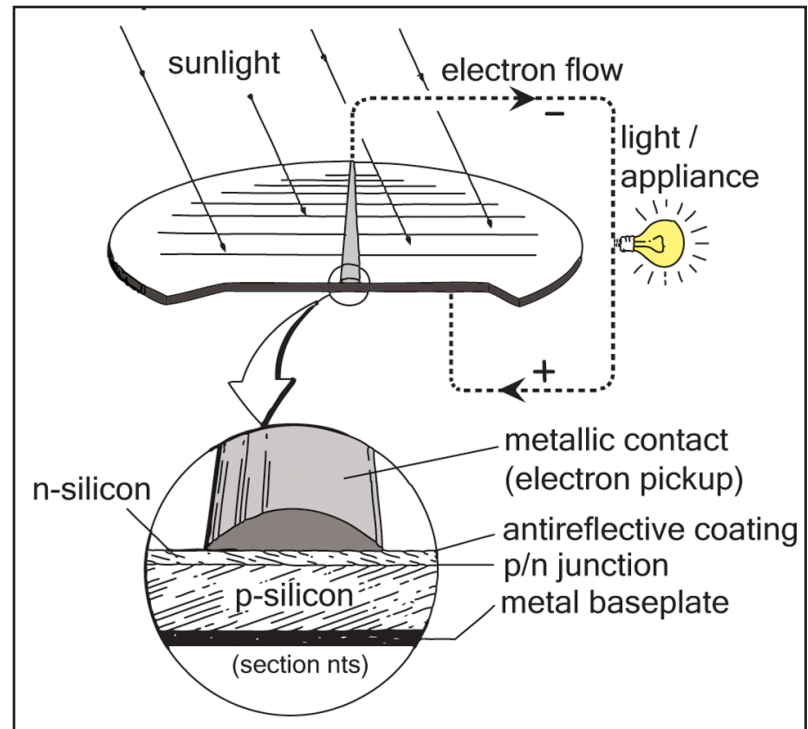

Diagram.3 - How Solar Cells Work (Maycock \& Stirewalt 1981, 27)

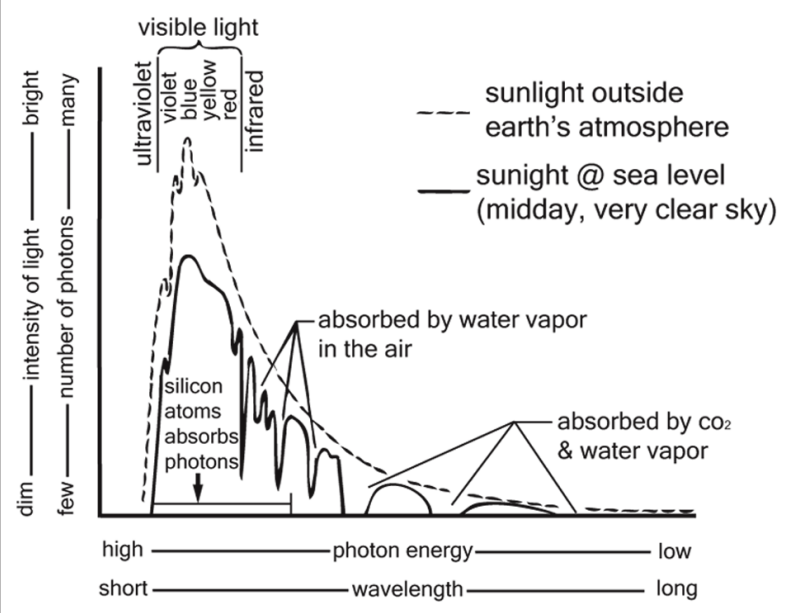

Diagram.4 - Visible Light Spectrum (Maycock \& Stirewalt 1981, 20)

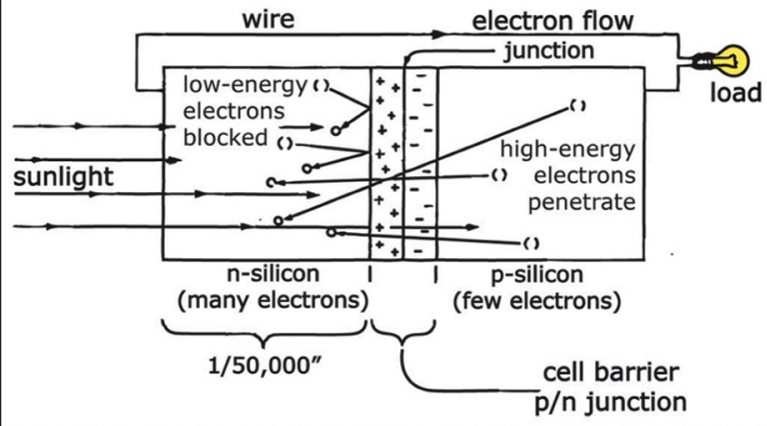

Diagram.5 - Solar Cell Composition (Maycock \& Stirewalt 1981, 30) light spectrum and barely has enough energy to free the electrons within the cell. This is why over $50 \%$ of the sunlight that hits the surface of the solar cell is unsuitable for electricity production because the photon energy is either too high or too low (The German Solar Energy Society 2005). Diagram.4 shows the entire light spectrum and demonstrates why solar cells are only able convert a small portion of the absorbed light into electricity by outlining the visible color range in relation to the entire spectrum.

When initially developed in the 1950s silicon solar cells were only able to convert 2-5\% of absorbed sunlight into electricity (Perlin 1999). It was not until scientists developed a way of controlling the flow of electrons within the cell, by altering the electrical charge of the silicon, that efficiencies increased substantially. By adding specific impurities to the silicon, scientists discovered that were able to change the electric charge of the semiconductor, adding gallium induced a positive charge and lithium a negative charge (Perlin 1999). This process of adding impurities to a pure semiconductor is 'doping'. Phosphorous and boron are two common impurities used by manufacturers during the doping process to alter the charge. If one adds phosphorous to the silicon, it posses more electrons and gives it a negative charge (N-layer). Conversely, if one adds boron to the silicon, it posses fewer electrons and gives it a positive charge (P-layer) (Komp 1995). When the two layers are sandwiched together, they create a $\mathrm{P} / \mathrm{N}$ junction or a permanent electric field where they meet. The junction is similar to a magnetic field where opposite poles/charges attract each 
other and like poles/charges repel each other. Simply stated as sun light hits the electron rich N-layer, the absorbed energy causes some of the electrons to break free from their atoms. The electric field pulls the freed electrons to the electron deficient P-layer, in turn creating an electric current within the cell. Electrodes at the cell's surface channel the current through an electrical circuit. This directed electrical current is electricity (The German Solar Energy Society 2005). Diagram.5 illustrates how the two layers work together to form an electric field and control and channel the flow of electrons from within the cell to the electrodes or contacts at the surface. The electrons freed in the process form a direct electrical current, which one can use to power their light bulbs, air conditioners, or any other electric appliance.

The amount of electricity that a solar cell can produce depends on the amount of sunlight it receives, but more specifically the amount of current or flow of electrons generated within the cell. This relationship between current (amps), voltage (volts) and watts is very important in understanding how solar cells work. The watt is the standard unit of electrical power. It describes the rate at which something does work. For example, a weight lifter lifting a dumbbell is an example of work, the rate at which they lift the dumbbell is power. Electric power or wattage is determined by the pressure exerted on the electrons in a circuit (volts), times the rate of flow (amps) (Miller and Miller 2002). A useful analogy is a garden hose, where voltage is the pressure exerted by the water inside the hose, and current is the amount of water flowing through the nozzle. Since current is dependent on how much sunlight the cell receives, and voltage depends on materiality, as solar irradiance levels change, current fluctuates while the voltage remains generally unaffected. Diagram.6(1) illustrates an I-V curve, which demonstrates how different amounts of sunlight affect the current and voltage in a typical crystalline silicon photovoltaic cell. Engineers use these curve to determine the optimal output of solar cell in different atmospheric conditions. The relationship between voltage and current explains why any shading on a crystalline photovoltaic system can be especially problematic. Using the example of a fire hose again, if the nozzle is closed, the voltage (pressure) remains high, but current (flow of water) reduces to zero. Just as a shadow cast on photovoltaic panel, does not affect the voltage of the system, but restricts the current flowing through each cell in the series as demonstrated in Diagram.6(2). This built up current in the cell eventually dissipates as heat, which can leave dark spots permanently damaging the cells and drastically reducing the total power output of the module. This is why even a small shadow can have a large impact on the output of a photovoltaic system, if the electrical engineer does not design it correctly. Alternatively, if the engineer connects the cells in parallel, as also demonstrated in Diagram.6(2), the array is less susceptible to output loses sue to shading (Prasad and Snow 2005) 


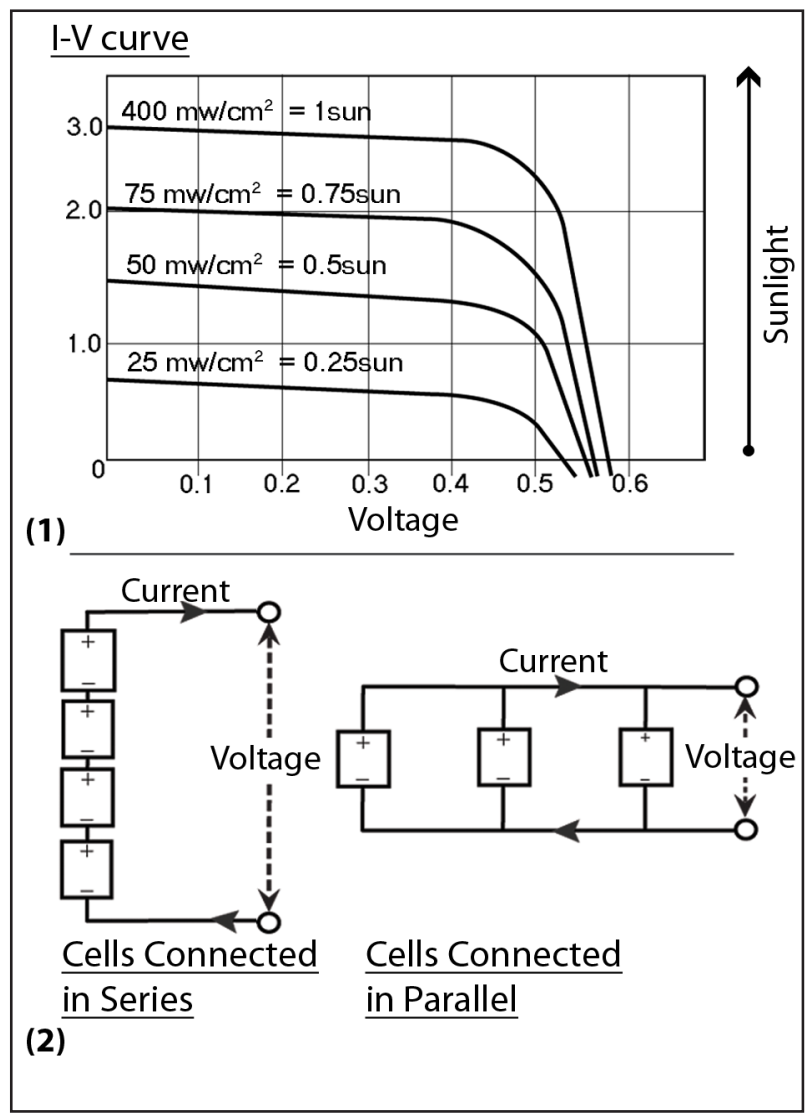

Diagram.6 - The Relationship Between Current and Voltage (Thomas \& Fordham, 2001).

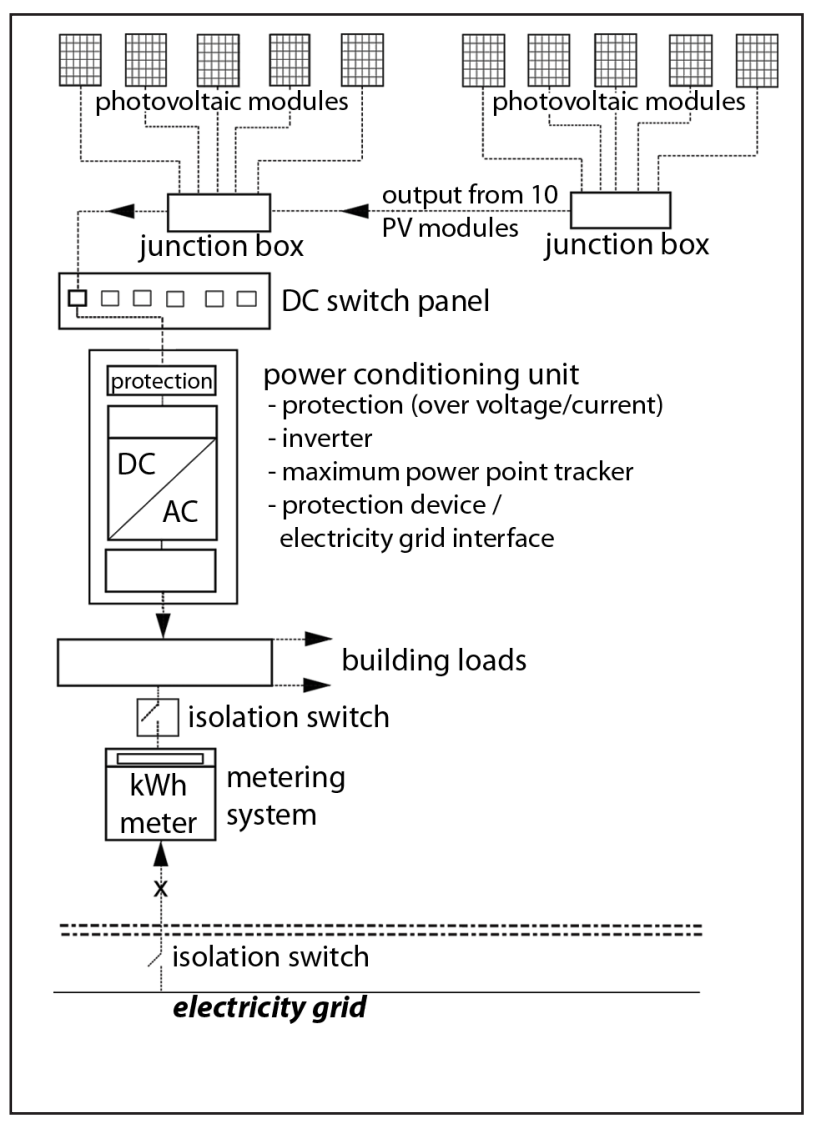

Diagram.7 - Grid Connected Photovoltaic System (Thomas \& Fordham, 2001)

The two types of photovoltaic technologies commercially available today are crystalline silicon and thin film cells. Eighty five percent of the solar cells produced today are crystalline silicon and thin film cells. Eighty five percent of the solar cells produced today are crystalline silicon, which use silicon as the semiconductor material (Bradford 2006). What distinguishes mono/poly crystalline silicon cells from each other and from thin film cells is the manufacturing process. Both mono and poly crystalline cells involve extracting ingots from molten silicon, cooling them, and then cutting them into individual cells about 300 microns or about 0.012 of an inch (Komp 1995). Technicians then 'dope' the cells through a diffusion process, add the required electrical contacts and lastly apply a nonreflective surface coating is added to the cell (Gevorkian 2008). Without any surface coating, crystalline silicon cells reflect rapproximately $35 \%$ of incident sunlight. Conversely, optical coatings applied to the surface of the cell reduce reflective losses to less than $3 \%$. Besides significantly improving efficiency, anti-reflective coatings also change the appearance of the cells, and are what give mono-crystalline panels their characteristic bluish hue as opposed to their native grey (The German Solar Energy Society 2005).

The key differences between mono and poly crystalline silicon wafers results from the manufacturing process and the grade of silicon used. Extruded polycrystalline silicon ingots cool at 
different rates, resulting in the formation of many small crystals or grains. While mono-crystalline cells cool uniformly due to the purer grade of silicon used, which results in a more homogeneous crystalline structure. The disadvantage of having heterogeneous crystalline structure is that the boundaries between the grains reduce the cells overall efficiency. However, using lower quality silicon makes them less expensive to produce (Stamenic and Ingham 1995). Alternatively, thin film cells involve a process of applying photoactive semiconductors to a substrate in thin layers rather than slicing them from a single ingot. These thin film materials are able to absorb much more light energy then typical crystalline cells, which allow manufactures to use thinner layers. They also require lower manufacturing temperatures, resulting in less embodied energy and lower manufacturing costs (The German Solar Energy Society 2005). Although thin film technologies are less efficient, at 4-8\% compared to $13-18 \%$, lower costs make them an attractive option. Besides cost, thin film modules have several other key advantages, they are more efficient in low light conditions, and are less susceptible to output losses from shading and high temperatures than crystalline cells. Many scientists believe that thin film technologies are the future of solar electricity, since they do not use crystalline silicon and have a less labor-intensive highly automated production process (Perlin 1999). Although they are less efficient than crystalline cells, recent technological advances in multi-layered cell structures where different layers of the cell correspond to specific sections of the light spectrum, promise to increase the overall efficiency of the technology (Ibid.). However, all types of solar cells rely on the same photovoltaic process to convert sunlight into electricity, which channels electrons in one direction from the cell through the electrical circuit.

Photovoltaic cells produce direct current (DC) electricity, while the majority of appliances and the central grid run on an alternating current (AC). Systems require an inverter to covert the current from DC to AC. Although there are many different types of inverters, the simplest ones work by segmenting the incoming direct current into specific portions. By alternating the current direction within the individual segments, the inverter creates oscillations or waves, which it can harmonize to match the desired frequency. In North America, the electricity grid has a frequency of 60 hertz, which means that the inverter has to change the direction of the current 60 times per second (Chiras, Aram and Nelson 2009). This allows the electricity produced by photovoltaic cells to power common electrical appliances, and makes grid connectivity possible. Electrical utilities have very strict policies regarding the selection of grid-connected inverters to ensure it matches the correct frequency (Gevorkian 2008). Although the inverter and the active solar modules are the two central components of a grid-connected system, other components such as metering devices, circuit breakers, isolation switches, junction boxes, and surge protectors are often required. These additional components help the customers quantify output by telling them exactly how much electricity the system uploads or downloads from the grid, and protects individual components of system and the main grid from electrical surges. Diagram.7 illustrates a schematic of a simple grid connected system. 


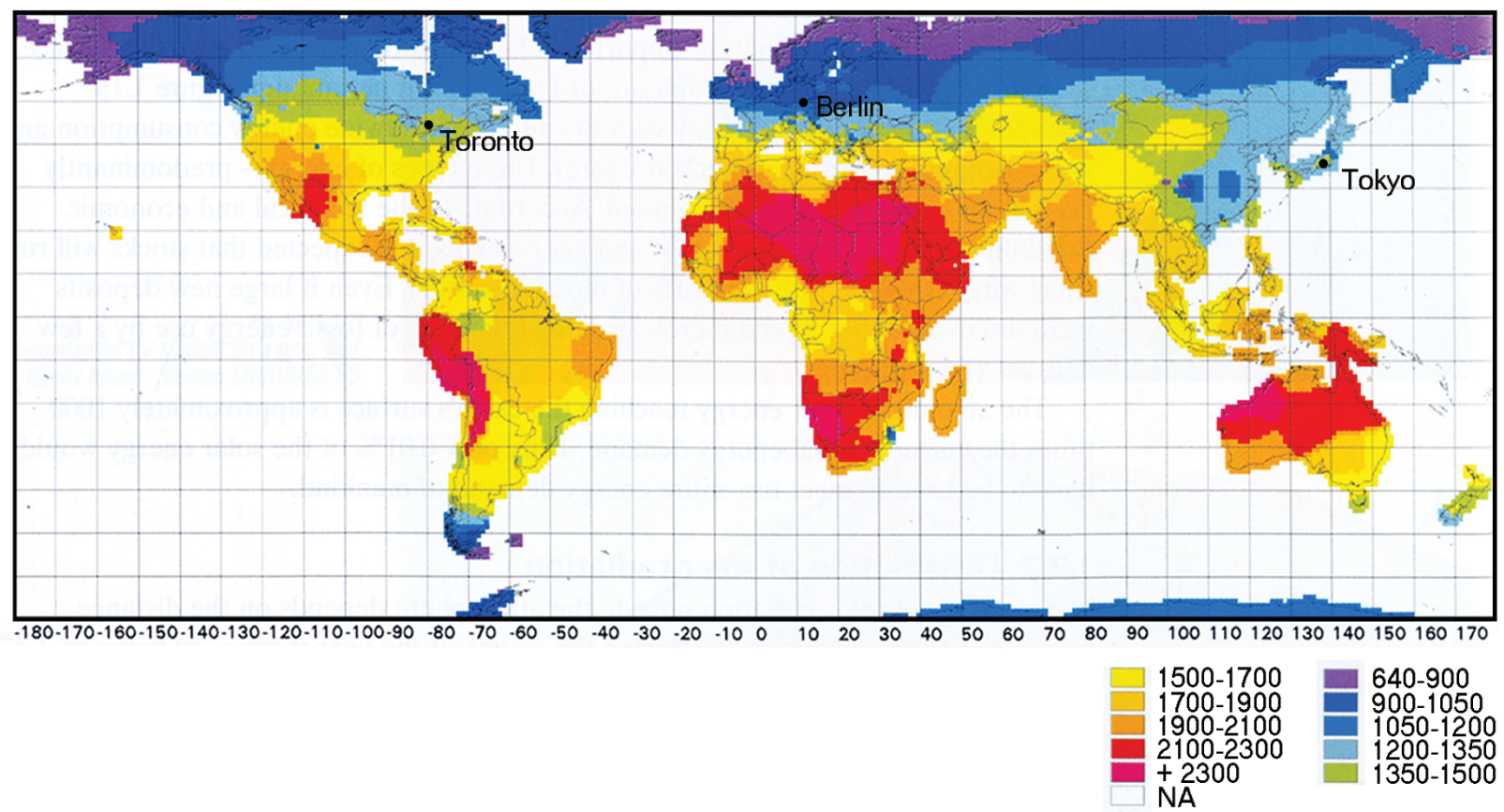

Diagram.8 - Annual Solar Radiation Values $\left(\mathrm{kWh} / \mathrm{m}^{2}\right)$

(The German Solar Energy Society, 2005)

The electrical output of a photovoltaic system is primarily dependent on five factors:

\begin{tabular}{l} 
- The location of the site in respect to solar \\
radiation values \\
- The tilt of the panels with respect to solar \\
altitude \\
- Orientation of the PV array with respect \\
to solar azimuth \\
- Shadows that are cast on the cells from \\
surrounding objects \\
- The operating temperature of the panels \\
\hline
\end{tabular}

Since the performance of photovoltaic modules depends on the amount of solar radiation it receives, insolation values a very important factor when designing the system. Insolation, irradiance, or solar radiation refer to the intensity of solar energy that strikes a given area, dependent on the geographic location and climatic conditions of the area in question. Locations near the equator and in arid climates receive the greatest amount of solar radiation. Diagram.8 illustrates varying levels of sunlight intensity throughout the globe. Solar radiation values combined with local electricity rates are the two biggest factors in determining the cost effectiveness of a system. This is why Germany, despite receiving relatively little amounts of sunlight, is next only to Japan in having the world's largest photovoltaic market, producing 
2200 GWh of solar electricity in 2006 (Johnson 2009). Consequently, the cost per kilowatt-hour of grid electricity in both Germany and Japan is more than double typical North American rates. The examples of Germany and Japan demonstrate that while high levels of solar radiation are advantageous for electricity production, they are only half the equation.

In addition to solar radiation values, the positioning of photovoltaic panels in regards to output of the array by 5\% (CANMET 1991). Regarding tilt angles, cells obtain maximum power output when the surface is directly perpendicular to the solar altitude angle (Gevorkian 2008). However, the since solar altitude is dependent on the season, the optimal tilt angle fluctuates during the year. Research from the University of Taiwan found that as a general rule of thumb for most locations in the Northern Hemisphere, tilting the panel at the same angle as the latitude of the location achieves 98.6\% of photovoltaic system performance (Cheng, Sanchez Jimenez and Lee 2007). Other research from previous studies published in the same report identified the need for two optimal tilt angles, one for the summer, and one for the winter. During the summer season, the optimal tilt angle is the angle of latitude minus $15-20^{\circ}$. Conversely, in the winter the optimal tilt angle is the angle of latitude plus fifteen to twenty degrees. Designers who are aware of this correlation between the latitude angle and optimal tilt angle can assume a very efficient panel position without any additional calculations or need for specialized data (Ibid.).

Since the sun's position is always in a state of constant flux, so are the optimal angles for the panels. Appendix. 1 shows solar radiation data collected by NASA over a 25-year period; the charts also demonstrate the optimal tilt angels for different times of the year in Toronto. Sophisticated installations often include support platforms that can automatically orientate the modules to the optimal solar position corresponding to daily and yearly solar movements. Panels can be orientated to correspond to either daily solar azimuth angles or seasonal altitude angles, or both, using two types of tracking systems, single and dual axis. Single axis trackers can only adjust in one direction, either responding to the azimuth or altitude angle. While dual axis trackers can adjust to both, azimuth and altitude. Regarding output, tracking systems can increase photovoltaic electric production by approximately $20-40 \%$, albeit while incurring higher initial capital costs. However, tracking mechanisms are relatively cheap compared to the total cost of the system (Gevorkian 2008). A study conducted at the University of Montreal compared electricity production from fixed photovoltaic modules versus arrays with tracking systems in twelve American Cities. It concluded that with fixed panel systems electrical production ranged from 1200-2100 kWh/year, compared to $1700-3200 \mathrm{kWh} /$ year with solar tracking systems. Based on 2003 solar panel prices, tracking systems cost about 12\% more than basic fixed panel systems (Bilgen 2004). The orientation of the panels in respect to solar altitude and azimuth are only two of the five factors that influence output. 
One can calculate the approximate annual output of a system by multiplying the area of photovoltaic surface by the average efficiency coefficient of the cells by the amount of solar radiation received. For example, in Toronto the average yearly incident radiation on a $60^{\circ}$ surface is approximately $1700 \mathrm{kWh} / \mathrm{m}^{2}$. If we use a $100 \mathrm{~m}^{2}$ crystalline array with an expect yield of $12-15 \%$, then total electricity production would be about 20.4 to $25.5 \mathrm{MWh}$ per year. For more accurate output calculations, the designer must account for the orientation of the array, the effect of temperature on the photovoltaic cells, surface dirt on the modules, losses due to shading, cabling and protective devices, and the efficiency of the grid-connected inverter (Prasad and Snow 2005). For example, heat can significantly reduce the efficiency of crystalline silicon cells, and lower the overall output of the system. Every degree increase in the surface temperature of the solar cell above $25^{\circ} \mathrm{C}$, results in a $0.5 \%$ decrease in power output. In areas with large amounts of solar radiation, the surface temperature of photovoltaic modules can reach twenty to forty degrees Celsius above the ambient temperature (Thomas and Fordham 2001). For example, on a normal summer day in Southern England, with an ambient temperature of $20^{\circ} \mathrm{C}$ and solar irradiance of $0.8 \mathrm{~kW} / \mathrm{m}^{2}$, a PV module would have an operating temperature of around $42^{\circ} \mathrm{C}$, reducing the output by almost $9 \%$.

Depending on the quality of the photovoltaic installation, one can assume a performance ratio of between $70-80 \%$, referring to the relationship between the ideal output values in standard test conditions and the real values under actual conditions. Generally, architects use a factor of 0.9 to attribute for losses to temperature and surface dirt, and a factor of 0.8 for losses due to inverters, cabling, and protective devices (Thomas and Fordham 2001). Therefore, in the above example where the system produces $20,400 \mathrm{kWh} /$ year, real production would be more like 14,500kWh/year $(20,400 * 0.9 * 0.8)$. Another way to calculate the approximate output of a system is to multiply how many hours of daylight a location receives by the maximum output of the modules. For example, a photovoltaic system rated at $2 \mathrm{kWp}$ under standard test conditions can produce a maximum of 2 kilowatts of power at any given time. Peak kilowatt output (kWp) is the industry standard for rating solar panels and refers to the performance of photovoltaic cells under Standard Test Conditions (STC). STC presumes an air mass index of 1.5 , a module temperature of $25^{\circ} \mathrm{C}$ and $1 \mathrm{~kW} / \mathrm{m}^{2}$ of solar radiation. These ideal conditions simulate a clear sunny day where the sun's altitude is approximately $60^{\circ}$ above the horizon, and the array is orientated towards the equator (Prasad and Snow 2005). Therefore, assuming standard test conditions for the duration of eight hours of daylight, the system in question could theoretically produce $16 \mathrm{kWh}$ of electricity a day. However, since the array receives varying amounts of solar radiation throughout the day, and since the ratings do not take in to account system losses, the actual output of the $2 \mathrm{kWp}$ system would be significantly less under real conditions as illustrated above. 


\section{"At EDP, it is crucial for the architect to feel that the building's overall volume, geometry and orientation can be easily modified by a mouse click. The changes made on these parameters should be connected to a direct, explicit feedback about predicted solar gains"}

- Task 41; State of the Art of Digital Tools Used by Architects for Solar Design

\subsection{Digital Tools}

The second part of the methodology focuses on the digital tools used during the EDP, and specifically how designers can use them to further the architectural integration of photovoltaic systems. Building integrated photovoltaic systems are much more successful if designers implement them at the EDP, when the buildings' overall massing is determined. During this phase, it is important that the architect is able to modify the volume, orientation, and geometry with a 'mouse click' (Dubois \& Horvat, 2010). This required flexibility requires a new type of CAD system, as opposed to traditional rigid digital tools. With conventional CAD systems every time the architect explores a new design option, a technician has to update the digital model to suit. This tedious process involves extra time, resources, and impinges on the creative form exploration process during the EDP. Conversely, a CAD system that captures design intent instead of graphic representation, would allow architects to try numerous design iterations precluding any mechanical rework.

\subsubsection{Parametric Systems}

The idea of capturing design intent over representation presumes a major paradigm shift in CAD technology. It requires the user to define a series of relationships between the objects in the building, based on dependencies or parameters, instead of drawing a digital representation of the object. Etymologically derived from parameters, parametric systems deal with a hierarchy of dependencies or rules that define the relationships between objects. In this system, if an object changes, objects related to it will automatically change based on the previously defined relationships. Therefore, designers can manipulate parts of the system, while maintaining the overall hierarchy of relationshipsthat make up the system (Dalziel 2008). For example, to modify the geometry of the building, all the architect has to do is change one of the underlying variables or parameters, which they can do with a 'mouse click', and see the results instantly. This CAD paradigm is precisely what the Task41 report prescribed as necessary to improve the architectural integration of photovoltaic systems.

With parametric systems, the focus is no longer on designing an object or building, but on designing a system of ordered dependencies, that designs the object (KPF 2008). Achim Menges, 


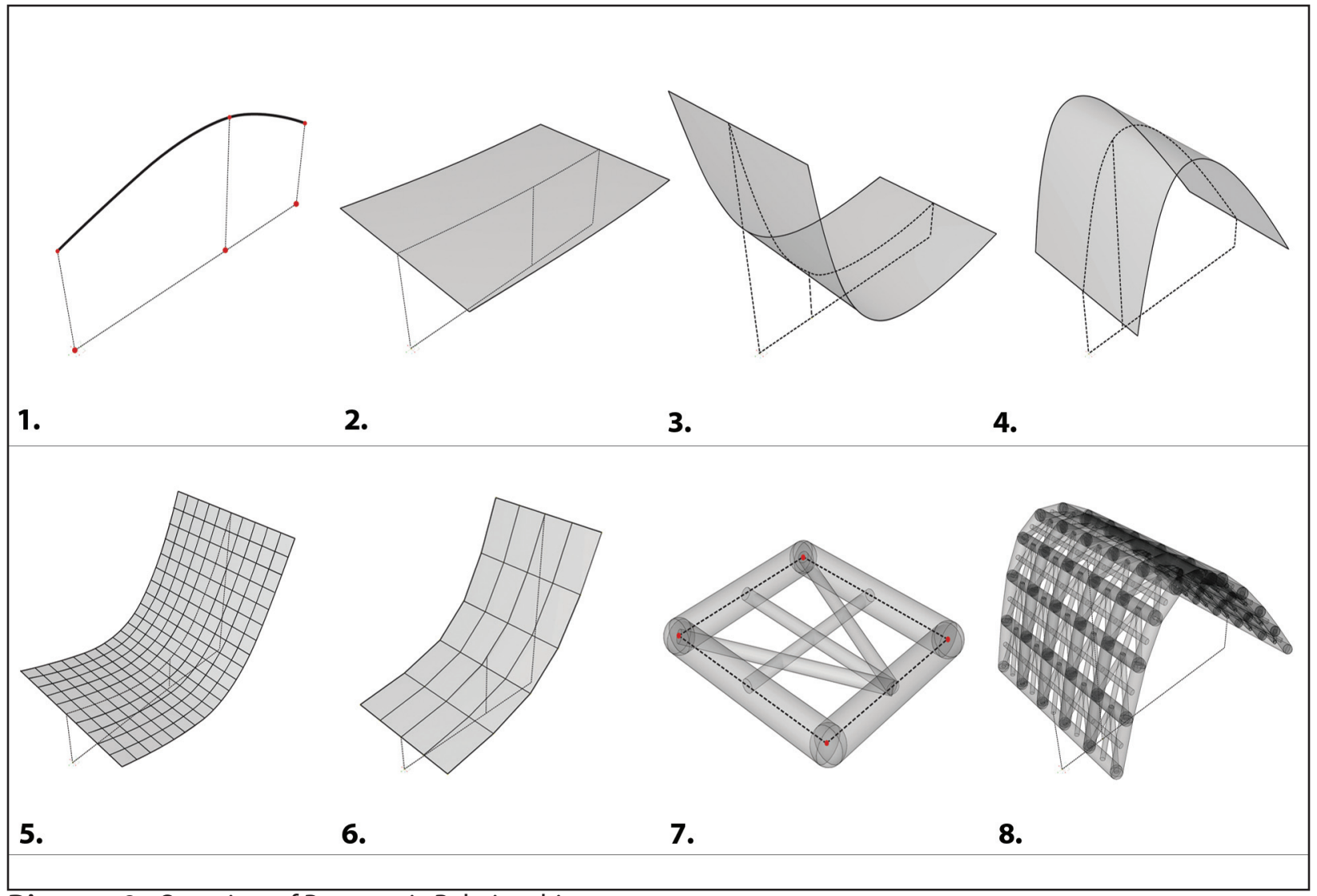

Diagram.9 - Overview of Parametric Relationships

a professor and advocate of advanced digital technology in architecture, summarizes this new design paradigm as a, "shift away from primarily designing the specific shape of the building to setting up geometric relationships and principles described through parametric equations that can derive particular design instances as a response to specific variables, expressions, conditional statements and scripts." (Menges 2006, 43). What are important now are not the digital objects, but the relationships between them. In this new workflow, the role of the digital architect is to build a hierarchy of relationships that ultimately design the object. Diagram.9 illustrates a simple example of how one can organize dependencies between objects into hierarchy of relationships in the design of a simple curved surface populated by a cladding element (7). This example involves three distinct objects, a base curve (1), a surface(2), and a user defined cladding element (7). The geometry of the surface depends on the base curve. If one changes the underlying curve, the surface responds to suit (3-4). One can also subdivide the surface into a polygon grid, in order to attach the cladding component (5-6). It is also important to note that the density of the polygon grid mandates the visual continuity of the surface, the denser the grid the smoother the surface. These relationships between the objects represent tiers in the parametric hierarchy, allowing the designer to modify specific variables in the individual objects with a'mouse click', while still maintaining overall hierarchy. For example, the 


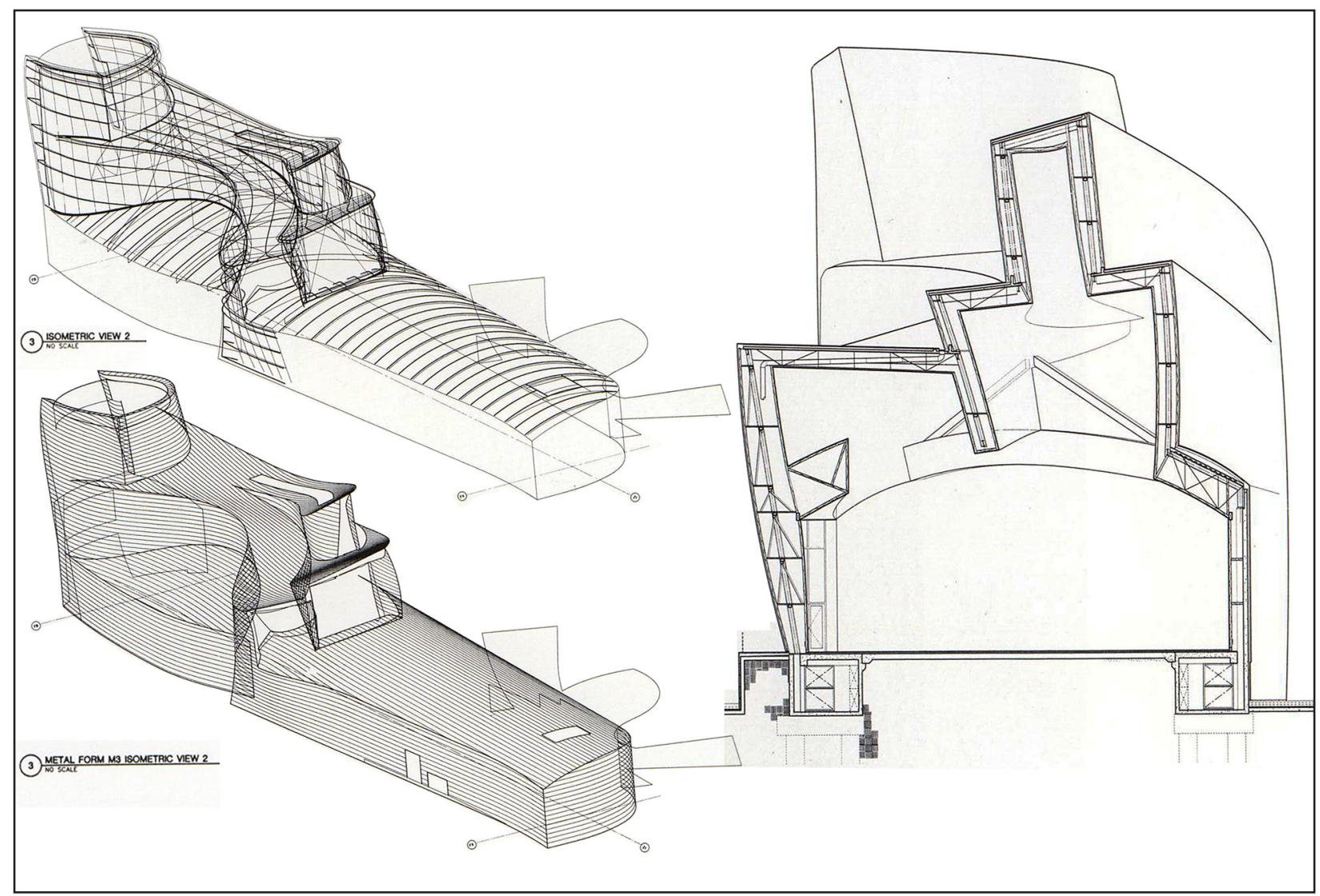

Diagram.10 - Guggenheim Museum Bilbao Digital Work Flow (El Croquis, 1995)

designer can change the diameter of the structural elements in the cladding feature, or the width of the supporting surface without affecting the overall design intent of the envelope. This simple example illustrates the relevance of parametric platforms to contemporary architecture, where designers could easily substitute the demonstrated cladding element with a glazing panel, photovoltaic array, insulated metal panel or any other architectonic object, immediately highlighting the architectural potential of the technology.

Within current architectural praxis, parametric systems bridge the gap between complex geometries and fabrication. For example, Gehry and Partners exclusively use Digital Project, a parametric modeling system based on CATIA (Computer Aided Three-dimensional Interactive Application) developed by French Aerospace Company Dessault Systems. Gehry and Partners were the first architects to see the innate advantages of applying software widely used in the automotive and aerospace industry to buildings. This new technology allowed the architects to explore new types of building forms and evidently redefine what was architecturally and structurally possible. The software's ability to develop, "simultaneously the forms in 3-D, and the constructive geometry, given a specific constructive specification", let them realize the multi-curved surfaces that are characteristic of their projects (Zaera 1995, 153). According to the firm, many of the forms developed by Frank Gehry 


\section{"Our idea was to create a process for controlling geometries and dimensions and for documenting the projects, which is an entirely different realm from using computers for presentation"}

\section{"Bilbao could have been drawn with a pencil and straight edge, but it would take us decades"}

- Gehry Partners

are only possible through the computer. Using the Guggenheim Museum in Bilbao as an example, "It might have been a sketch idea, but we would never be able to build it. Bilbao could have been drawn with a pencil and straight edge, but it would take us decades" (Ibid.). Parametric models allowed them to produce standard two-dimensional drawings from the 3-D CATIA model almost a decade before most architects had even heard of Building Information Modeling (BIM). Diagram.10 illustrates an example where the designers used complicated 3-D models to extract an accurate 2-D sectional drawing. Being able to translate complex 3-D models in to traditional construction drawings allowed the firm to document and communicate design information to fabricators, contractors, and engineers to produce the building on time, and within budget. Although CATIA was the first parametric modeling system to be applied to the architectural design process, other software developers saw the inherent potential of the technology and followed suit. Currently besides Digital Project, other programs such as Generative Components and Grasshopper developed by Bob McNeel are gaining popularity among students and practicing architects alike. For this project, we used Bentley System's Generative Components because of its availability, functionality, and ease of integration into a traditional 3-D design workflow. Firstly, student licensees for the software are widely available through academic institutions, especially ones with established architecture schools. Secondly, there are documented instances where researchers have used the program in conjunction with other environmental analysis modeling systems. Showcased the 2008 Smart Geometry Conference, several projects from students and architects illustrated the potential of integrating solar analysis data into form generating algorithms. Lastly, since Generative Components is an extension of Bentley's Microstation CAD platform, it integrates seamlessly in to a traditional BIM workflow. This lets the designers translate any geometry, regardless of complexity, in two traditional two dimensional representation modes such as building sections, plans, elevations, or photorealistic computer renderings for presentations. 


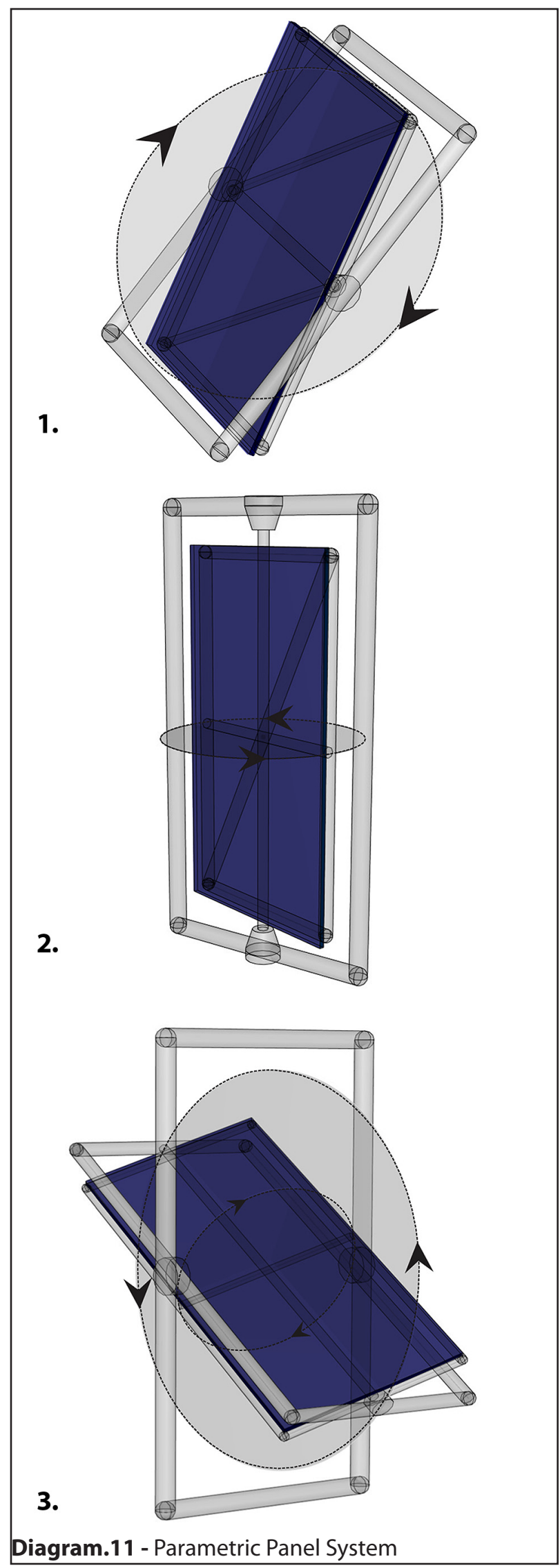

\subsubsection{Parametric Panel System}

Besides flexibility, another advantage of using parametric models to support a solar design methodology is the ability to integrate solar data parameters into the project. By using actual solar azimuth and altitude metrics, the designers could orientate photovoltaic modules to the optimal position for the specified period, just as conventional tracking systems do. However, unlike traditional tracking structures that are essentially free to rotate themselves towards any orientation, the static nature of architecture severely restricts the movement of building integrated panels. A more plausible solution would allow the individual panels to orientate themselves towards the optimal solar position, irrespective of the base surface geometry. Such a solution would compensate for the fixed orientation of the structure, in relation to the suns constantly changing position. Since the best surface geometry in regards to solar exposure changes hourly, daily, and monthly, there is no perfect fixed solution. Allowing the individual modules to reposition themselves independently of the overall architectural massing is a good design compromise between maintaining the fixed orientation of the envelope while maximizing incident radiation. The major benefit of this hybrid solution is that it will increase the electrical output of photovoltaic modules by at least $20 \%$. It offers other benefits, especially in northern climates. During the winter, snow accumulation on individual panels renders them useless. Since the suns altitude is lower in the horizon during this time, tracking modules 
would assume a steeper angle of inclination preventing any snow accumulation on the individual panels. Conversely, during the summer months, the individual panels would assume a more horizontal orientation that could in certain situations double as a passive solar shading device.

This parametric tracking system works by orientating the surface normal of each panel to the desired altitude or azimuth angle. The program places a point in the model by translating the altitude and azimuth angles to Cartesian coordinates relative to a base reference point. Using meteorological databases as illustrated in Appendix.1, the user can either hard code the metrics into the point function or have the program access them from an external Excel spreadsheet. This same function can place as many points as desired, corresponding to different solar positions over the course of the day, month, or year. Since the solar data is dependent on the location of the site, if the designers want to move the installation to another continent, all they have to do is update the underlying dataset. Now that the function has placed a solar reference point representing the optimal orientation for the specified season, the program knows in which direction to orientate the panel. If the user changes the solar reference point, the panel repositions itself accordingly. Diagram.11 illustrates three possible panel units, including single axis (1-2) and dual axis combinations (3). Single axis units consist of an outer and inner frame, the outer frame attaches to the fixed geometry of the surface, while the inner frame, which includes the actual photovoltaic panel, is free to rotate independently in regards to the optimal solar angles. The dual axis unit works in the same fashion, except instead of two frames it has three, allowing the panel to correspond to both azimuth and altitude angles.

\subsubsection{Solar Analysis Modeling}

Solar analysis modeling is crucial in advancing the architectural integration of photovoltaic systems. It provides the information for the architects to inform and validate the design during the EDP. According to Michael Kohn of Slider Studio, this, "metrification of design allows objective evaluation at a level not previously manageable with manual methods...For better or worse, design measurement is here to stay" (Kohn 2008). The above is especially relevant in the design of intelligent solar architecture, especially with complex curved surface geometries. For simple photovoltaic systems consisting of flat planar arrays, it is relatively simple for one to determine how much incident radiation it receives based on meteorological data, which give radiation values per square meter on surfaces in standard inclinations $\left(0^{\circ}, 45^{\circ}, 90^{\circ}\right)$, as well as the optimal angles for different times of the year as previously mentioned. However, manually determining incident radiation on complex surfaces with one or more curves with a moderate degree of accuracy is relatively impossible. Conversely, manually calculating how shading from individual objects such as a surrounding tree or building impacts the incident radiation on a simple photovoltaic system is tedious, but is impossible for installations with complex surface geometries in dense urban conditions. Therefore, without the help of solar analysis tools architects would have limited options regarding the design of photovoltaic 


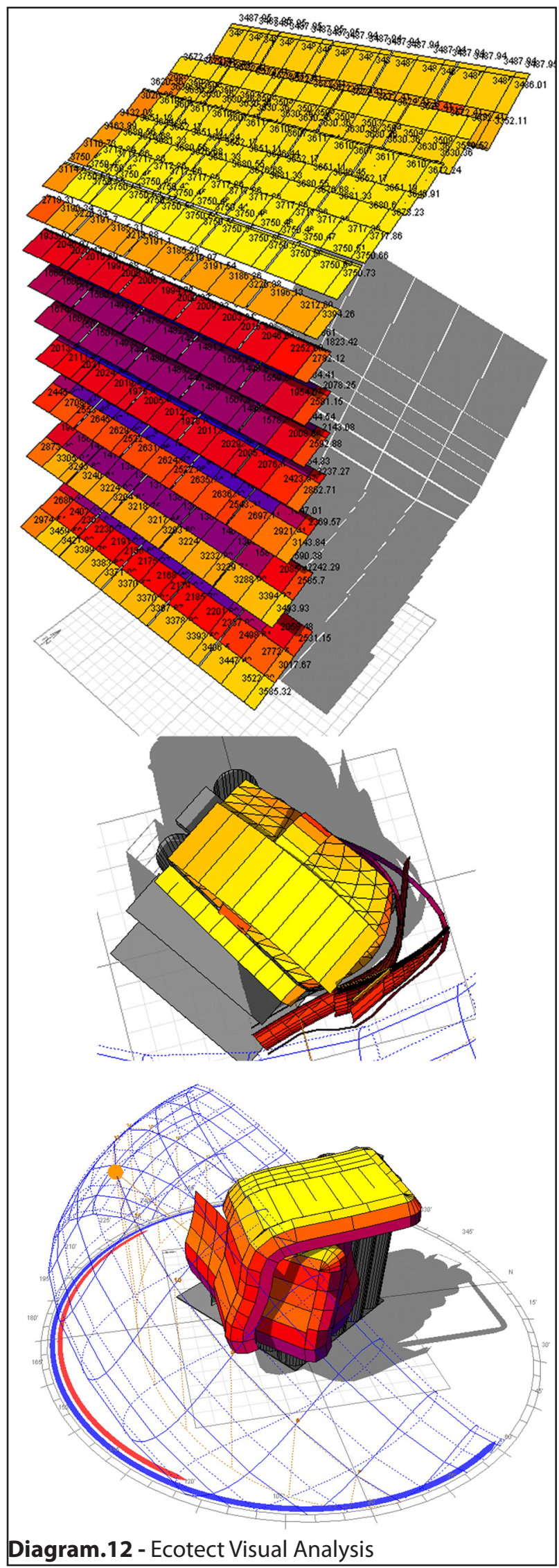

installation. They would be restricted to only using flat planar surfaces, not having any recourse with the exception of aesthetics to validate their form to clients.

Currently, there are a multitude of solar analysis programs commercially available, such as PVSYST, PV*SOL, Polysun, AllPlan, EcoDesigner, TAS, and Ecotect. The majority of the available programs are more inclined towards the engineering or technical aspects of the design process. The exception is Ecotect, which is the only program specifically developed by architects for architects. It can perform numerous different analyses within a 3-D platform such as shadow, reflection, incident solar radiation, day lighting, thermal, and acoustic analysis (Dubois \& Horvat, 2010). For the purpose of this study, only solar and shadow analyses were required. One of the benefits of the program is that it displays the analysis data in a visually rich and intuitive fashion, making it easy to convey information to clients and for public presentations, as demonstrated in Diagram.12. However, it is important to note that since the colors correspond to radiation values that are indicative of the maximum and minimum values for each instance it can be deceiving when trying to compare different design options. Ecotect uses a 'Radiance' rendering engine to calculate solar radiation. Essentially, "Radiance is a physically based backwards rendering tool" (Dubois \& Horvat, 2010, 89), meaning that an algorithm traces light rays in reverse from the illuminated surface in question until it reaches the origin light source, in this case the sun. 
The direction of the tracing is dependent on the surface normal, or the face exposed to the light source. If during the course of tracing the light rays back to the origin, they hit another object, the algorithm employs a secondary calculation to determine the luminance of the object in question. This secondary calculation is important because it explains how the program calculates how shadows from surrounding objects affect irradiance. The calculations depend the on the geographical location (latitude and longitude) of the site, and atmospheric conditions (clear, cloudy, urban, and rural). Although, software developers claim that radiance is very accurate in determining incident solar radiation on a variety of surfaces, other sources raise doubts as to the extent of its accuracy. However to support the early design phase, Ecotect is more than suitable.

\subsubsection{Parametric + Analysis Workflow}

The next step in the development of the methodology was to establish a means of communication between the form generation process and the solar analysis models. The obvious method was to import the CAD geometry directly from GC into Ecotect. However, since Ecotect does not yet support Microstation (.dgn) files, one had to export the CAD model to a drawing exchange file (.dxf). Drawing exchange files were developed by Autodesk to allow AutoCAD users to export and import simple 2-D drawings from other cad platforms, not complicated 3-D models. Luckily, the exchange files generated in GC translated into Ecotect with no major complications, except for some minor scaling issues and isolated instances of backward surface normals. Subdividing the surface in GC into polygons before exporting it to an exchange file simplified the geometry and allowed the user to control the level of analysis, hence calculation speed. Since Ecotect calculates the incident radiation for each polygon, the denser the surface subdivision the greater number of calculations the program has to run but the more in depth the analysis is. With the GC geometry now successfully translated into an Ecotect model, the designer can run the various solar and shading calculations. Ultimately, it is up to the architect to successfully interpret the analysis data and apply it to the digital model in an attempt to increase solar exposure. They are essentially the mediator between the analysis data and the massing, in a trial and error process of continually refining and validating the geometry in terms of maximizing incident radiation as illustrated in Diagram.13. The final part of the methodology deals extensively with the anthropocentric aspects of the process, and the fundamental relationship between the designer and their tools as an extension of the creative process. 


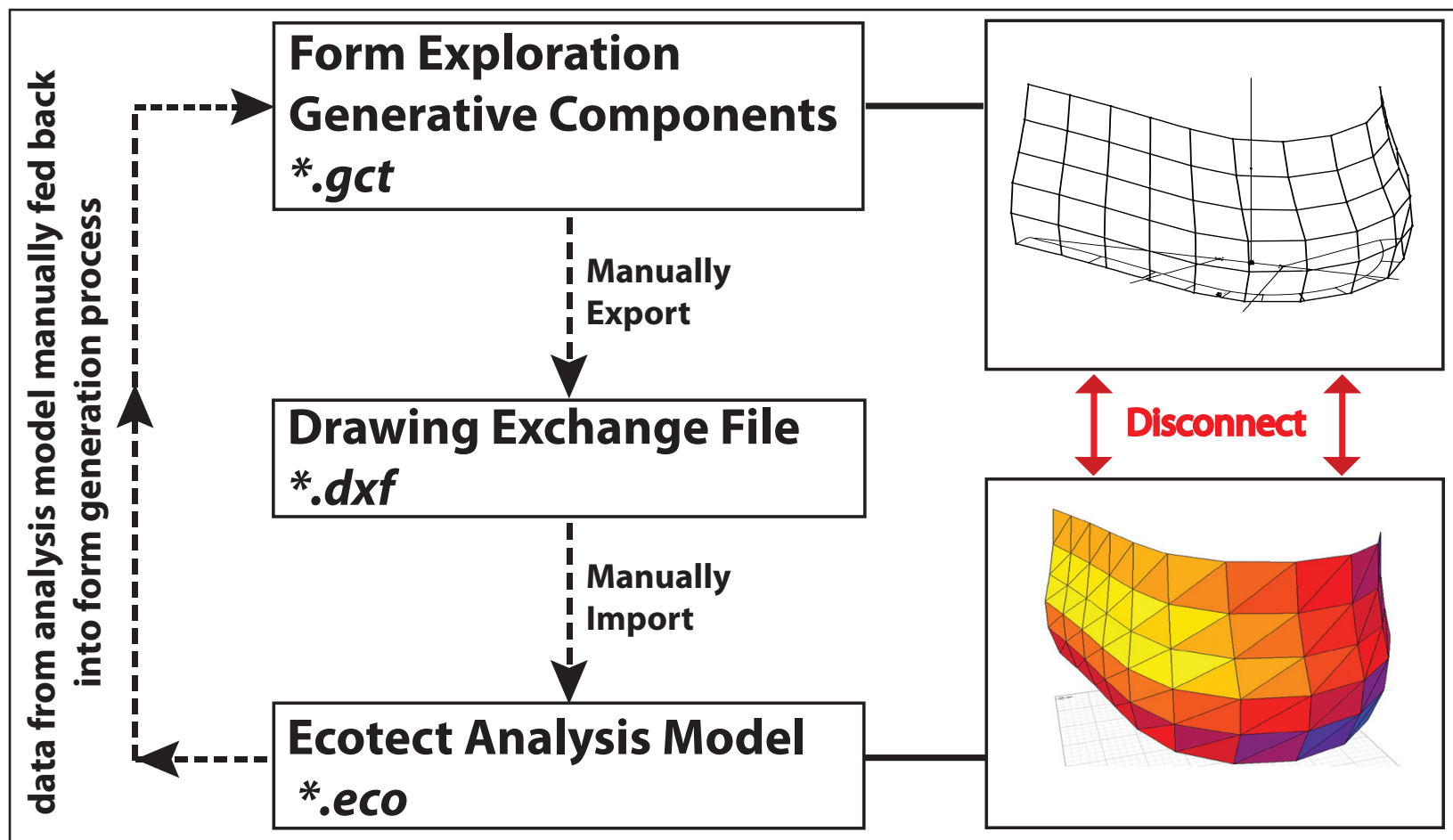

Diagram.13 - Ecotect/GC File Exchange

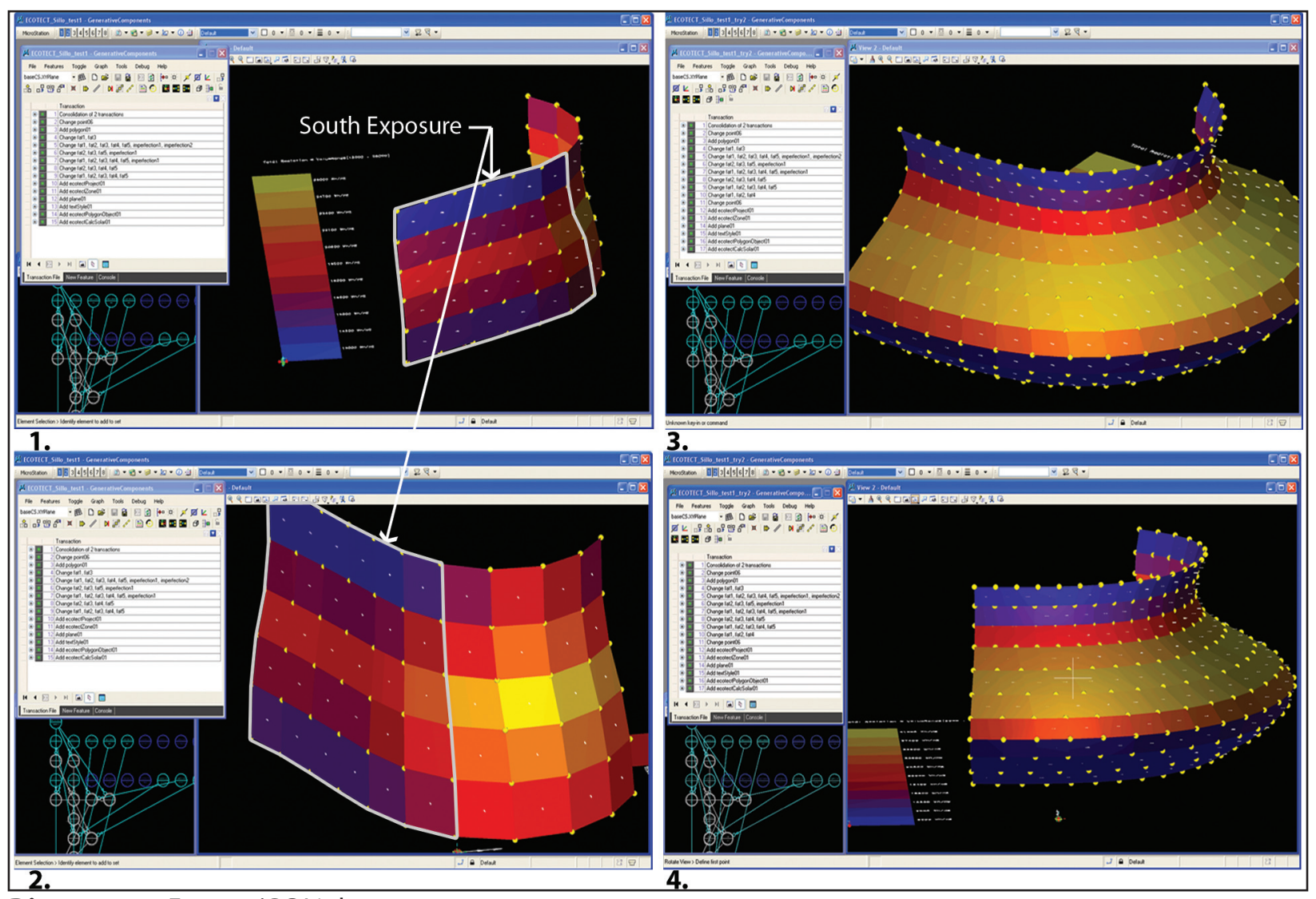

Diagram.14- Ecotect/GC Link 


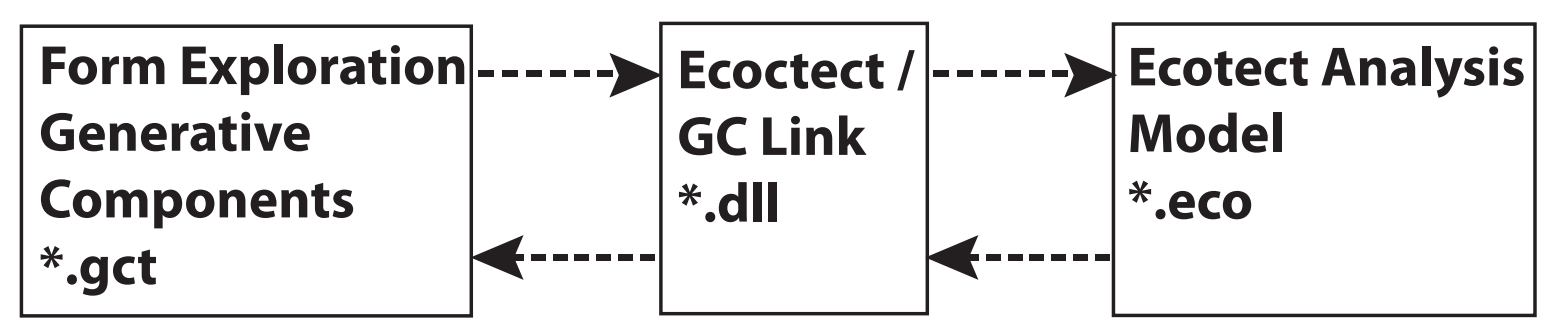

Diagram.15- Ecotect/GC Link Work Flow

The problem with the design exchange files was the inherent disconnect between the analysis and form generation process. Having to export and import files between two programs was not very intuitive and ultimately lead to file management issues. A better, more intuitive option was to run the calculations within the GC modeling interface, giving the designer direct feedback into the form at the early design phase. Bentley Systems, the makers of GC, developed a data link layer (.dII) allowing the program to communicate with Ecotect as outlined in Diagram.15. The link allowed users to run dynamic solar analysis calculations in the GC interface, with Ecotect minimized in the background as demonstrated in Diagram.15. Theoretically, this meant that as the designer modified the form, they would receive real time solar analysis feedback. In reality, the process was extremely slow and unstable because it involved having to undertake three steps each time the designer modified the surface. First, the link had to translate and import the geometry from GC to Ecotect, then run the calculations, and finally retranslate the analysis data back into the modeling interface. For example, in Diagram.14, examples (1-2) had a calculation times of about ten minutes. Increasing the polygon density and modifying the geometry of the surface as shown in examples (3-4) in the same diagram, increased the calculation time to about 35 minutes. Granted the calculation time would vary between computers, dependant on hardware specifications and the examples where calculated using a $2.50 \mathrm{GHz}$ dual core processor with $2 \mathrm{MB}$ of memory. In this simple scenario, every time the designer modified the surface, they would have to wait 10-30 minutes for feedback from the analysis software. Although calculation times will vary depending on the performance specifications of the computer running the analysis, the feedback process is far from being in 'real time'.

Besides slow calculation speed, the accuracy of the link was questionable. For instance, in Diagram.15 the analysis illustrates that the south face of the surface receives less yearly incident radiation than the east face, which clearly contradicts commonsense and immediately raises doubts about its accuracy. Many of the problems with the link likely stem from the fact that it was never intended for commercial release, but only as a research project developed by Bentley Systems for the Annual 2008 Smart Geometry Conference. Which explains its limited functions, given that the link can only process incident radiation and basic day lighting without shadows, and its under performance in regards to accuracy and stability. 
Between the two methods, using exchange files to translate information between the modeling and analysis programs was the best method given the greater degree of reliability, stability, and accuracy. Although, the ability to run the solar analysis calculations within the modeling interface is more in tune with the design process, the tools are not yet sufficiently developed. The example illustrated in Diagram.14, clearly demonstrates problems with accuracy and slow calculation times. Given the importance of designing energy intelligent buildings, it is safe to assume that eventually all 3-D CAD platforms will be able to run simple environmental analysis calculations. Advances in CAD software coupled with ever-increasing computer processing power will make communication between the two platforms much more efficient, quicker, stable, and intuitive.

\subsection{The Human Interface}

The digital tools as described are only half of the methodology; the other, more important half is human interface, which is responsible for interpreting and applying the analysis data to the model. It is important to remember that the digital models used in the process are only tools, referring to Marshal McLuhan's definition as the extension of one's reach. Just as the microscope extends the reach of the eye, as a hammer extends the reach of the arm, or a bicycle extends the reach of the legs, the digital design tools extend the architects creative reach. By its nature, this extension automatically postulates the acceleration of the existing process, as a bicycle, which is an extension of one's legs, allows them to travel greater distances much quicker than they could by simply walking (McLuhan, Understanding Media - The Extensions of Man 1994, 152). The logical conclusion of this continued acceleration is automation, where the machine or tool entirely replaces the human, raising itself, "to the level of conscious awareness, so that the computers seem to think" (McLuhan, Understanding Media - The Extensions of Man 1994, 351). However, even at this level of complete automation and perceived artificial intelligence, "a conscious computer would still be one that was an extension of our consciousness... as a ventriloquist dummy is an extension of the ventriloquist" (lbid). Following this line of thinking computer scientists, presumably without much difficulty, could develop an algorithm that calculates the most effective form as to maximize solar exposure as to completely automate the design process. All the architect would have to do is input a series of variables such as the latitude, longitude, and orientation of the building into the system and the program would automatically compute the 'best' surface geometry. Such an algorithm could presumably incorporate feedback with conditional statements by, "introducing a loop or circuit, where before there had been merely a oneway flow", to fine tune and perfect the process (Ibid). This relationship between automation and the design process is not only relevant to solar architecture, but is part a larger polemic within twentieth century architectural theory. 


\section{“Architecture, no matter}

how much it resists the idea,

cannot renounce its origin in

intuition. While construction

as a technological process

is prosaic- deriving directly

from a mathematical

equation ... architecture

is poetic, necessarily an

abstract order but in itself

a metaphor emerging from

a vision of the world and

being" - Alberto Pérez-Gómez

The industrial age brought about a major shift in the means of production, initiated by the automobile, which introduced the concept of mass production. Almost immediately, architects attempted to apply the principles of industrial mass production to the architectural design and construction process. This new paradigm transformed architectural theory, "into a set of operational rules, into a tool of exclusively technological character" (Perez-Gomez 1998, 467). Hence, the new aim of architecture became, "how to build in an efficient and economical manner, while avoiding questions relating to why one builds and whether such an activity is justified in the existential context"(Ibid.). In this light, architectural theory in the industrial age neglected fundamental design questions, such as how buildings relate to their surrounding context. Since every project is unique, with its own set of variables, one cannot reduce the entire design process to a set of generalized rules or formulas. Hence, without any existential context, or how the architecture, "relates to cultural systems outside itself" (Agrest 1998, 200), all buildings are reduced to mere functionalism, nothing more than a means to an end. It is the irreplaceable role of the architect to decipher and apply the applicable 'cultural systems' to the design process, which include issues at the micro scale of the building and ones at the macro scale of the larger urban context (ibid.). Hence, any design process involves some aspect of arbitrariness, as does any human activity, which is where the role of intuition enters this project (Anderson 1998).

The importance of intuition in the design process makes any attempt at complete automation impossible. A computer algorithm could never decipherer historical context, evaluate aesthetics, and understand the ephemeral experience of the space in question, while considering the pragmatic qualities. Since by their nature, one cannot quantify these metaphysical aspects metrically, instead they are products of the designer's intuition. This inherent flaw in modern societies attempt to reduce the design process to an automated process, as seen with modernism, is summarized by Alberto Perez-Gomez, "Architecture, no matter how much it resists the idea, cannot renounce its origin in intuition. While construction as a technological 


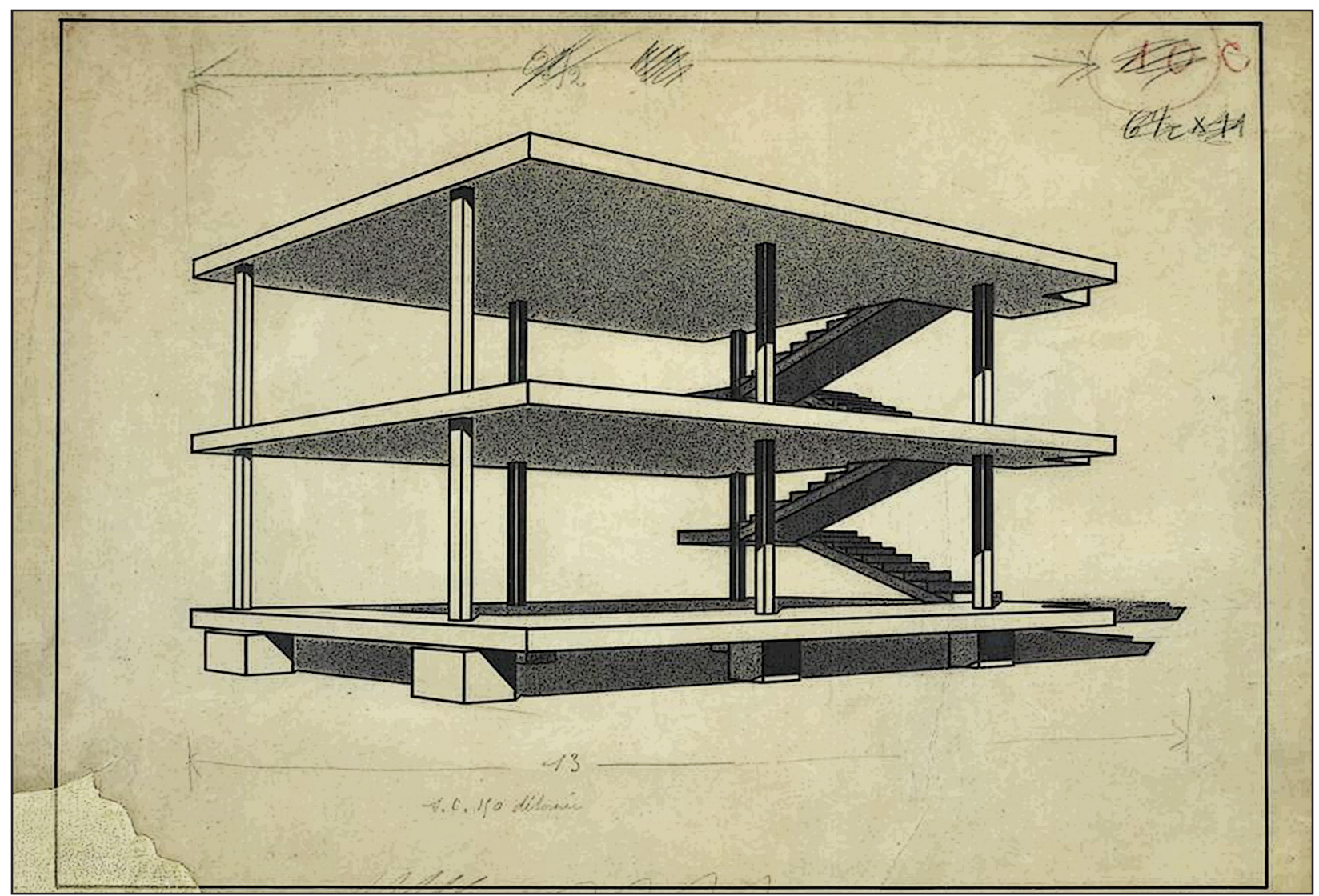

Diagram.16 - Maison Domino (Fondation Le Corbusier)

process is prosaic- deriving directly from a mathematical equation, a functional diagram, or a rule of formal combinations - architecture is poetic, necessarily an abstract order but in itself a metaphor emerging from a vision of the world and being" (Perez-Gomez 1998, 473).

The role of Technology in the design process is not to automate it, but is a means of extending the creative reach of the architect in regards to discovering the architectural potential of the new technology. In this case, creative reach refers to the architect's ability to solve larger and more complex problems. For example, with Europe's housing crisis in the wake of the First World War, Le Corbusier looked toward new technologies to extend the reach of his architecture. In the twentieth century new building materials and construction techniques, notably reinforced concrete and steel framing, extended the possibility of what was architecturally possible. These new materials inspired the architect, "Already interested in the relatively new building material, reinforced concrete, Le Corbusier sought a way to provide a rational and economic solution to the emergency housing need" (Anderson 1998, 499), after the war. Out of this paradigm, 'Maison Domino', a plausible solution to the crisis was developed. The housing prototype was a standardized mass-produced reinforced concrete frame consisting of slabs, columns, and stairs connecting the levels as illustrated in Diagram.16. He envisioned that the French government, in support of developing a modern construction industry, 
would provide the standardized structural frames. With the structure in place, one would only need to add the walls and functional program of the house in-situ according to the local vernacular and individual requirements (Ibid.). In this sense, the Maison Domino was a research project that proposed how, "new materials and new technologies in the hands of a rationalized industry can effectively provide a primary structure which will facilitate the solution of a crucial housing problem" (Anderson 1998, 500). Le Corbusier was one example of an architect who used technology to extend architectures reach, in this case socially and economically. Eighty years after Maison Domino, Frank Gehry used technology in the form of CAD systems to extend the creative possibilities of architecture with the design and construction of the Guggenheim Museum in Bilbao. Both Gehry and Le Corbusier leveraged technology in an attempt to solve macro-scale problems such as the need for housing, or micro-scale problems such as the construction of a geometrically complex building. In this spirit, one could extrapolate the potential of architecture leveraging new digital design tools with renewable energy systems to address the large-scale problems of climate change and sustainable energy.

Understanding the irreplaceable role of the architect's intuition and the role of technology in design, the proposed process strives to support and extend the creative possibilities of the designer, rather than any attempt at automation. This is vital for the next portion of the research, which illustrates the application of the process to three sites in the Greater Toronto Area. Placing the installations on specific sites, introduces a social context to which the structures have to reflect. Given this, many non-quantifiable variables enter into the design equation besides aesthetics, such as public perception, interaction, financial feasibility, and economic benefits to the surrounding neighborhood. These secondary, non-quantifiable, variables are as important for the architect as the objective performance criteria in designing a successful urban integrated photovoltaic system. During the early design phase, the architect must simultaneously apply their technical knowledge of solar energy systems with the existing physical and and social site conditions. This process relies, as does any design process, primarily on the architect's intuition. The digital tools only extend the creative reach of the architect, opening up new design possibilities. Ultimately, the methodology relies on both poles. Without the prescribed digital tools, the design of building integrated photovoltaic systems would be limited in terms of exploring the architectural potential of the technology. However, without intuition, any solar data would prove useless to the design process, only serving as a post-hoc analysis and negate the need for a flexible design process. 


\section{Chapter Three: Applicability}

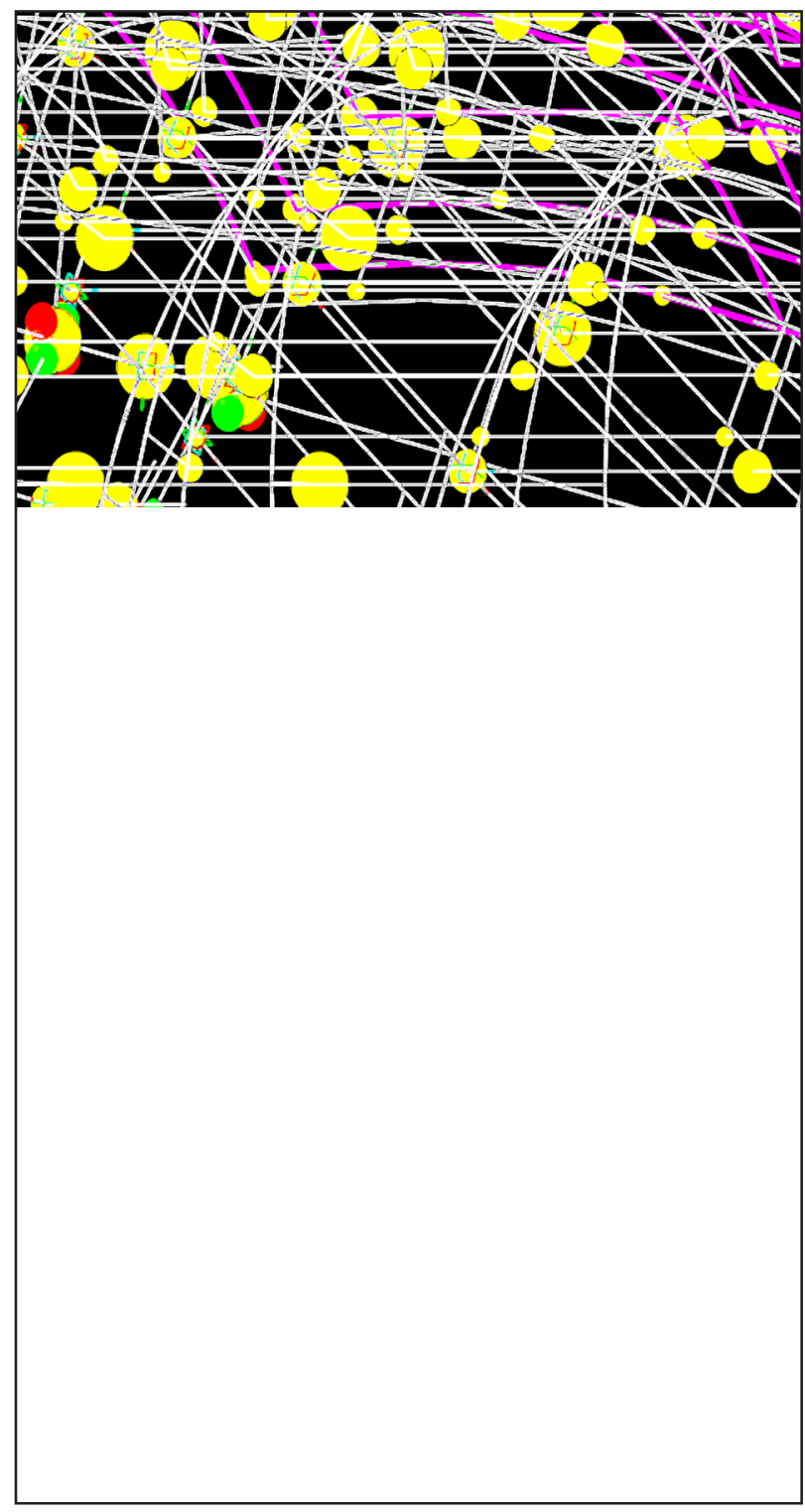

The final part of the thesis applies the proposed design methodology to three different sites in the Greater Toronto Area. Each site has a unique set of social and physical attributes that the designer must understand and integrate in to the design. This relationship between the physical or measurable aspects of the design, which include solar and shading data, with the metaphysical attributes such as aesthetics and existing social conditions is a vital component of the design methodology. In designing a successful urban integrated photovoltaic system, the geometry of the structure must not only correspond to optimal solar patterns, but also to the surrounding social patterns. For the design component to be successful in demonstrating its applicability, it must document the methodology as it applies both the subjective and objective attributes to the three sites. Since the purpose of the methodology is to support the EDP of solar buildings, where the massing and geometry of the architecture are determined, the three installations are primarily concerned with form generation rather than traditional programming or issues of human occupancy. In this case, it is important that the installations demonstrate the inherent flexibility of a parametric modeling platform during the EDP, and that the form reflects the solar analysis data in an intuitive and pragmatic fashion. The three interventions include redefining the Canadian Malting Silos as a symbol of innovation, designing a pedestrian canopy in Kensington Market, and rethinking how advertising space on Yonge Street can double as solar energy collectors. While the direct aim of the interventions is to demonstrate the 
applicability of the design methodology, they also serve as strategies as to how society might begin integrating solar energy into the urban environment on a large scale.

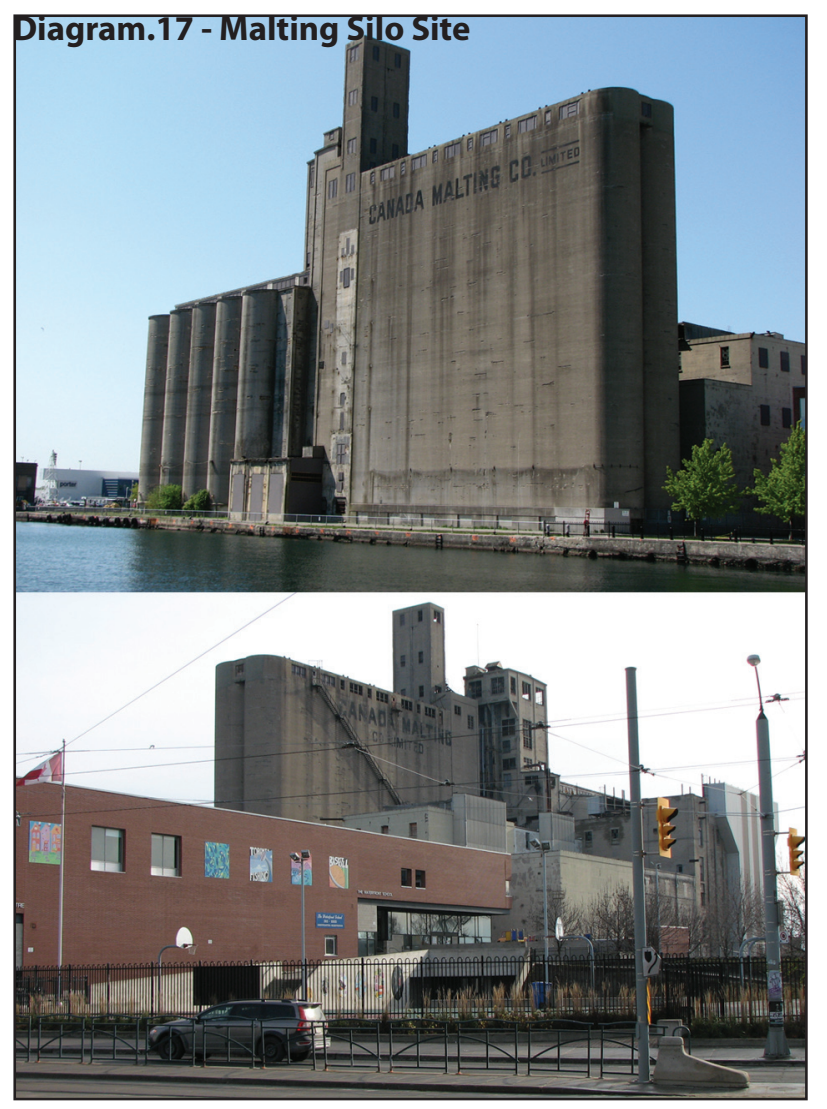

\subsubsection{Silos in Context}

The first intervention is to redefine the existing silos at the foot of Bathurst Street as a symbol of innovation and the cities dedication to non-polluting sustainable energy. For over 80 years, the silos have been a prominent visual landmark on Toronto's waterfront. Originally built by the Canadian Malting Company in 1928 to store grain, they decommissioned and abandoned the complex in the early eighties. Shortly after the silos ceased to function, the City of Toronto designated them as a heritage site, with historians citing the structures as an important example of modernist industrial architecture and a crucial artifact of Toronto's history. More recently in 2003, the site was the location of Kuwabara Payne McKenna Blumberg Architect's ill-fated Metronome project, which proposed to reuse the silos as part of a cultural institution dedicated to the musical arts in an intention to help revitalize the waterfront. Although, the Metronome project never got past the preliminary design phase, it won an award of excellence from The Ontario Association of Architects. With the tentative success of the Metronome project, the city announced a tentative plan to retrofit the malting silos into a museum dedicated to the history of Toronto. Open to other options, the city held a large design charette in 2007 to help generate ideas. At the same time, they also commissioned an engineering study pertaining to the structural condition of the complex and the feasibility of retrofitting the silos. The report concluded that the silos are in need of drastic repair, that any plans for retrofitting the silos with new functions would not be feasible and ultimately recommended to demolish the structures (City of Toronto 2009). Currently, the city is in the process of deciding whether to demolish the silos or to preserve them as icons of Toronto's industrial heritage. The most plausible scenario suggested in the engineering report is to demolish all but the original 1928 cluster of silos at the south end of the complex. 


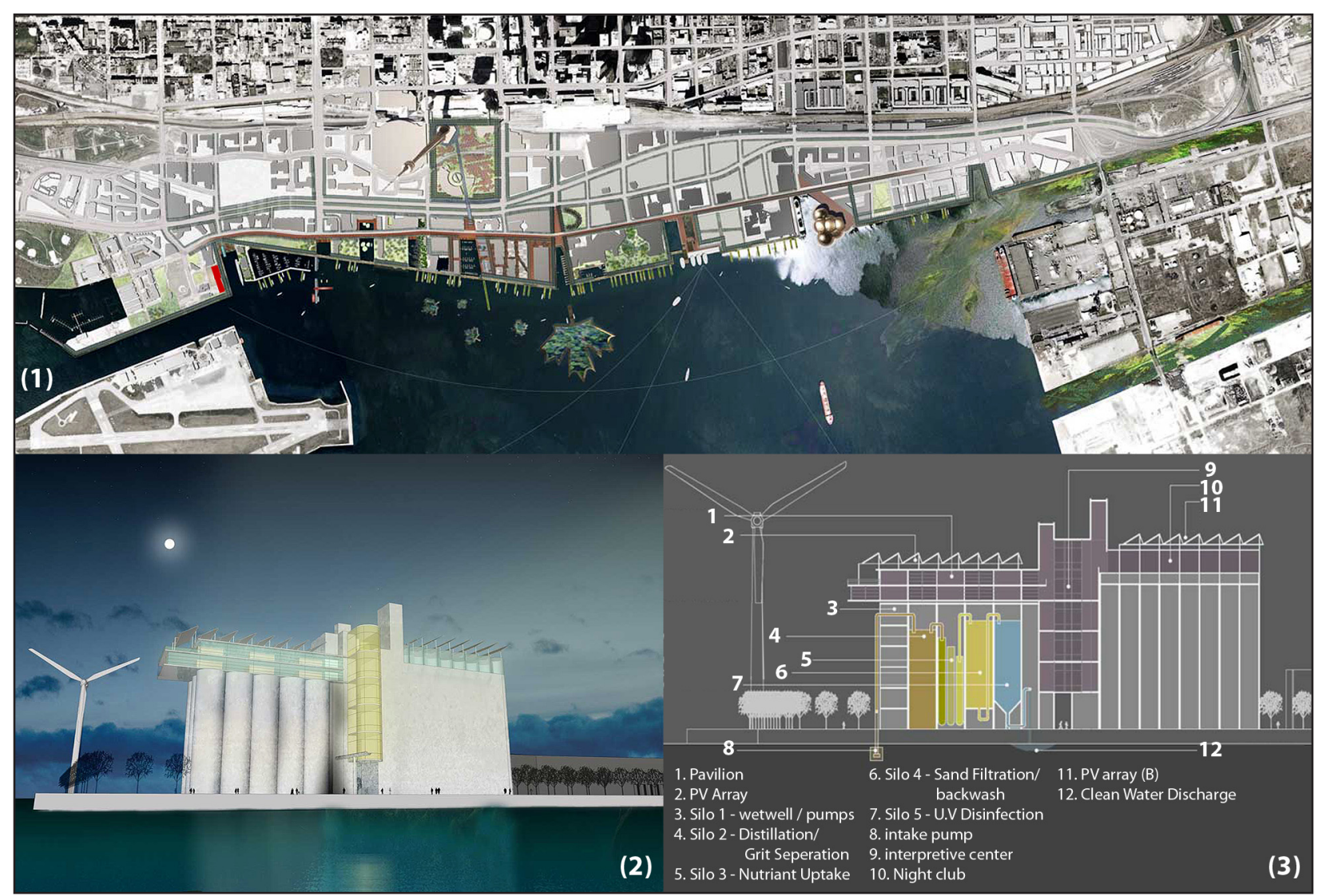

Diagram.18 - West8 + DTAH Toronto Waterfront Master Plan (West8+DTAH, 2006)

In 2006, the silos regained prominence when Toronto held an international design completion to redesign the city's central waterfront, which encompassed the shoreline between the Parliament Street slip to the East and the Portland Street Slip to the West. One of the parameters of the initial competition brief pertaining to the silos was that the, "massive concrete structures are a designated heritage site and must be preserved" (City of Toronto 2006, 15). Hence, whatever design teams proposed, they had to maintain the existing malting silos, or at least somehow reuse them. The brief also ensured that any design for the area around the silos must adequately address the water's edge and provide access to Ireland Park, a sculptural installation dedicated to great Irish Famine situated at the southern edge of the site. The winning entry for the waterfront master plan was from West8+DTAH design team, illustrated in Diagram.18 (1). They proposed to turn the silos into a bio filtration system for lake water, using electricity from solar and wind for the ultraviolet disinfection process. In addition to the bio filtration system, their proposal also included a nightclub and interpretive center on top of the silos silos as illustrated in Diagram.18 (2-3). However, since the winning proposal contradicts the structural condition of the silos and is slightly farfetched, the city is still trying to figure out what to do with the Silos. Ultimately, the silos are distinctive and prominent feature of Toronto's skyline, and are opportunity to make a strong gesture proclaiming the city as center of sustainable innovation. 

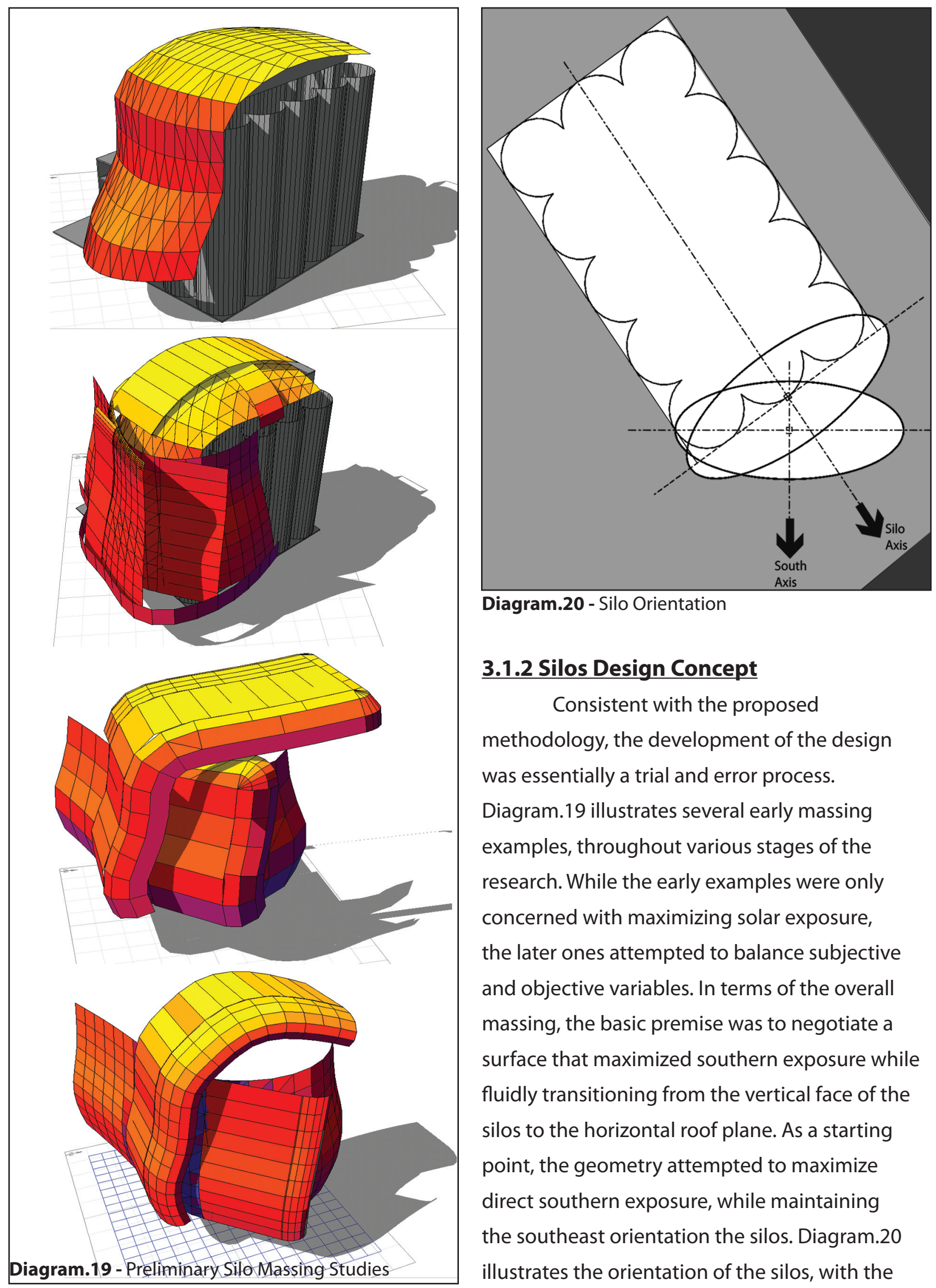

Diagram.20 - Silo Orientation

\subsubsection{Silos Design Concept}

Consistent with the proposed

methodology, the development of the design was essentially a trial and error process.

Diagram.19 illustrates several early massing examples, throughout various stages of the research. While the early examples were only concerned with maximizing solar exposure, the later ones attempted to balance subjective and objective variables. In terms of the overall massing, the basic premise was to negotiate a surface that maximized southern exposure while fluidly transitioning from the vertical face of the silos to the horizontal roof plane. As a starting point, the geometry attempted to maximize direct southern exposure, while maintaining the southeast orientation the silos. Diagram.20 illustrates the orientation of the silos, with the 


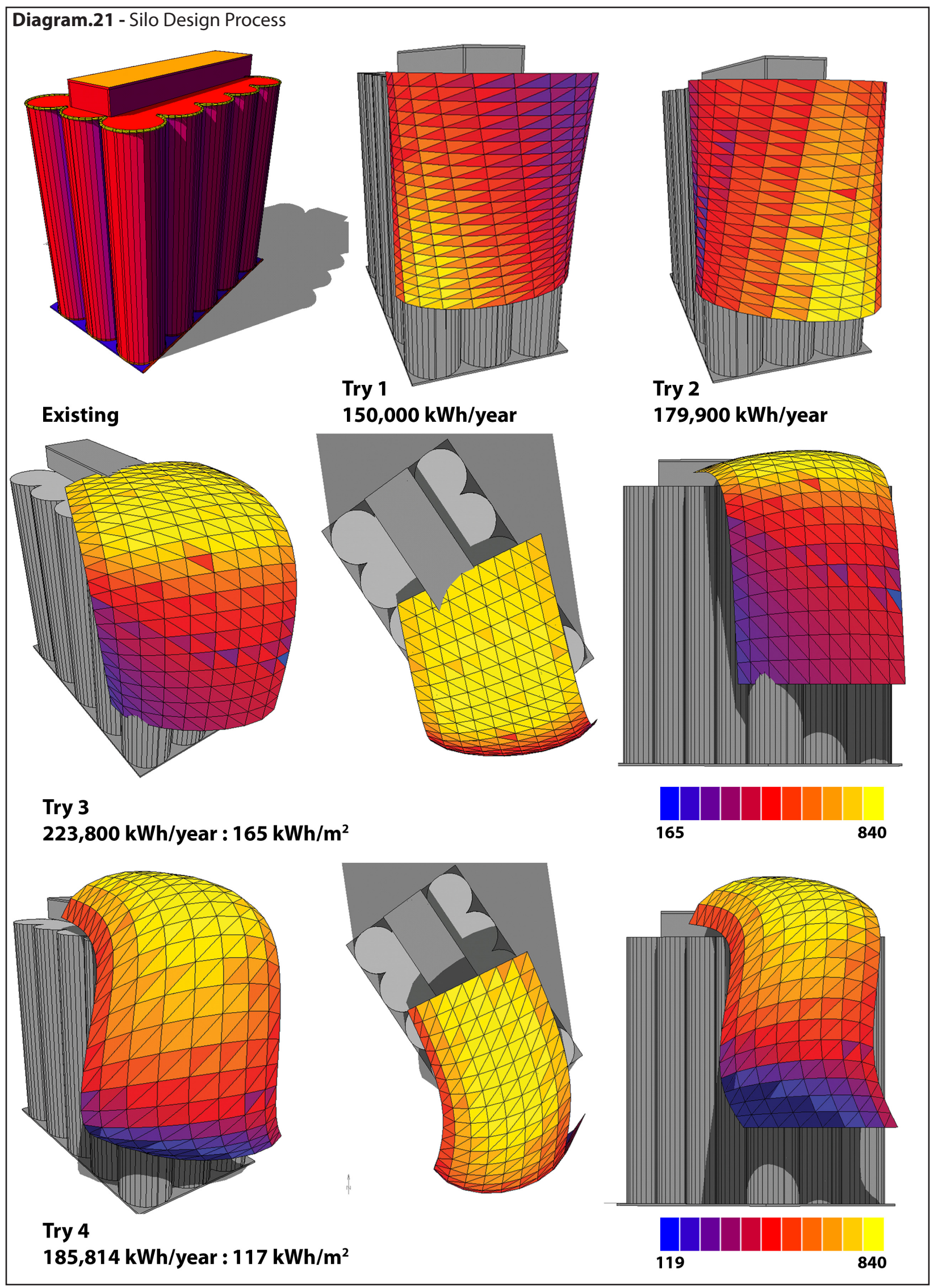


Diagram.22
- Silos 2-D Work Flow

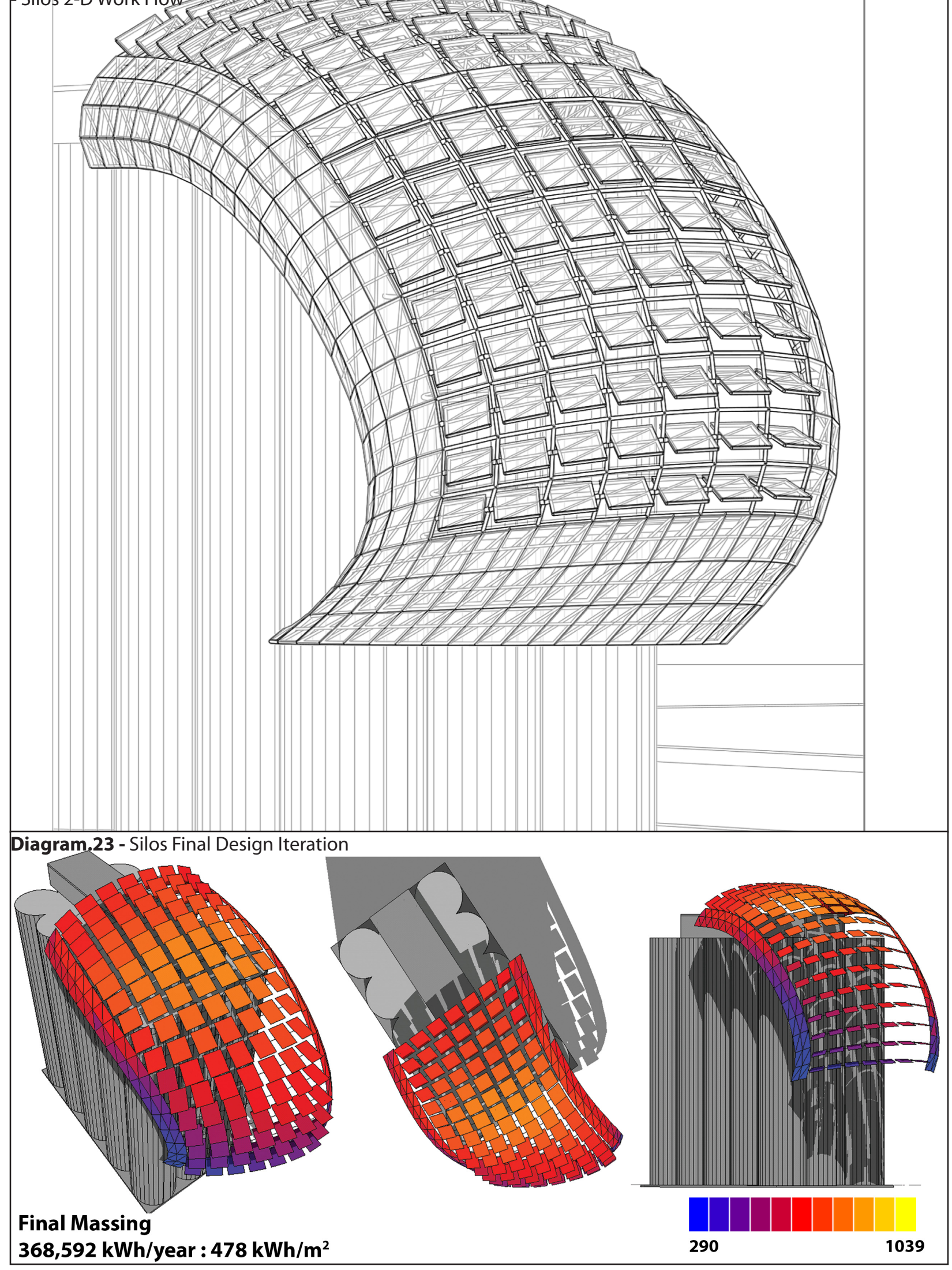




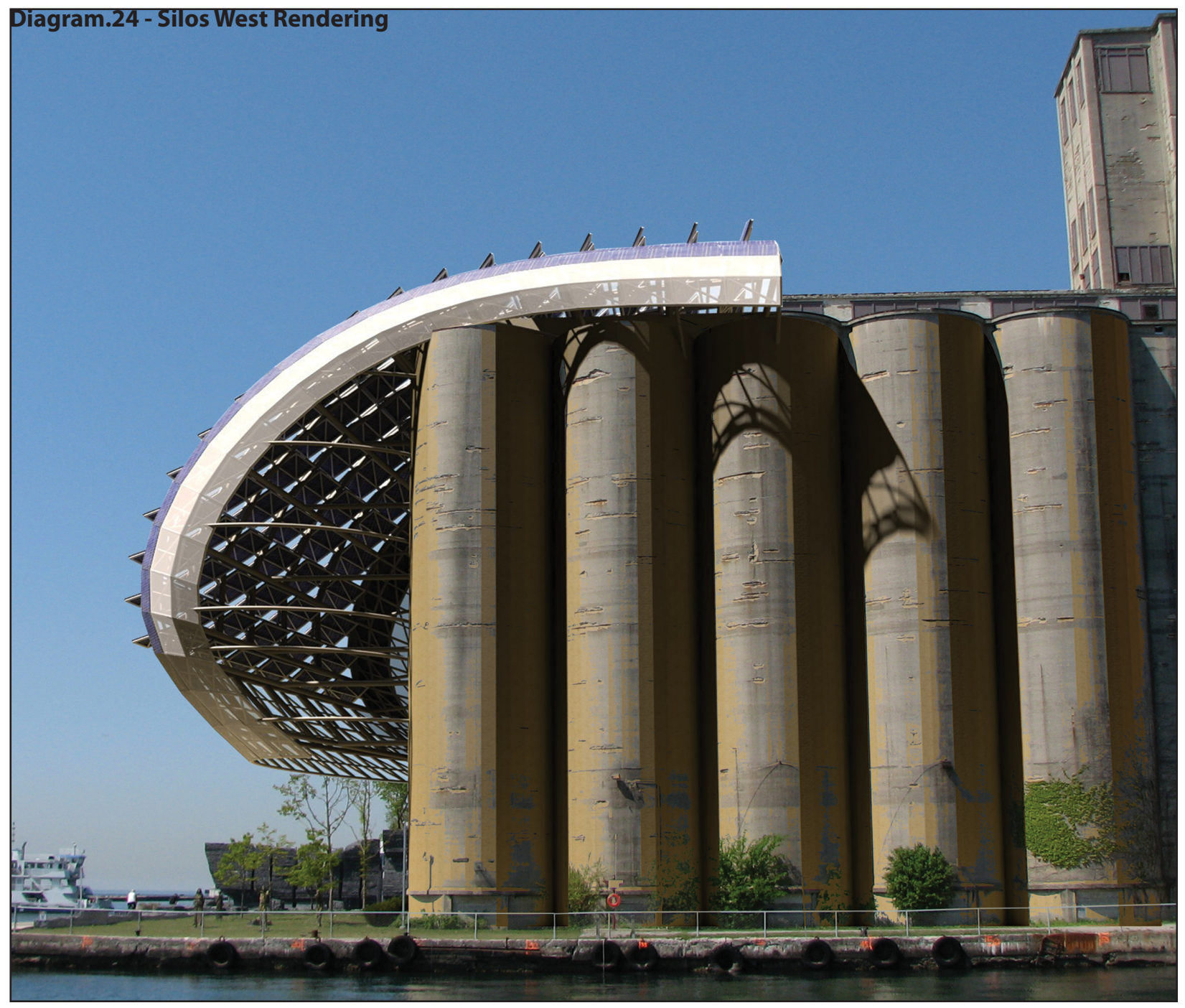

two ellipses serving as the base curves for the surface as shown in Diagram.21 (Try1-2). Extending the surface over the roof of the silos further increased solar exposure, as illustrated in (Try3). With the basic surface geometry intact, the massing underwent a process of continued refinement, which supported by feedback from the analysis models (Try1-4). By using a parametric design model, the user could try numerous different geometric variations quickly, without having to remodel the surface at each try. Knowing how to modify the form was an innately intuitive and largely arbitrary process informed by a combination of feedback from the solar analysis model, the designer's innate knowledge of local solar patterns, and aesthetics. Fitting to the nautical theme of the waterfront, the form ended up albeit somewhat intentionally, visually resembling a large 'billowing' spinnaker at the bow of the silos. In addition to controlling the geometry of the surface, Generative Components allowed the user to add a supporting structure, extract additional 2-D drawings as demonstrated by Diagram.22, and orientate the individual modules to optimal solar angles as described in section 2.2.3. Diagram.23 illustrates the final design iteration, validated by the analysis data. 


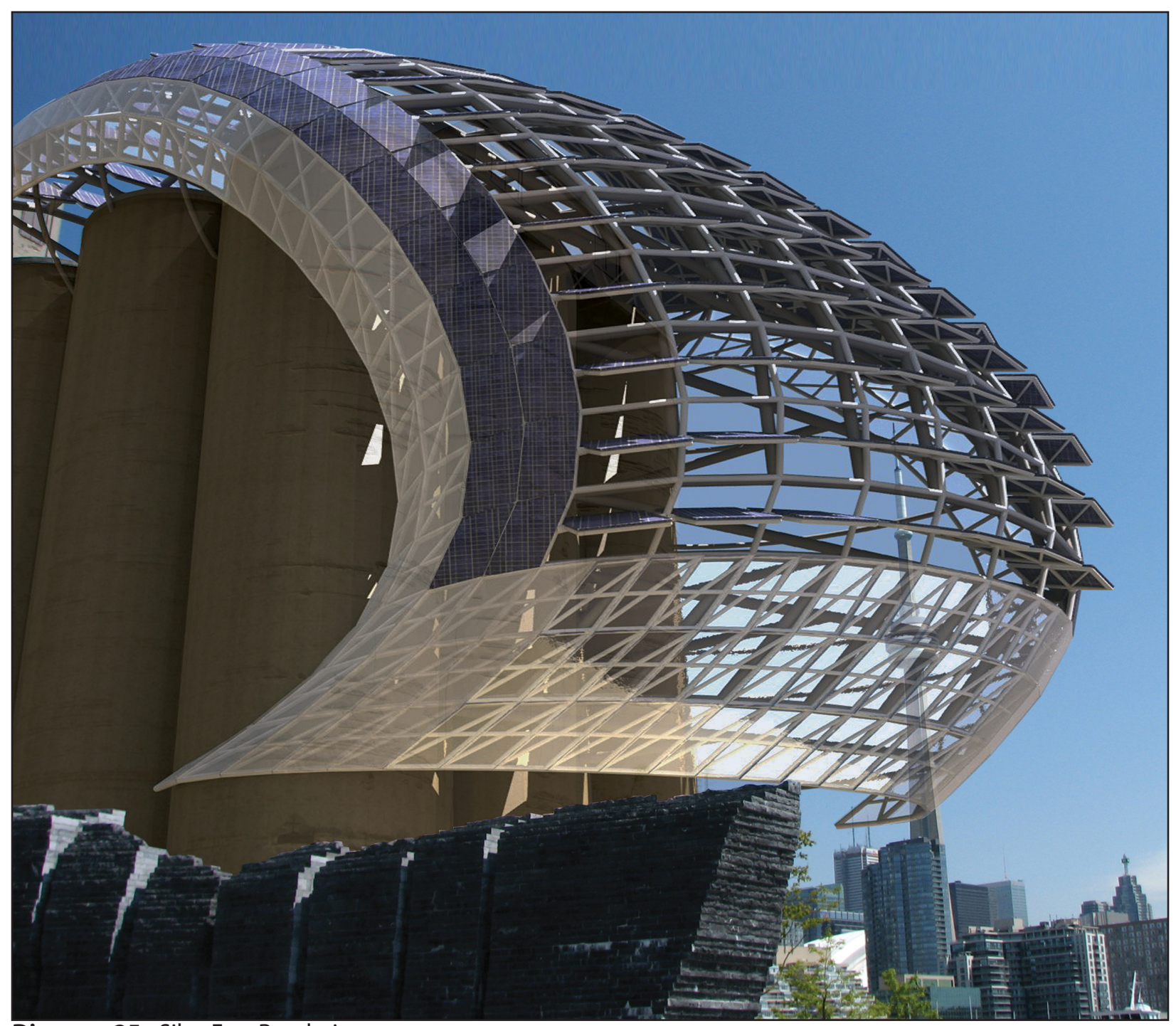

Diagram.25 - Silos East Rendering

In addition to maximizing solar exposure, the design had to respect the sculptural installation at the base of the silos. It was important that the form did not completely overpower Ireland Park, not hovering above it resembling an ominous opaque mass. By using three different types of modules, alternating between standard fixed crystalline silicon photovoltaic panels, modules with mechanized tracking systems, and translucent glass panels it helped to give the installation a degree of transparency and lightness. Using different modules also allowed sunlight to filter through the installation and not overshadow the sculptures beneath. Diagrams 24-25 show renderings of the proposed installations in situ, demonstrating the permeability of the structure in relation to the site and sunlight. Ultimately, the design methodology illustrates the importance of balancing nonquantifiable variables such as aesthetics, cultural, and site-specific issues with objective solar analysis data in the design of intelligent solar structures. 


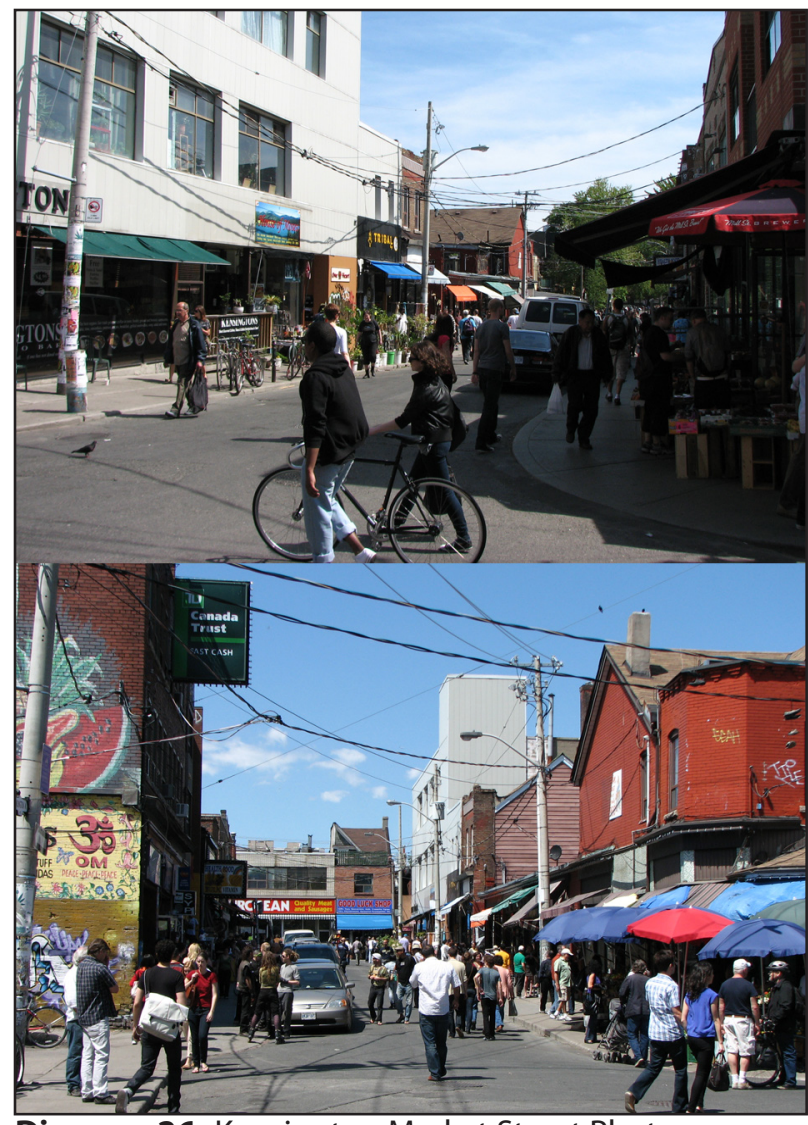

Diagram.26- Kensington Market Street Photos

\subsubsection{Pedestrian Canopy in Context}

A design for a pedestrian canopy in

Kensington Market is the second intervention.

The goal of the installation is to introduce solar energy in to the area while enhancing the pedestrian energy and economic prosperity of local businesses. Kensington Market is one of Toronto's most coveted neighborhoods, is a hugely popular tourist attraction, and is widely regarded as a national treasure. It is also one of the most active and conscious neighborhoods in the city, home to numerous political, social, and environmental advocacy groups. Kensington's collective consciousness is conducive to support ideas of renewable energy generation, and is therefore a logical site to introduce photovoltaic systems into the urban fabric. However, successfully integrating a large photovoltaic installation into the area is a difficult. Since one does not want to interfere with the neighborhoods existing energy, which is a result of the areas pedestrian friendly residential scale, combined with the eclectic mosaic of ethnic cultures. Throughout its history, the market has been home to numerous ethnic groups, with each one leaving it own unique palimpsest on the area. Originally, the market was Toronto's first Jewish settlement, home to 60,000 Jewish Immigrants from Eastern Europe. To date the area is still home to two of the oldest synagogues in the City, the Anshei Minsk Synagogue on St. Andrew Street built in 1913 and the Kiever Synagogue on 25 Bellevue Avenue built in 1923, both of which are still in use today (Ehrenworth 2003). After the Second World War, much of the markets Jewish population moved to nicer neighborhoods uptown. In the 1950's a wave of immigrants from the Caribbean and East Asia filled the vacancy, followed by Americans trying to avoid the Vietnam War Americans in the 1960s. This influx of politically charged American immigrants gave the neighborhood its reputation for social advocacy. Around this time, the city built Alexandra Park, a large apartment style public housing project, south of Dundas Street that accommodated immigrant groups from Somalia, Ethiopia, Vietnam, and Iran among others, each of which added their distinct cultural flavor to the area. Today this rich cultural mosaic, combined with the pedestrian scale of the area and density of downtown Toronto, generates a palpable energy that makes the area so unique. 


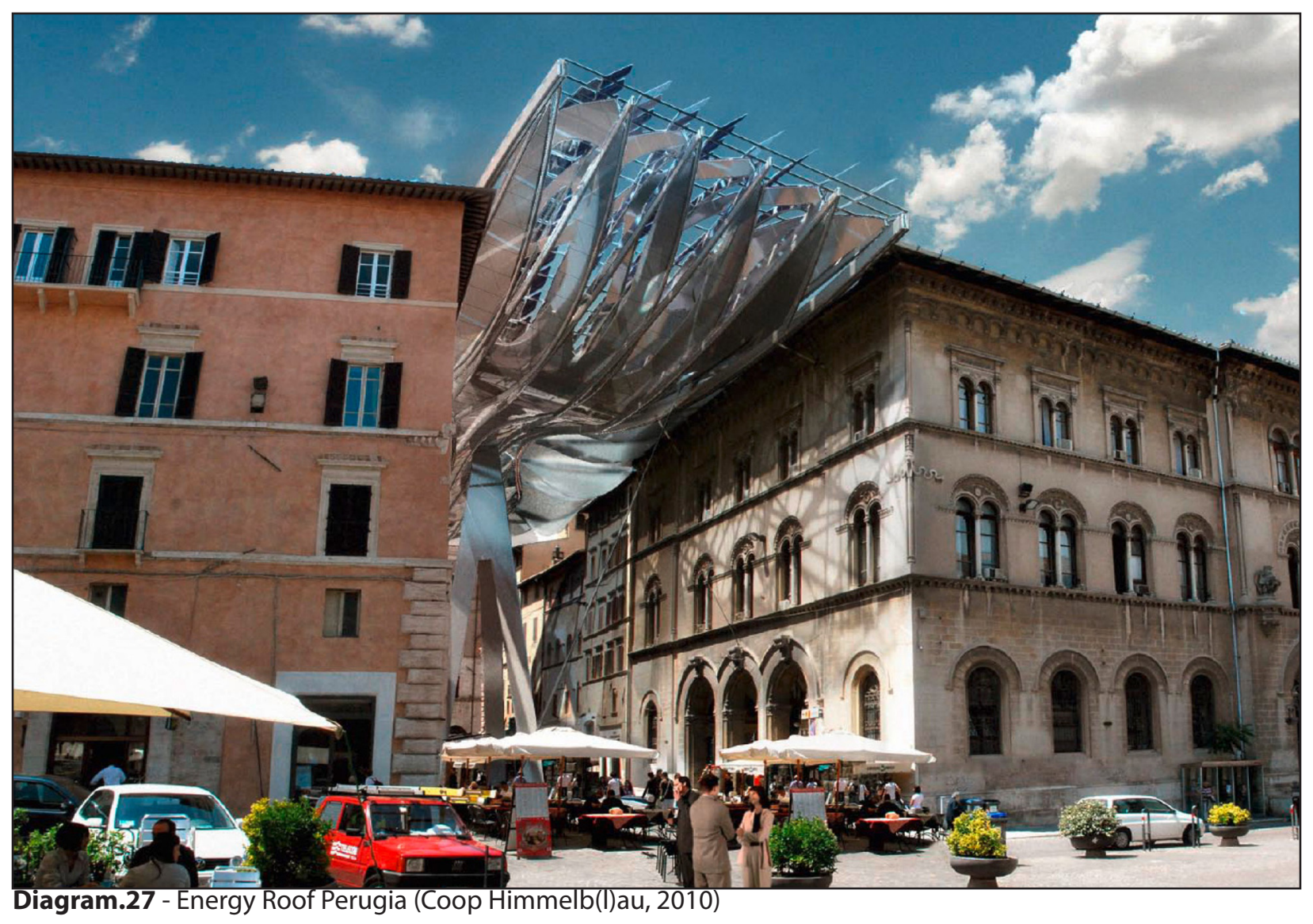

From a design perspective, incorporating a large solar energy installation in Kensington area is difficult, because one does not want to interfere with the existing vibrancy of the street, but act as responsible catalyst to enhance it. Two contemporary case studies, demonstrate strategies as how to integrate photovoltaic systems into a dense urban and cultural context. The first is a is a recent design proposal by Coop-Himmelb(l)au for a canopy, or covered gallery. The purpose of the project is to connect the city center to the newly built metro station in Perugia, a medieval town in Northern Italy. Diagram.27 shows a rendering done by the architects showing the energy roof situated in the town square. The architects needed to respect the historical context of the square, while creating an instantly recognizable symbol for the city. Their solution was a fluid 'cloud-like' structure floating above the surrounding buildings, as not to disturb the historical fabric of the surrounding buildings. They also paid careful attention to how the canopy would affect the ephemeral qualities on the underlying streetscape, and for this purpose selected modules with voids in between the individual cells to allow sun light to filter through the installation. In total, the canopy included a $73 \mathrm{kWp}$ photovoltaic system combined and a $25 \mathrm{kWp}$ wind turbine system (Coop Himmelb(I)au 2010). Structurally, ten steel members carry the loads from the $80 \mathrm{~m}$ long and $16 \mathrm{~m}$ wide canopy to a tripod in the middle, minimizing its impact at street level (ibid.). 


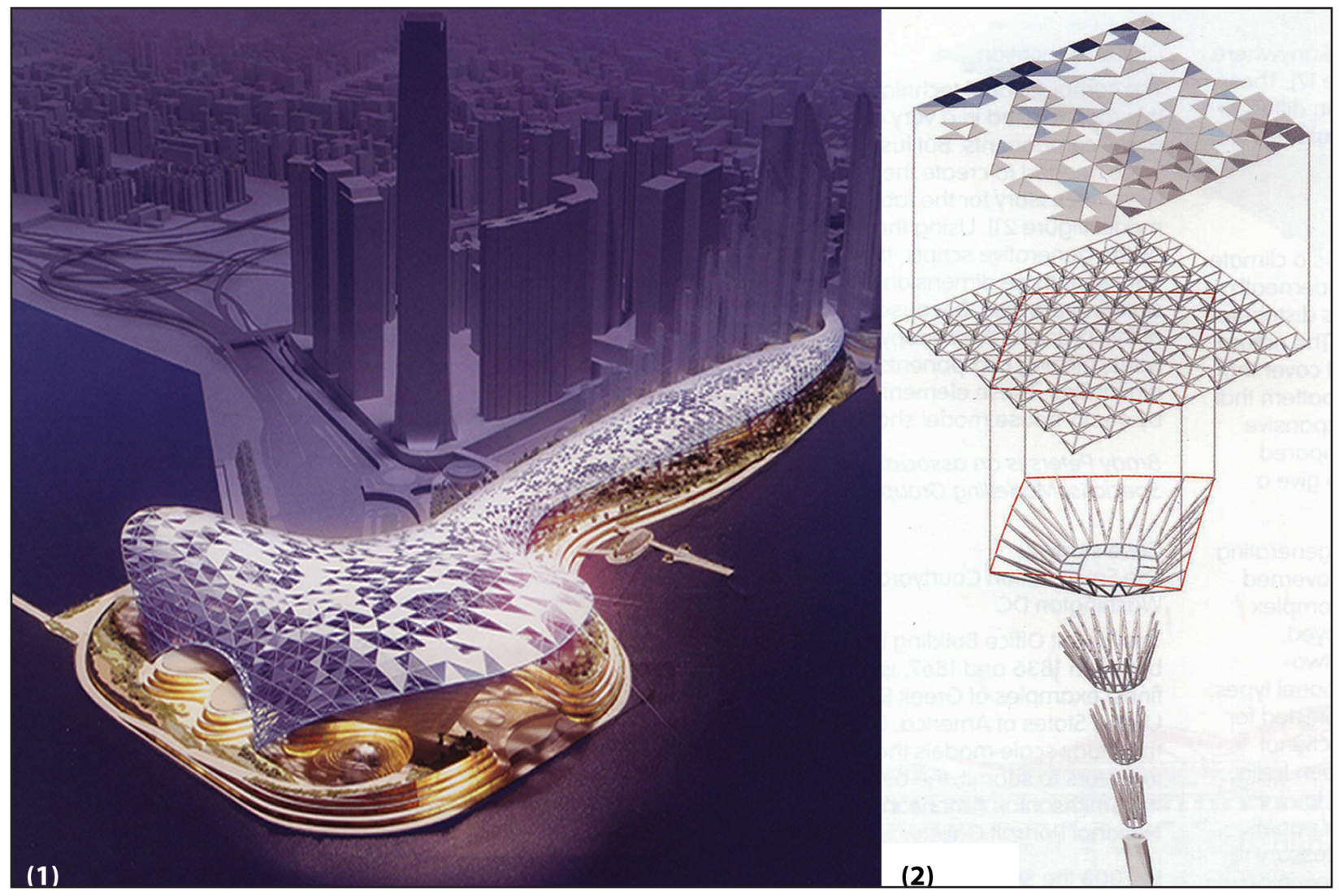

Diagram.28 - The Great Canopy, West Kowloon Cultural District, HK. (Whitehead \& Peters, 2008)

The second example is also a design proposal for a urban canopy, in Hong Kong's Kowloon Cultural District, designed by Foster + Partners. The district was an effort by the city to attract cultural and entertainment venues connected by a giant pedestrian canopy. Conceptually the architects envisioned the canopy as a semi permeable surface that floated over the site and controlled the climate underneath. Diagram.28(1) is a rendering by the architects illustrating the canopy situated along Hong Kong's waterfront. By cladding the canopy with panels offering varying levels of permeability, the architects could control the ventilation, level of enclosure, oxygen levels, day lighting, and even produce electricity with photovoltaic modules. Modeling the canopy with GC allowed the designers to experiment with complex geometries, while maintaining the overall fluid aesthetic and intentions of the project. In addition to supporting the form generation process, the software also supported a seamless collaboration with structural designers. From the digital model, engineers were able to analyze loads acting on the surface, select appropriate structural profiles, and design the space frame to support the cladding system (Whitehead and Peters 2008). The design proposal not only suggests how society can rethink a pedestrian canopy as a cultural catalyst within urban neighborhoods, but also how to integrate to incorporate photovoltaic modules into the surface of such a structure using parametrically controlled cladding panels as illustrated in Diagram.28(2). 

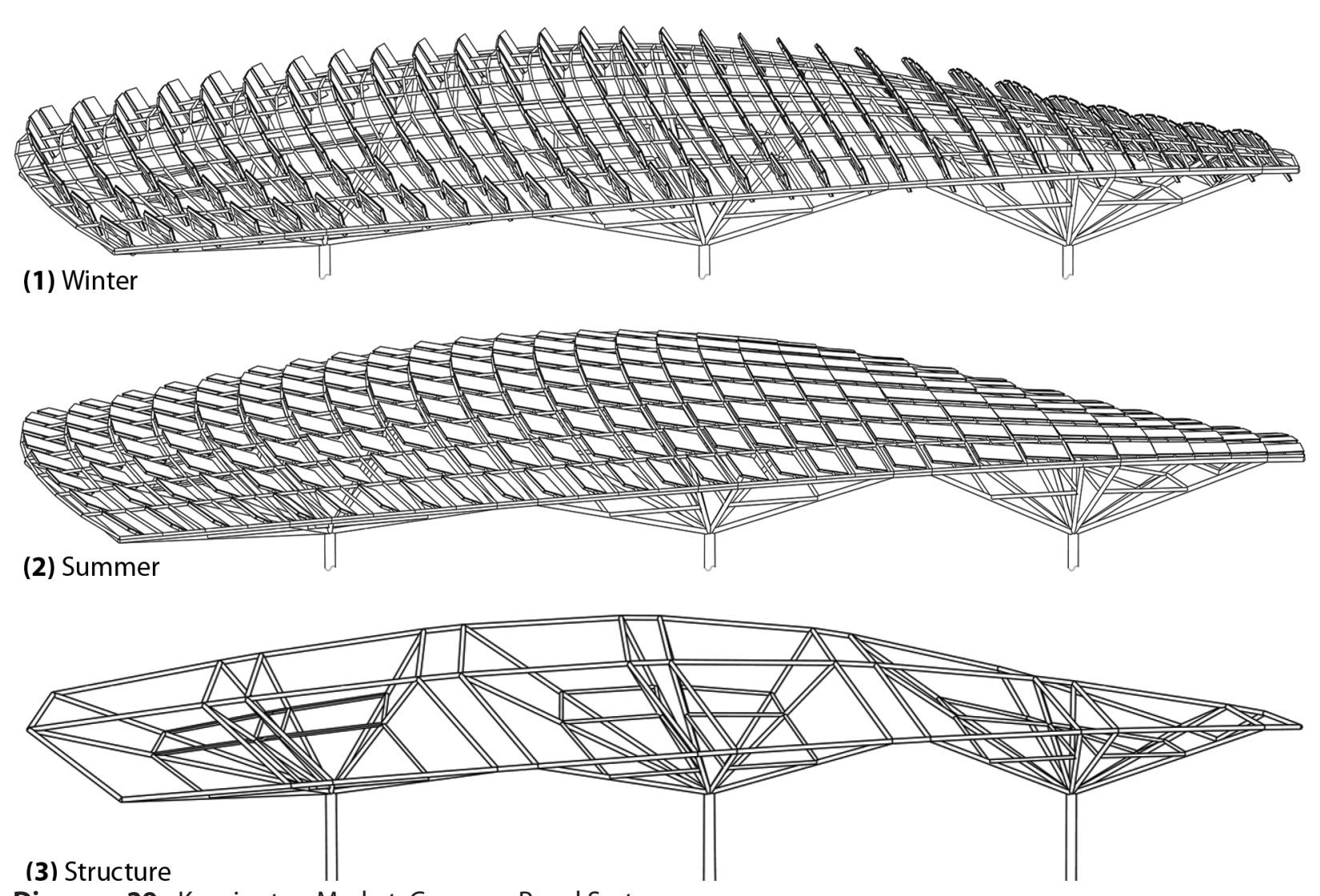

Diagram.29 - Kensington Market Canopy - Panel System

While the scale and context of Perugia and Kowloon vary from Kensington Market, the essential design problem is the same. In all three cases, the architects need to incorporate a pedestrian canopy into a dense and culturally rich area. Besides how to work within an existing urban context, the two case studies also illustrate how society can rethink canopy structures as a way of introducing renewable energy generation into the built environment. In this light, it makes sense to introduce the same type of intervention in Kensington Market, proposing a photovoltaic integrated pedestrian canopy aimed at enhancing the area's rich cultural energy. Attempting to capture and emulate the markets palpable pedestrian energy has long been a fixation of the city. Over the years, numerous proposals have called to turn the area into a car free zone. In 2004, area residents introduced Pedestrian Sundays an event that once a month would transform the market in to a street festival during the summer. While the event has become extremely popular, it is not very feasible to turn the entire area into a permanent car free zone. Restricting vehicular access would negatively impede on the daily activities of the local retailers who depend on logistical access to stock their shelves. An alternative solution is to designate specific sections of the area into pedestrian zones, which would limit any negative logistical impacts. Following this logic, the design proposal is to designate the stretch of Kensington Avenue between Baldwin Street and St. Andrews Street as a pedestrian district, 


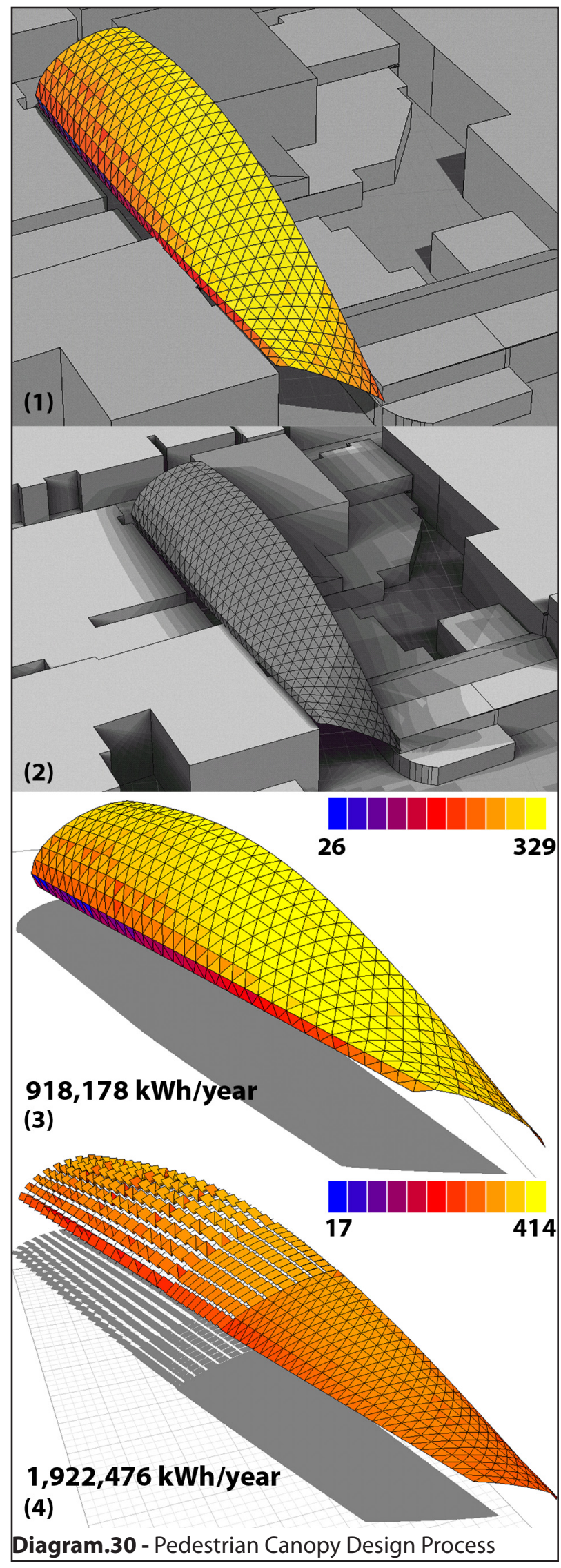

covered by a photovoltaic integrated canopy. The canopies distinctive form would not only serve as a visual icon for the neighborhood, but would also draw visitors into the market.

\subsubsection{Pedestrian Canopy Design Concept}

Since the horizontally orientated surface of the canopy is already ideal for incident radiation collection as demonstrated in Diagram.30(1), there is no need for an extensive form generation process as with the previous installation. Instead, the canopies flowing curvature corresponds to the existing building heights at its four vertices. Elevating the canopy above the surrounding buildings with the lowlying residential scale of the neighborhood means that there are no objects to cast shadows on to the modules as illustrated in Diagram.30(2). With the individual panels able to rotate independently of the base surface geometry to the optimal solar altitude at different times of the year, the aggregate output of the installation increases significantly, as illustrated in Diagram.30 (3-4). Besides increasing the performance of the modules, the idea was that the rotating panels would double as passive shading devices. During the summer months, when the suns altitude angle is the steepest, the panels are close to parallel with the surface geometry of the canopy, providing shade for the pedestrians beneath. Conversely, during the winter months the panels would be almost perpendicular to the surface geometry, impeding any snow accumulation on the individual modules. Diagram.29 illustrates the panel's range of movement, between the winter (1) and summer (2) solstices. 


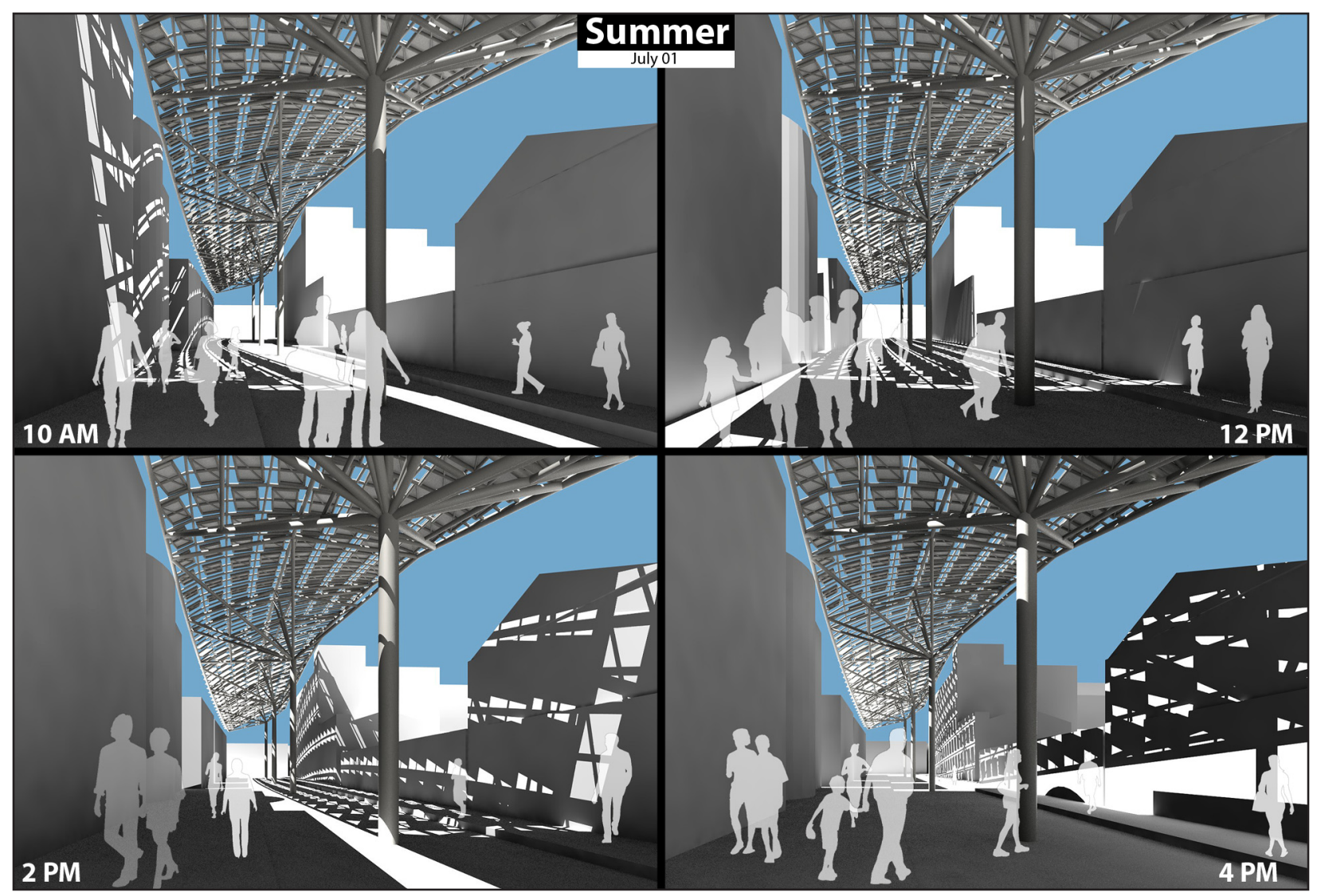

$\bigwedge$ Diagram.31 - Summer Shadow Study

V Diagram.32 - Winter Shadow Study

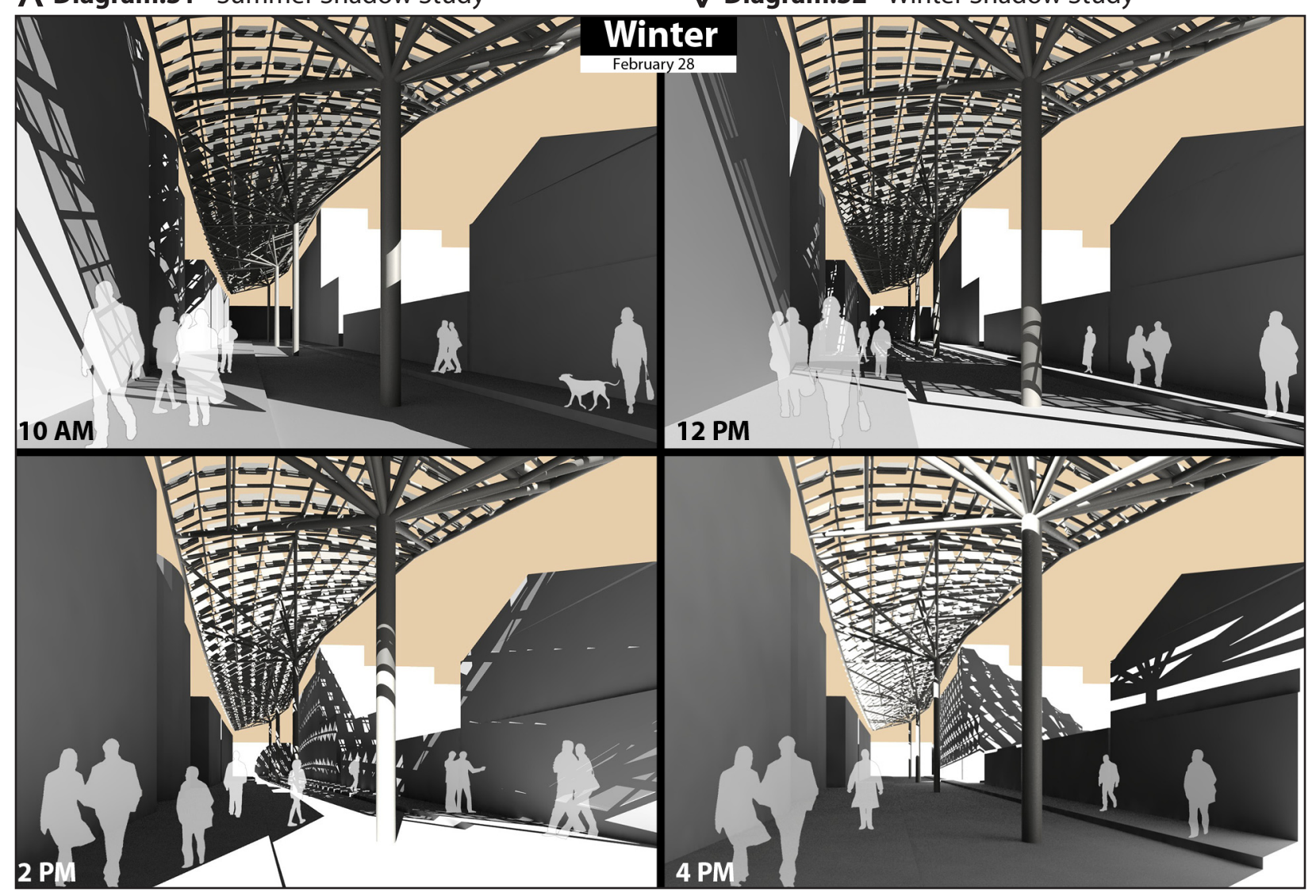




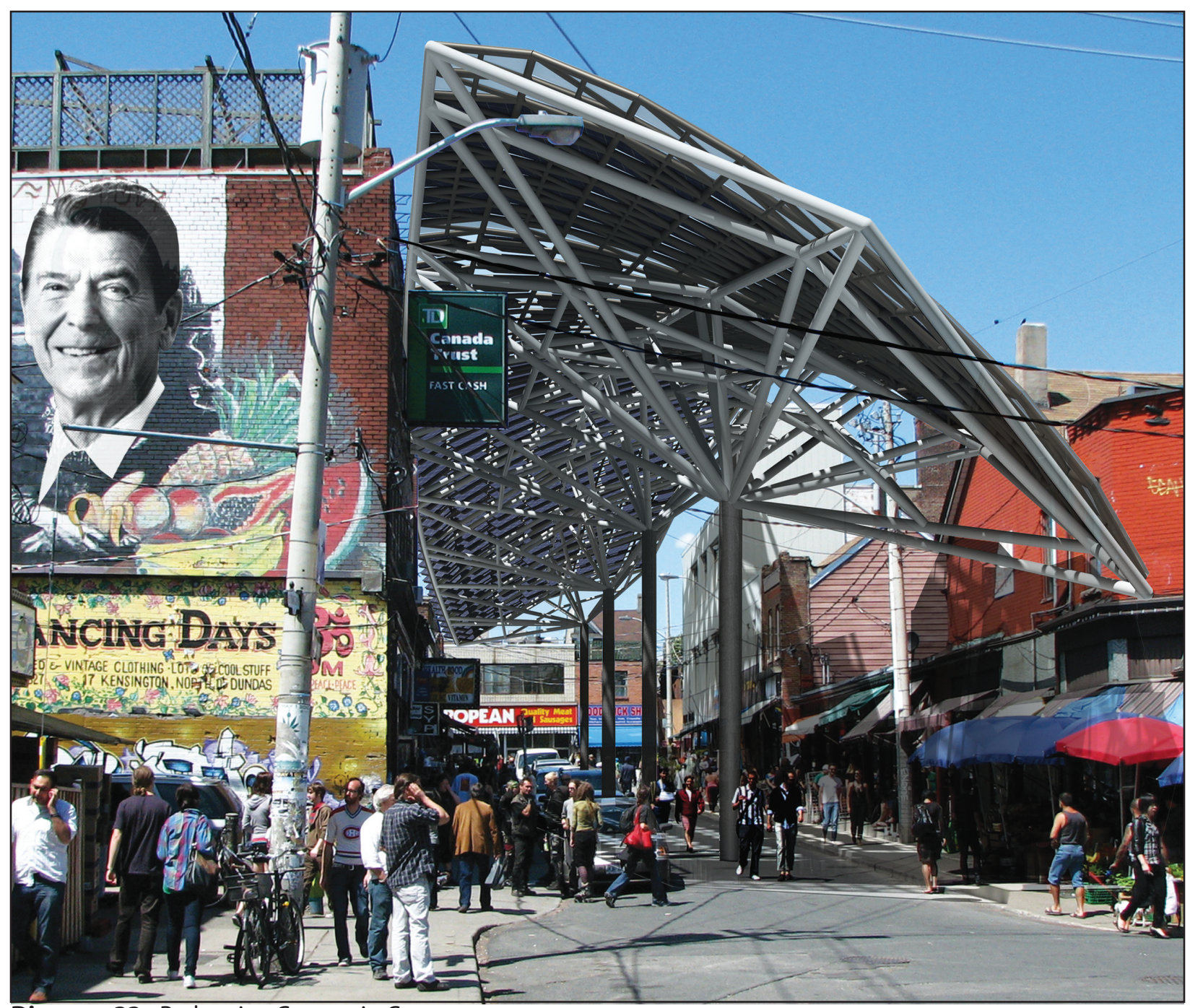

Diagram.33 - Pedestrian Canopy in Context

Since one of the secondary objectives for the installation was to enhance the existing pedestrian energy of the area, it was important to understand the ephemeral qualities of the structure in respect to streetscape shading during different times of the day, as demonstrated in Diagrams 31-32. During the summer months, any shading is advantageous as it passively helps to cool the area beneath the canopy as illustrated in Diagram.31 and Diagram.33. However, during the winter months with sub zero temperatures and limited sunlight, complete shading can make the area underneath the canopy uninviting to pedestrians. Diagram.32 illustrates that during the winter with the modules at a steeper inclination, more daylight filters through the canopy. Adding a row of translucent non-active panels at the south end of the canopy, helps to further lighten up the installation, making it more inviting to pedestrians during the wintertime. Although the final perception pertaining to the success of the installation is ultimately highly subjective, the final rendering as shown in Diagram.33, envisions a future market that embraces the future while being careful to protect its unique identity. 


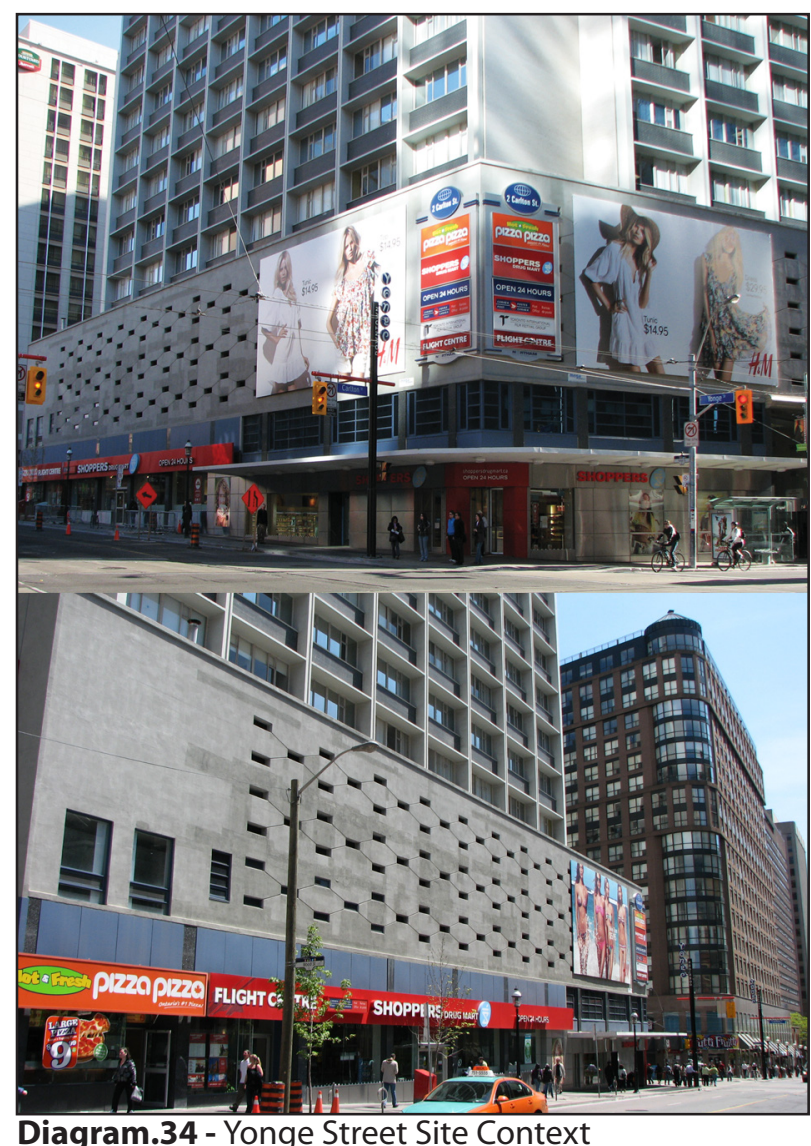

Diagram.34 - Yonge Street Site Context

\subsubsection{AD Space in Context}

The final design intervention looks at rethinking advertising space along Yonge Street in an attempt to facilitate a dialogue between public space, outdoor media, and renewable energy generation. While billboards have little to do with developing a flexible and quantifiable solar design process, they are significant in the larger context of the urban integration of photovoltaic systems. It is important to remember that the ultimate aim of the project, as it relates to architecture, is to promote the mainstream acceptance of the technology. Outdoor advertisements have long been an omnipresent aspect of urban living, with countless large billboards scattered throughout

\section{"The metropolis today is a}

\section{classroom; the ads are its}

\section{teachers." - Marshal McLuhan}

the city. These forms of outdoor media unwillingly subject people to carefully orchestrated images of everything from automobiles to hamburgers everyday in an attempt to persuade their purchasing decisions. This saturation has reached the point where people just accept outdoor media as a natural part of the urban landscape, as trees in a forest. If the goal is to reach a critical mass regarding the popularity of urban integrated photovoltaic systems, solar architects can learn how corporations have made billboards an allpervading aspect the urban landscape. It is the aim of the installation to purpose how architects can reprogram the photovoltaic medium as a technological extension of outdoor media.

It is the hope that in the future, photovoltaic installations will be as ubiquitous as outdoor advertisements are today. Over the past century, advertisers have expanded the integration of outdoor media well beyond the scope of the city, to include installations alongside major highways, railroad corridors, and countless other examples of modern infrastructure. There is no reason why photovoltaic installations cannot follow suit. According to Marshal McLuhan, the reason why outdoor media has become so ubiquitous, in the sense that one barely notices them, is by careful design. Advertising was never, "meant for 


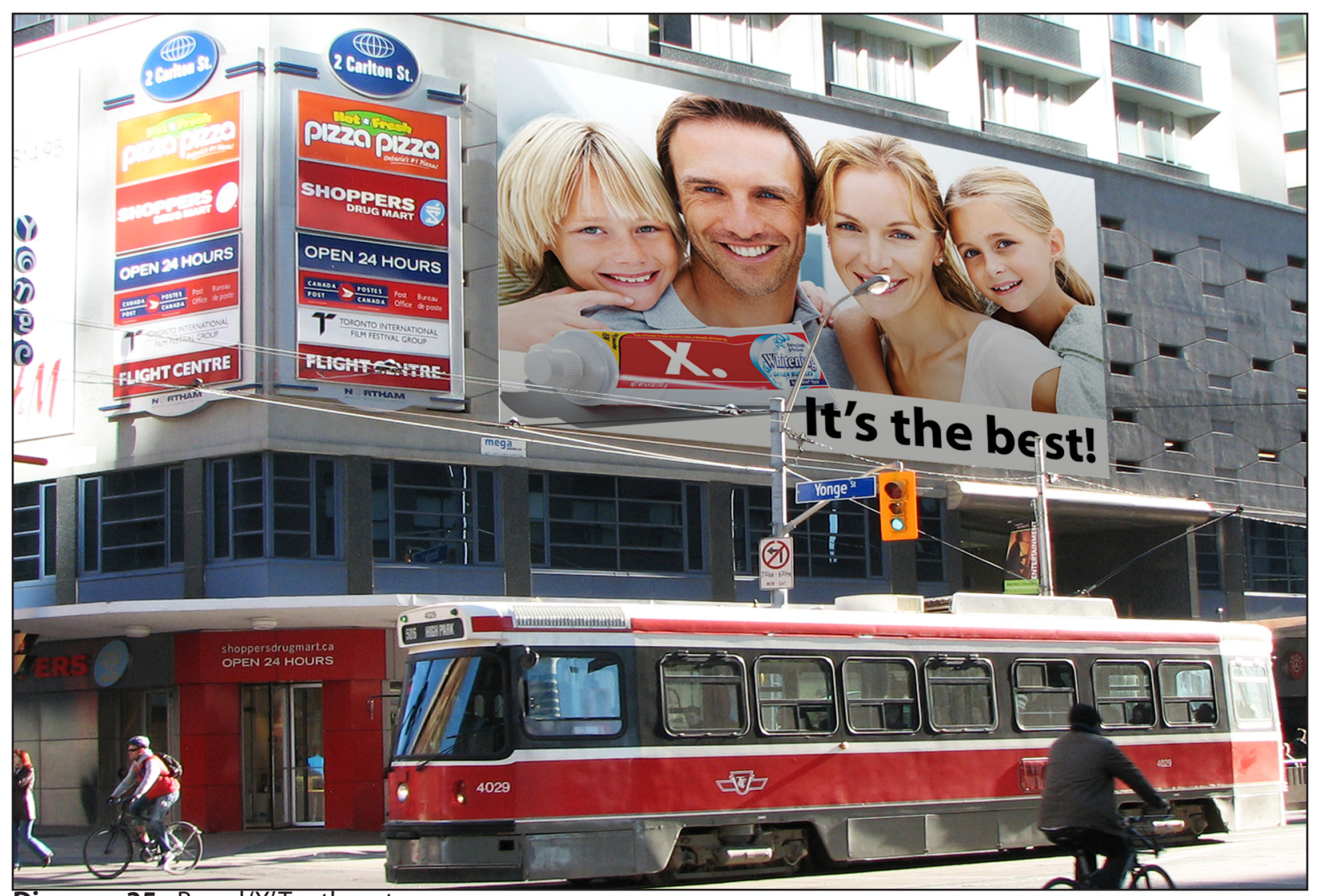

Diagram.35 - Brand $X{ }^{\prime}$ Toothpaste

conscious consumption", but, "intended as subliminal pills for the unconscious in order to exercise a hypnotic spell" (McLuhan, Understanding Media - The Extensions of Man 1994, 228). Corporations spend billions of dollars annually on advertising to achieve this hypnotic effect, saturating our visual senses to the point of exhaustion. The intended result is a, "semi conscious exposure", and, "is a testimony, as well as contribution, to the somnambulistic state of a tired metropolis."(Ibid.). This is why outdoor media or advertising is so effective in persuading our purchasing choices, because it works without our awareness at the subliminal or semi conscious level. As a hypothetical example, when one is exposed to the billboard in Diagram. 35 for brand ' $X$ ' toothpaste which depicts an attractive family with perfect smiles, they barely notice it, almost as if they were sleepwalking or in a 'somnambulistic state.' Unconsciously, this split second exposure is enough to create a subliminal impression on the person. So that when they are out shopping for toothpaste, trying to decide among the various brands, they suddenly remember the pleasurable image from the advertisement seen previously. This association between the brand and the image ingrained in their consciousness causes them to choose the brand ' $X$ ' product over the other competitors on the shelf. The problem advertiser's face is creating the association between the artificially created image or brand and the product, while competing with the other brands vying to do the same thing. In essence, the process is a subtle type of subliminal 
mind control harmlessly used to sell consumer products, "To put the matter abruptly, the advertising industry is a crude attempt to extend the principles of automation to every aspect of society" (McLuhan, Understanding Media - The Extensions of Man 1994, 227). It is easy for someone to interpret this automated cycle of controlled consumption as a negation of personal freedom, but the fact remains that advertising is a major element of the urban environment and is here to stay, "The metropolis today is a classroom; the ads are its teachers" (McLuhan, Essential McLuhan 1995, 210).

Rather the purpose of this installation is not to sell a particular brand of solar cell nor is a critique on the nature of advertising, but is an attempt to hijack or detour the ubiquitous nature of outdoor billboards in an attempt to integrate solar energy into urban environments. Both billboards and photovoltaic arrays are exposed to sunlight, require significant amounts of surface area, and generate varying levels of financial return. In many cases, outdoor billboards and solar installations are essentially interchangeable, especially within an urban context. The best scenario would is photovoltaic installations could double as lucrative outdoor advertising media, using technologies that allow advertisers to etch or print corporate images on to thin-film photovoltaic panels. Given that solar cell manufacturers already use a silk-screening process, similar in nature to one used to print graphics on to clothing, to apply thin film photovoltaic cells to their substrate. It is only a matter of time until researchers develop ways of imprinting graphics on to the modules, dramatically changing the nature of the medium. A hybrid photovoltaic media surface is an unquestionable means of making the technology more attractive to investors. According to IMA Outdoor Advertising, leasing a $14.5 x .4 .25 \mathrm{~m}$ billboard at a busy intersection in downtown Toronto would cost approximately $\$ 14,000-$ 16,000 per month plus a $\$ 3350$ installation fee (IMA Ooutdoor 2010). Hypothetically, if that same area of $61 \mathrm{~m} 2$ doubled as a $90^{\circ}$ thin film photovoltaic surface at $10 \%$ efficiency, it could generate around $6300 \mathrm{kWh}$ annually. While the output of one standard billboard is about half the average electricity consumption of a typical Canadian household, imagine if there were a hundred photovoltaic advertisements across the city, they would be able to power around 50 homes in addition to collecting lucrative advertising revenues. Until a viable hybrid photovoltaic advertising media becomes available, architects can explore the potential of combing photovoltaic systems into advertising installations as an alternative, albeit potentially financially profitable, means of integrating solar energy into the urban environment. The above is only a simple example of how society by thinking beyond conventional means, can increase the urban integration of photovoltaic electricity in a way that makes financial sense. A critical mass regarding the acceptance of clean renewable energy generation will only occur when private economic interests are simultaneous with environmental interests. 


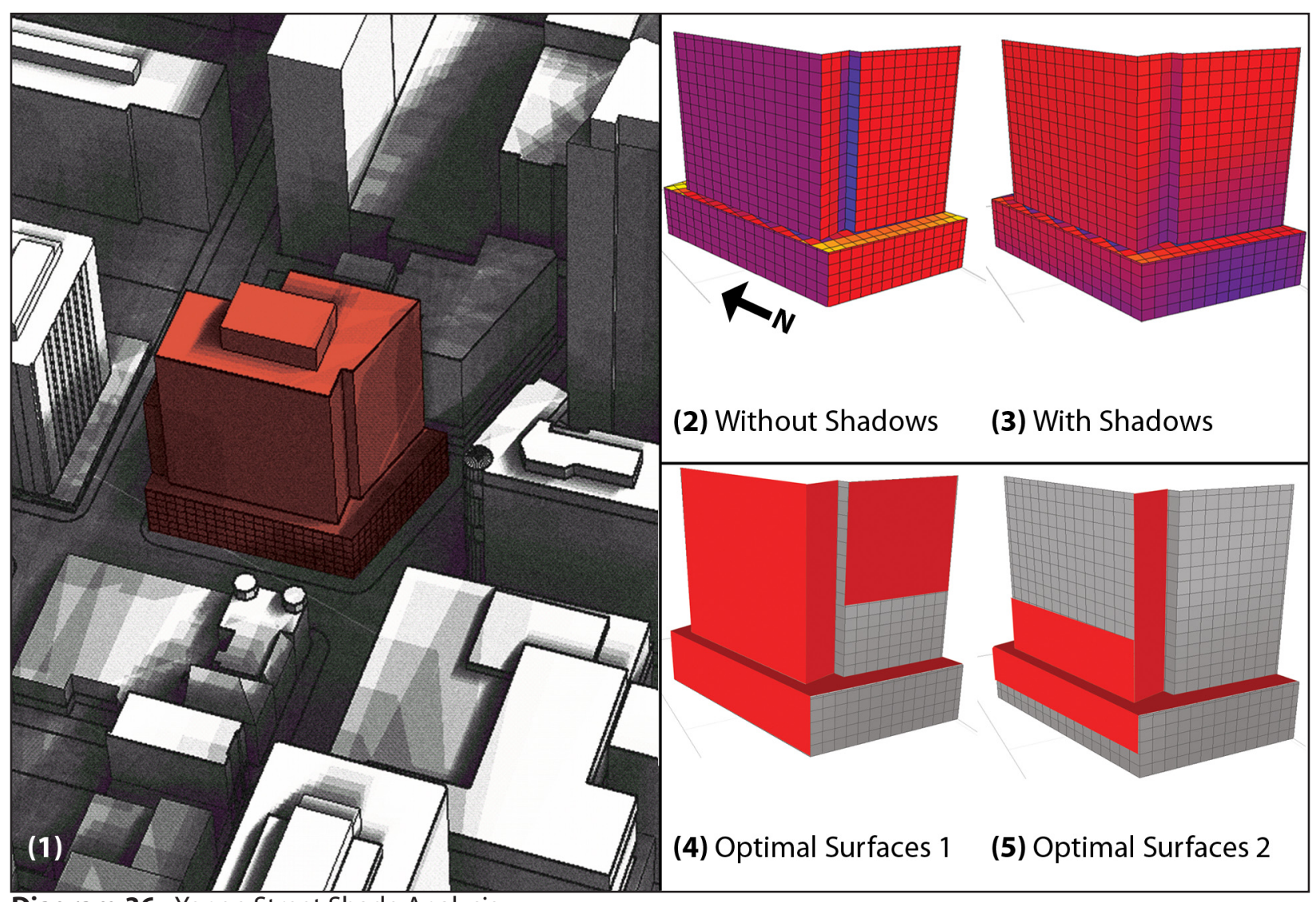

Diagram.36 - Yonge Street Shade Analysis

\subsubsection{AD Space Design Concept}

The third installation differs from the previous two, as it is located in an area of the city with greater vertical density. Shadows cast on the site from the surrounding buildings create less than optimal solar conditions as demonstrated in Diagram.36(1), as opposed to the previous two examples that had unhindered solar exposure. In any case, shading on solar arrays caused by surrounding buildings is an unavoidable aspect when designing in a dense urban context. Demonstrating how the methodology accounts for site-specific shading is central in illustrating its wide scale applicability, as is the aim of the design component. The first step is to determine how the surrounding shading affects the solar exposure on the site. Diagram.36(2) illustrates the incident radiation on the building surface without taking into account shading from the surrounding buildings. As expected in this case, the south elevation receives the greatest amount of sunlight. Conversely, if one takes into account aggregate shading as illustrated in Diagram.36(3), it becomes evident that the west elevation is the most suitable for solar energy collection. In this situation, it would be almost impossible to calculate the shading patterns on the site using analog means. The example clearly demonstrates how digital tools act to extend the creative reach of the designer, offering them new insights that were previously unavailable with older methods. 


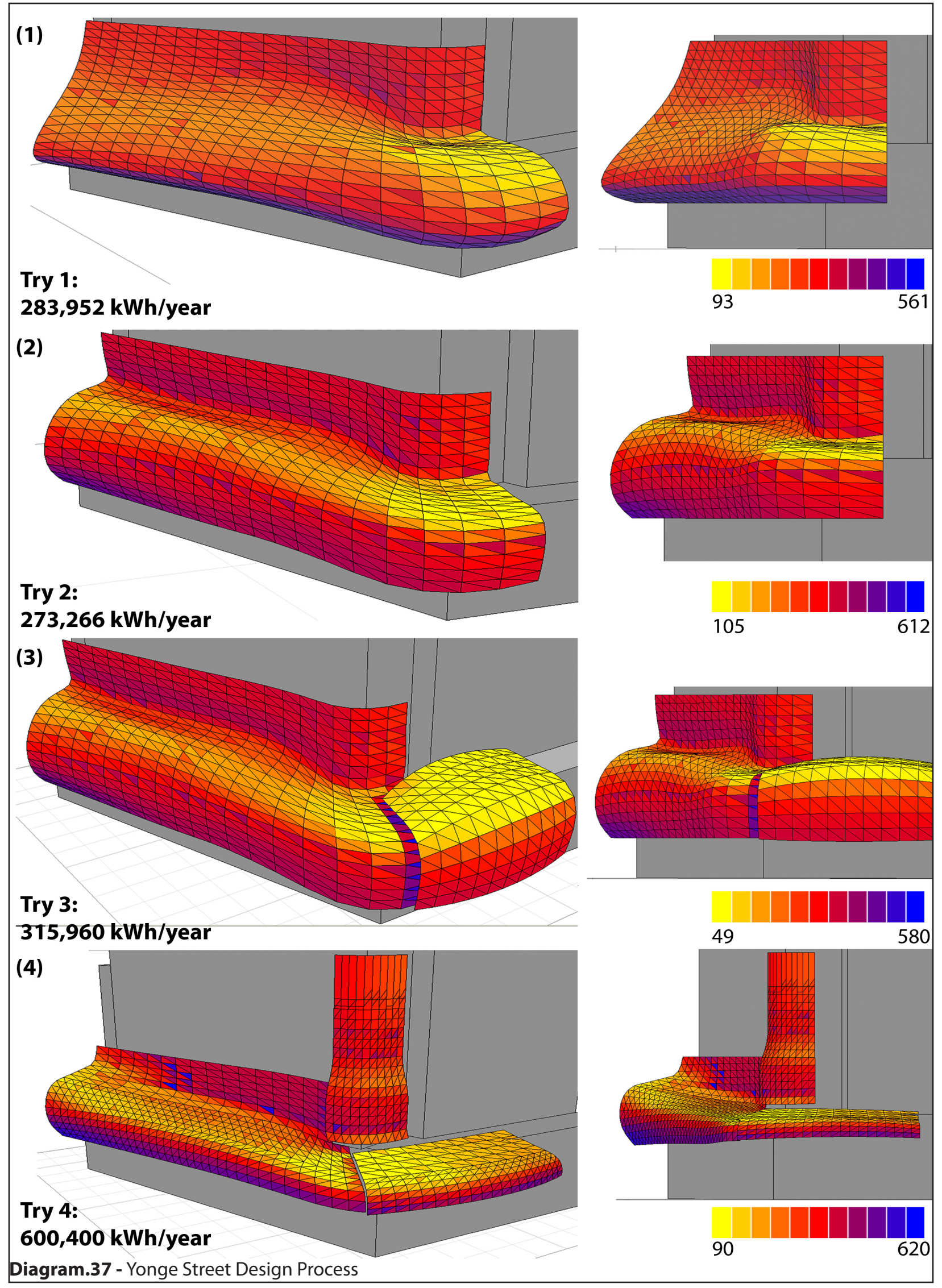




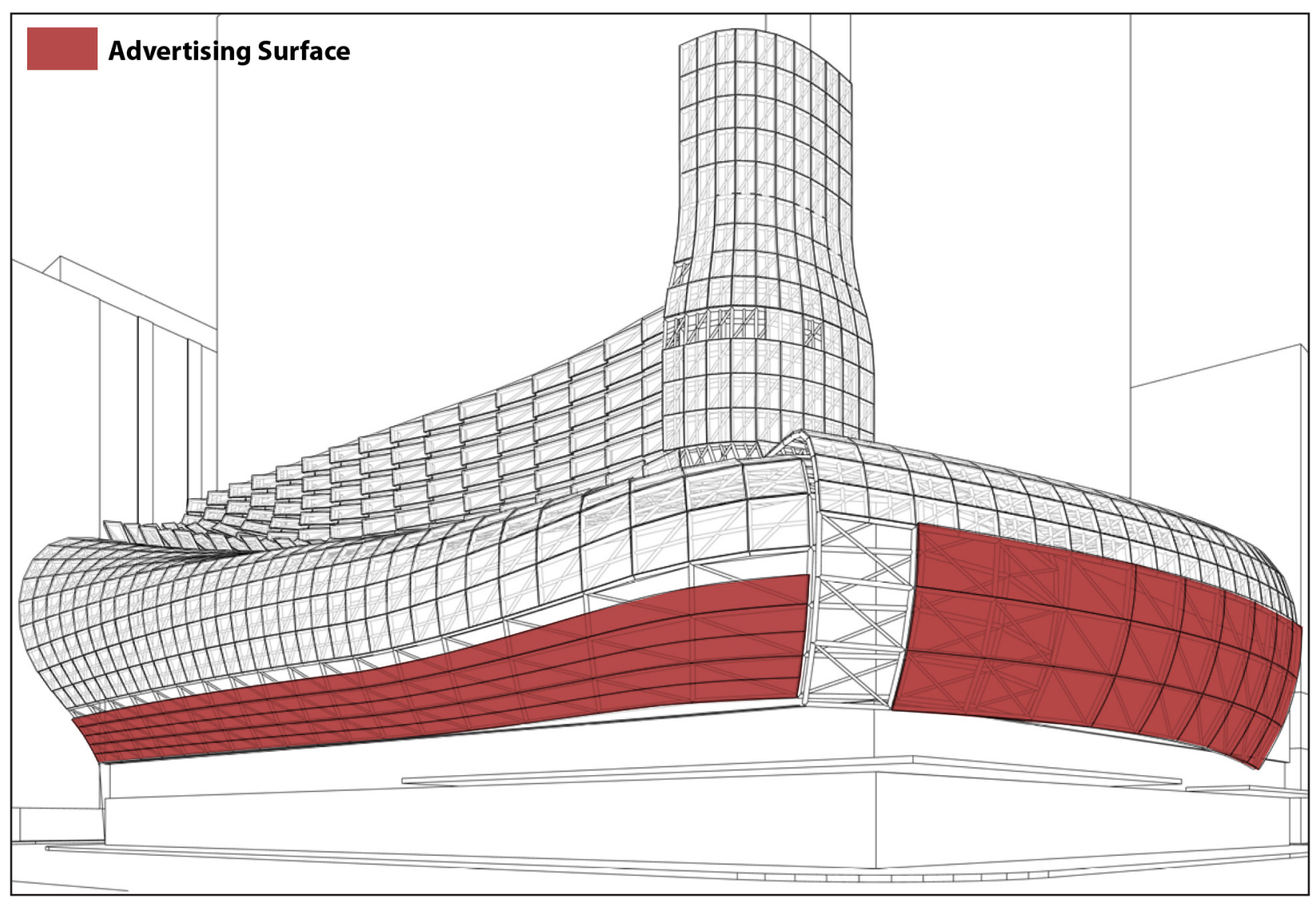

Diagram.38 - Yonge Street AD Space

With the analysis having validated which surfaces of the existing building are suitable for solar collection as illustrated in Diagram.36(4), the designer could then start incorporating these areas in to the form. The second step was to loft a unified surface over the highlighted areas as illustrated in Diagram.36(5), which then underwent a process of continued refinement as illustrated in steps Diagram.37(1-4). Informing the form generation process was a combination of feedback from the solar analysis model coupled with the designer's aesthetic vision and knowledge of local solar patterns. As with the previous two installations, the design process was a negotiation between contorting the surface geometry to maximize incident radiation and non-quantifiable variables such as aesthetics and user experience. Understanding how the installation would appear from the perspective of people walking down Yonge Street was an important consideration in the design process. Offsetting certain portions of the surface created visual emphasis to the massing, creating gaps between the modules where pedestrians could catch a glimpse of the supporting steel structure underneath. The surface space reserved for advertising as shown in Diagram.38, is orientated towards pedestrians walking down Yonge Street increasing its exposure and overall effectiveness. The installation is successful not only in demonstrating the applicability of the design methodology in less than perfect solar conditions, but also how a proposed hybrid photovoltaic medium can improve the urban 


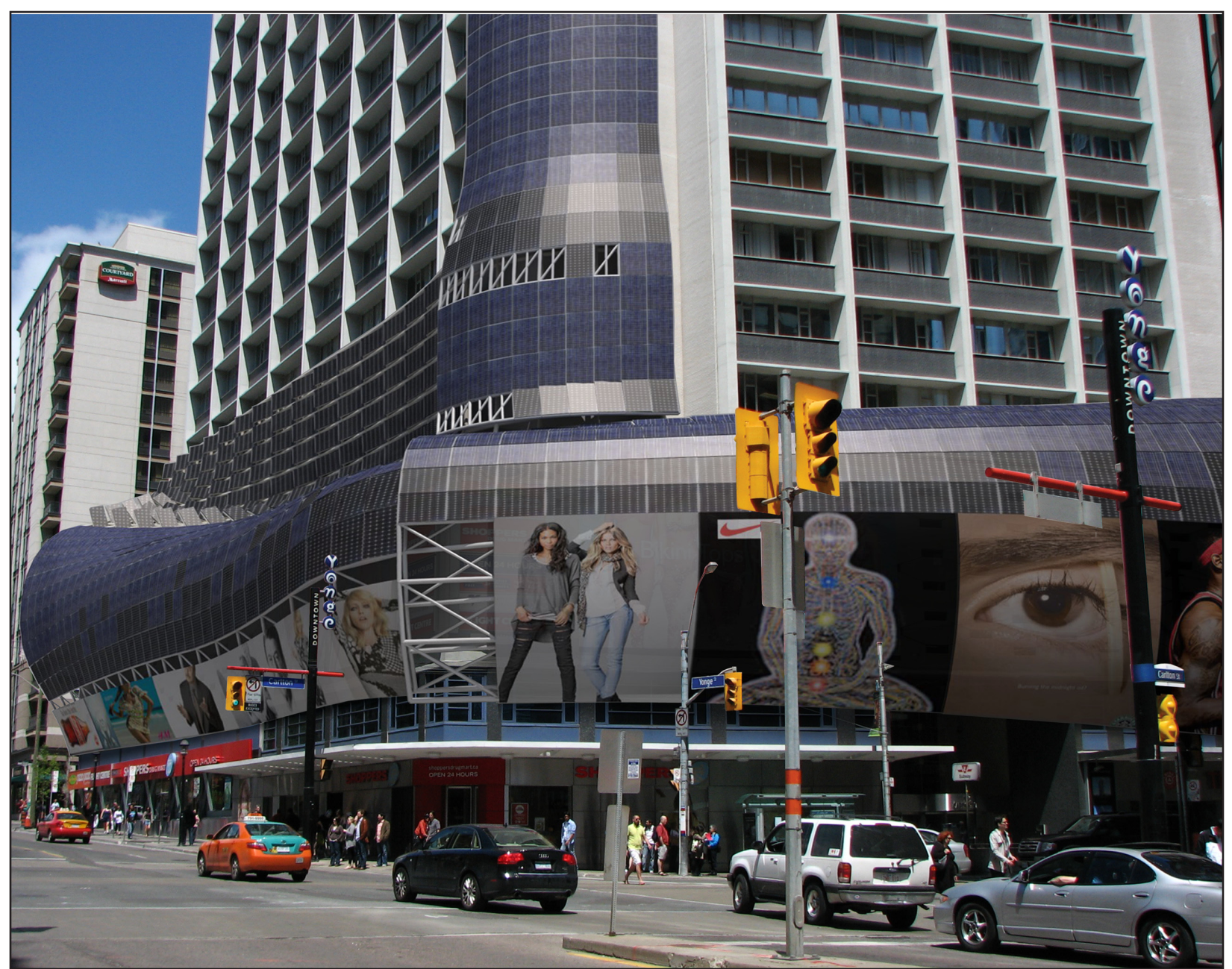

Diagram.39 - Yonge Street Installation in Context

integration and public acceptance of the technology. Diagram.39 shows a rendering of the installation within in situ, demonstrating that if society is willing to accept outdoor media as an omnipresent factor of the landscape, there is no reason why solar energy systems cannot follow suit. 


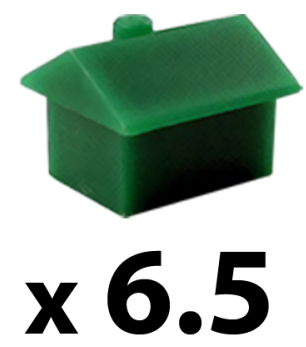

The Silos

$53,077 \mathrm{kWh} /$ year

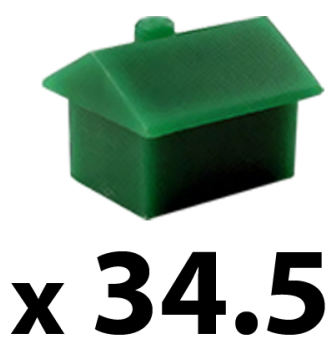

The Market

$276,836 \mathrm{kWh} /$ year

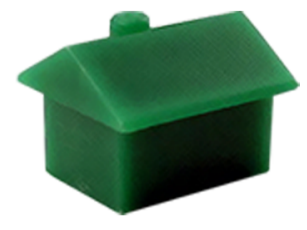

$\mathbf{x} 10$

AD Space

$81,287 \mathrm{kWh} /$ year

Diagram.40 - Output in Context

\subsection{Output}

As previously mentioned at the beginning of this report, solar analysis models allow designers to quantify incident radiation on complex surfaces in a fashion previously not possible with manual calculation methods. The ability to quantify the output of photovoltaic installations is important as to not deceive the reader and provide unrealistic expectations for the technology. While providing a photorealistic rendering of a photovoltaic installation may entice some readers, it is not enough to sell the idea of solar electricity to investors and policy makers. Without any idea to the output of the installations, it is easy to dismiss the project as a superficial exercise in form generation. If architects are serious about integrating photovoltaic electricity generation into the build environment on a large scale, they need to educate themselves concerning the output and general economics of the systems. In this light, the three hypothetical installations could produce approximately $400,000 \mathrm{kWh}$ of electricity annually. Assuming that the average energy conscious house hold consumes $8000 \mathrm{kWh}$, as is the average in Germany and California two locations generally associated with environmental awareness, the three installations could power approximately 50 homes for a year (Silverman, 2007). Germany and California are good examples because they are able to reduce their electricity consumption while still maintaining a very high quality of life, serving as a positive model for other industrialized nations to follow. While this number seems underwhelming, especially when taking into account that the average North American household uses $12000 \mathrm{kWh}$ of electricity per year, it is important to view the possibilities of the technology in the broader context (Ibid.). Imagining if instead of three installations, there were hundreds of such structures scattered across not only Toronto, but in every city around the world. Although it is highly unlikely that photo will ever meet all of humanities electricity needs, but in combination with other renewable energy methods, it can play a significant role in helping humanity limit the disastrous consequences of global warming. 


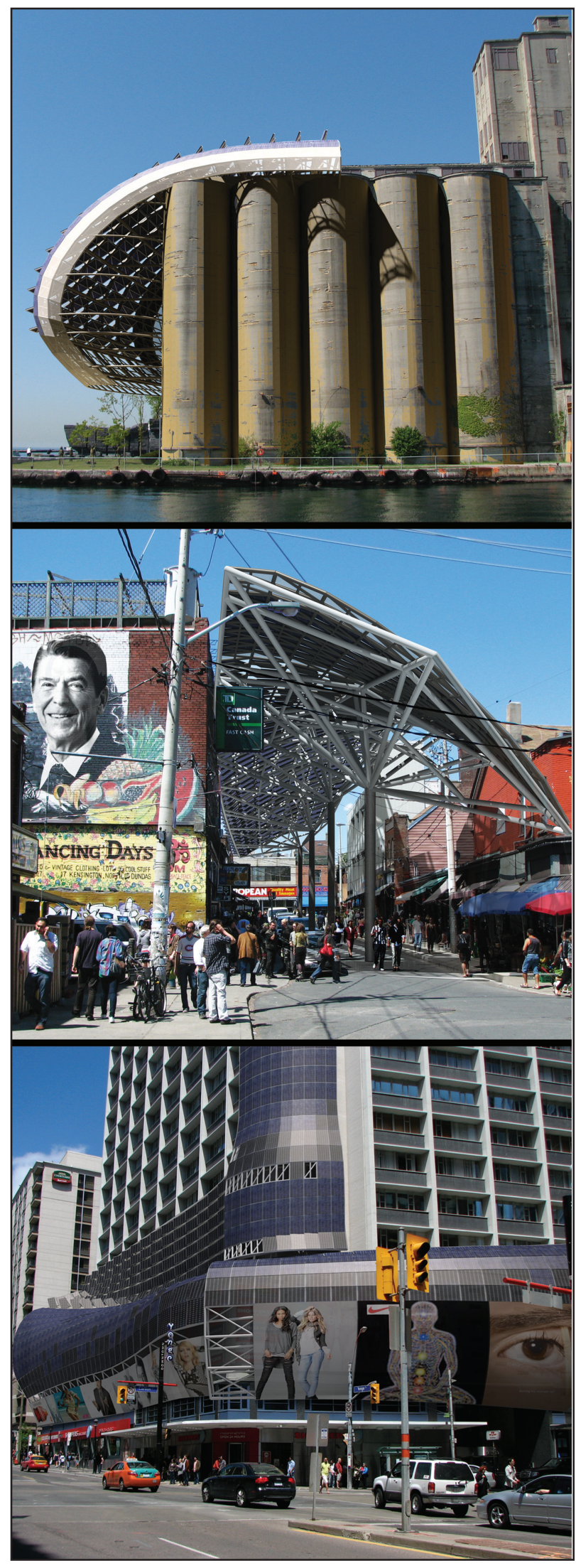

Diagram.41 - Conclusion

\subsection{Conclusion}

The three installations clearly demonstrate the applicability of the proposed methodology, while simultaneously reiterating the need for more developed design tools to support a solar design process. The disjunction between the analysis tools and the modeling software made fine-tuning the surface geometry to maximize incident radiation difficult. While the methodology acknowledged the arbitrary nature of the design process, it relied heavily on digital tools to facilitate an extension of the architect's creativity. The parametric and analysis tools not only provided a flexible workflow that allowed the designer to seamlessly validate and modify the geometry as needed, but redefined and expanded the possibilities of urban integrated photovoltaic systems. Assuming the growing popularity of intelligent energy conscious buildings in lieu of the impending energy and climate crisis, demand for intelligent CAD systems that combine real time solar analysis into a flexible parametric modeling platform will increase. If nothing else the ongoing research into building integrated photovoltaic systems by credible international groups such as Task41 is growing, clearly demonstrates a growing interest and eventual demand in such products. Rather, the more pertinent question for architects does not pertain to the development of digital tools, but to the lack of interest and technical knowledge needed to integrate photovoltaic systems in the urban environment on a large scale. Without the architect's innate knowledge of solar patterns and photovoltaic technology 
driving the early design phase, even the most efficient and highly developed digital tools would prove useless. Given the severe consequences of global warming, it is the social responsibility of architects and like minded engineers, to present society with strategies as how to they might begin integrating renewable energy into its cities on a large scale. Considering the innate creativity and intellectual rigor present in the architectural profession, one would expect that these strategies go beyond mere pragmatic integration, looking at how solar energy can affect the nature of public space, or how it can be refined as outdoor media to increase its financial feasibility. Most importantly, these strategies must inspire the public en mass, because ultimately their votes can help determine the government's policy toward renewable energy technologies. At the end of the day in a democratic society, the politicians work for the public. If the public shows enthusiasm and support for sustainable electricity, politicians will eventually try to deliver, even if their only motive is possible reelection. Within the next decade, architects must strive to generate public enthusiasm for solar power by designing bold and innovative structures that integrate traditional architectural functions with photovoltaic systems. In an attempt to reach a critical mass, relinquishing society's dependence on non-renewable fuel sources and ultimately providing a better world for future generations. 


\section{Appendix}

ATMOSPHERIC NASA Surface meteorology and Solar Energy - Available SCIENCE DATA CENTER

\section{Tables}

Latitude 43.39 / Longitude 79 was chosen.

Geometry Information
Elevation: 1192 meters

averaged from the USGS GTOPO30

digital elevation model

Northern boundary

44

Western boundary

79
Center

Latitude $\mathbf{4 3 . 5}$

Longitude 79.5

Southern boundary

43

Parameters for Sizing and Pointing of Solar Panels and for Solar Thermal Applications:

\begin{tabular}{|c|c|c|c|c|c|c|c|c|c|c|c|c|c|}
\hline \multicolumn{14}{|c|}{ Monthly Averaged Insolation Incident On A Horizontal Surface $\left(\mathrm{kWh} / \mathrm{m}^{2} /\right.$ day $)$} \\
\hline \begin{tabular}{|l} 
Lat 43.39 \\
Lon 79
\end{tabular} & Jan & Feb & Mar & Apr & May & Jun & Jul & Aug & Sep & Oct & Nov & Dec & $\begin{array}{l}\text { Annual } \\
\text { Average }\end{array}$ \\
\hline 22-year Average & 1.96 & 2.85 & 3.96 & 5.23 & 5.93 & 6.37 & 6.09 & 5.68 & 4.80 & 3.42 & 2.27 & 1.67 & 4.19 \\
\hline
\end{tabular}

Solar Geometry:

Monthly Averaged Maximum Solar Angle Relative To The Horizon (degrees)

\begin{tabular}{|c|c|c|c|c|c|c|c|c|c|c|c|c|}
\hline $\begin{array}{l}\text { Lat } 43.39 \\
\text { Lon } 79\end{array}$ & Jan & Feb & Mar & Apr & May & Jun & Jul & Aug & Sep & Oct & Nov & Dec \\
\hline Average & 25.8 & 34.2 & 44.8 & 56.3 & 65.4 & 69.6 & 67.8 & 60.3 & 49.6 & 38.1 & 28.4 & 23.7 \\
\hline
\end{tabular}

Parameters for Tilted Solar Panels:

Monthly Averaged Radiation Incident On An Equator-Pointed Tilted Surface (kWh/m²/day)

\begin{tabular}{|l|l|l||l|l|l|l|l|l||l||l|l||l||l||}
\hline $\begin{array}{l}\text { Lat 43.39 } \\
\text { Lon 79 }\end{array}$ & Jan & Feb & Mar & Apr & May & Jun & Jul & Aug & Sep & Oct & Nov & Dec & $\begin{array}{l}\text { Annual } \\
\text { Average }\end{array}$ \\
\hline SSE HRZ & 1.96 & 2.85 & 3.96 & 5.23 & 5.93 & 6.37 & 6.09 & 5.68 & 4.80 & 3.42 & 2.27 & 1.67 & 4.19 \\
\hline \hline K & 0.53 & 0.54 & 0.54 & 0.55 & 0.54 & 0.54 & 0.54 & 0.57 & 0.59 & 0.58 & 0.55 & 0.51 & 0.55 \\
\hline Diffuse & 0.62 & 0.90 & 1.34 & 1.78 & 2.18 & 2.33 & 2.26 & 1.86 & 1.35 & 0.96 & 0.67 & 0.56 & 1.40 \\
\hline Direct & 4.22 & 4.89 & 5.29 & 5.96 & 6.01 & 6.36 & 6.08 & 6.36 & 6.49 & 5.69 & 4.74 & 3.81 & 5.49 \\
\hline Tilt 0 & 1.95 & 2.79 & 3.92 & 5.20 & 5.88 & 6.39 & 6.10 & 5.65 & 4.72 & 3.39 & 2.25 & 1.67 & 4.17 \\
\hline Tilt 28 & 3.36 & 4.05 & 4.87 & 5.66 & 5.88 & 6.08 & 5.91 & 5.93 & 5.65 & 4.80 & 3.74 & 3.02 & 4.91 \\
\hline Tilt 43 & 3.85 & 4.41 & 5.02 & 5.49 & 5.46 & 5.54 & 5.43 & 5.64 & 5.72 & 5.18 & 4.25 & 3.51 & 4.96 \\
\hline Tilt 58 & 4.12 & 4.53 & 4.89 & 5.04 & 4.78 & 4.74 & 4.70 & 5.07 & 5.48 & 5.26 & 4.50 & 3.79 & 4.74 \\
\hline Tilt 90 & 3.86 & 3.92 & 3.79 & 3.39 & 2.89 & 2.76 & 2.80 & 3.22 & 4.02 & 4.45 & 4.15 & 3.63 & 3.57 \\
\hline \hline OPT & 4.16 & 4.53 & 5.02 & 5.66 & 6.01 & 6.41 & 6.14 & 5.96 & 5.73 & 5.27 & 4.53 & 3.86 & 5.28 \\
\hline \hline OPT ANG & 67.0 & 57.0 & 44.0 & 27.0 & 14.0 & 5.00 & 8.00 & 21.0 & 39.0 & 55.0 & 65.0 & 69.0 & 39.1 \\
\hline
\end{tabular}

Diffuse radiation, direct normal radiation and tilted surface radiation are not calculated when the NOTE: clearness index $(K)$ is below 0.3 or above 0.8 . 


\section{Works Cited}

Agrest, D. (1998). Design Versus Non-Design. In M. Hays, Architecture Theory Since 1968 (pp. 200-212). Cambridge: The MIT Press.

Anderson, S. (1998). Architectural Design as a Systems of Research Programs. In M. Hays, Architecture Theory Since 1968 (pp. 492-505). Cambridge: The MIT Press.

Berrah, N., Feng, F., Priddle, R., \& Wang, L. (2007). Sustainable Energy in China. Washington: The World Bank.

Bilgen, E. (2004). Domestic Hydrogen Production Using Renewable Energy. Solar Energy, 77, 47-55.

Borasi, G., \& Zardini, M. (2007). Sorry Out of Gas. Verona: Grafiche siZ.

Bradford, T. (2006). Solar Revolution- The Economic Transformation of the Global Energy Industry. Cambridge: MIT.

Canadian Electricity Association. (2006). Power Generation In Canada - A Guide. Ottawa: CEA.

CANMET. (1991). Photovoltaic Systems Design Manual. Ottawa: Energy, Mines and Resources Canada.

Cheng, C., Sanchez Jimenez, C. S., \& Lee, M.-C. (2007). Research of BIPV Optimal Tilted Angle, Use of Latitude Concept for South Orientated Plans. Renewable Energy (34), 1644-1650.

Chiras, D., Aram, R., \& Nelson, K. (2009). Power from the Sun. Vancouver: New Society Publishers.

City of Toronto. (2009). Preservation Alternatives for the Former Canada Malting Complex. Toronto: City of Toronto.

City of Toronto. (2006). Toronto Central Waterfront Innovative Design Competition. Toronto: Toronto Waterfront Revitalization Corporation.

Coop Himmelb(I)au. (2010, April 1). Recent Works: Press Sheet. Retrieved July 8, 2010, from http://www.coop-himmelblau.at/: http://www.coop-himmelblau.at/files/100401_Press\%20Sheet.pdf

Dalziel, B. (2008). Interoperability and Collaboration. In D. Littlefield, Space Craft: Developments in Architectural Computing (pp. 170-179). London: RIBA Publishing.

Dubois, M., \& Horvat, M. (2010). State of the Art of Digital Tools Used by Architects for Solar Design. Retrieved August 29, 2010, from http://www.iea-shc.org/publications/: http://www.ieashc.org/publications/downloads/IEA-T41_STB-DB1_SOA-DigitalTools.pdf

Ehrenworth, D. (2003). Toronto's First Synagogues. Retrieved July 8, 2010, from http://www.ontariojewisharchives.org/exhibits/TorontoSynagogues/index.html

El Croquis. (1995). Frank O. Gehry 1991-1996. Madrid: IDEA Books. 
Fondation Le Corbusier. (n.d.). Retrieved July 29, 2010, from http://www.fondationlecorbusier.fr: http://www.fondationlecorbusier.fr/corbuweb/morpheus.aspx?sysld=65\&sysLanguage=enen\&itemPos=1\&sysParentld=65\&clearQuery=1

Geller, H. (2003). Energy Revolution. Washington: Island Press.

Gevorkian, P. (2008). Solar Power in Building Design. Toronto: McGrawhill.

Hawkins, D., Lashof, A., \& Williams, R. (2007). What to do About Coal. In D. Green, Oil and the future of energy (pp. 62-71). Guilford: The Lyons Press.

Herzog, T., Krippner, R., \& Lang, W. (2004). Facade Construction Manual. Basel: Birkhauser.

IMA Ooutdoor. (2010). http://www.imaoutdoor.com/. Retrieved July 6, 2010, from http://www.imaoutdoor.com/content/view/17/33/

Johnson, G. (2009). Plugging in to the Sun. National Geographic , 28-51.

Kohn, M. (2008). Drawing out the Model. In D. Littlefield, Space Craft: Developments in Architectural Computing (pp. 55-61). London: RIBA Publishing.

Komp, R. (1995). Practical Photovoltaics, Electricity from Solar Cells. Ann Arbor: Aatec.

KPF. (2008). Architectural Structure - Computational Strategies. In D. Littlefield, Space Craft: Developments in Architectural Computing (pp. 3-13). London: RIBA Publishing.

Krippner, R. (2003). Solar Technology From Innovative Building Skin to Energy Efficient Renovation. In C. Schittich, In Detail - Solar Architecture, Strategies, Visions, Concepts (pp. 27-37). Boston: Birkhauser.

Maciel, A. (2008). Artifical Intelligence. In D. Littlefield, Space Craft: Developments in Architectural Computing (pp. 62-66). London: RIBA Publishing.

Maycock, P., \& Stirewalt, E. (1981). Photovoltaics, Sunlight to Electricity in One Step. Andover: Brick House Publishing.

McLuhan, M. (1995). Essential McLuhan. (E. McLuhan, \& F. Zingrone, Eds.) Toronto: Anansi Press Limited.

McLuhan, M. (1994). Understanding Media - The Extensions of Man. Cambridge: The MIT Press.

Menges, A. (2006). Instrumental Geometry. Architectural Design , 76 (2), 42-53.

Miller, M., \& Miller, R. (2002). Electronics the Easy Way Fourth Edition . USA: Barrons.

Munari-Probst, M. C. (2008). Architectural Integration and Design of Solar Thermal Systems. Programme Doctoral en Environment. Lausanne: Ecole Polytechnique Federale De Lausanne.

Patterson, W. (2007). Keeping the Lights On. London: Earthscan. 
Perez-Gomez, A. (1998). Introduction to Architecture \& The Crisis of Modern Science. In M. Hays, Architecture Theory Since 1968 (pp. 466-475). Cambridge: The MIT Press.

Perlin, J. (1999). From Space to Earth, The Story of Solar Electricity. Ann Arbor: Aatec Publications.

Prasad, D., \& Snow, M. (2005). Designing with Solar Power. London: Earthscan.

Rifkin, J. (2002). The Hydrogen Economy. New York: Penguin.

Roberts, P. (2004). The End of Oil. New York: Houghton Mifflin Company.

Scheer, H. (2002). The Solar Economy - Renewable Energy for a Sustainable Global Future. London: Earthscan.

Silverman, D. (2007, October). Southern California Household Energy Savings. Retrieved July 29, 2010, from http://www.physics.uci.edu/:

http://www.physics.uci.edu/ silverma/actions/HouseholdEnergy.html

Stamenic, L., \& Ingham, G. (1995). A Power for the World, Solar Photovoltaics Revolution. Vancouver: Sunology International Inc.

The German Solar Energy Society. (2005). Planning and Installing Photovoltaic Systems, A Guide for Installers, Architects and Engineers. Berlin: Ecofys.

Thomas, r., \& Fordham, M. (2001). Photovoltaics and Architecture. London: Spon Press.

West8+DTAH. (2006, June). Toronto Central Waterfront. Retrieved July 21, 2010, from http://www.dtah.com/waterfront/

Whitehead, H., \& Peters, B. (2008). Geometry, Form and Complexity. In D. Littlefield, Space Craft: Developments in Architectural Computing (pp. 22-33). London: RIBA Publishing.

Zaera, A. (1995). Information Technology at Frank O. Gehry \& Associates. El Croquis , 152-155. 